\title{
norden
}

Nordic Council of Ministers

Ved Stranden 18

DK-1061 Copenhagen $\mathrm{K}$

www.norden.org

NORDISKE ARBEJDSPAPIRER

NORDIC WORKING PAPERS

\section{Seizing Ecolabelling and Sustainable Public Procu- rement Opportunities in the Southern Cone Region}

Edmundo Claro, Cristian Emhart, Ben Kneppers and Santiago Sinclair

NA2013:919

http://dx.doi.org/10.6027/NA2013-919 


\section{Seizing Ecolabelling and Sustainable Public Procurement Opportunities in the Southern Cone Region}

Final Report

Authors: Edmundo Claro, Cristian Emhart, Ben Kneppers and Santiago Sinclair
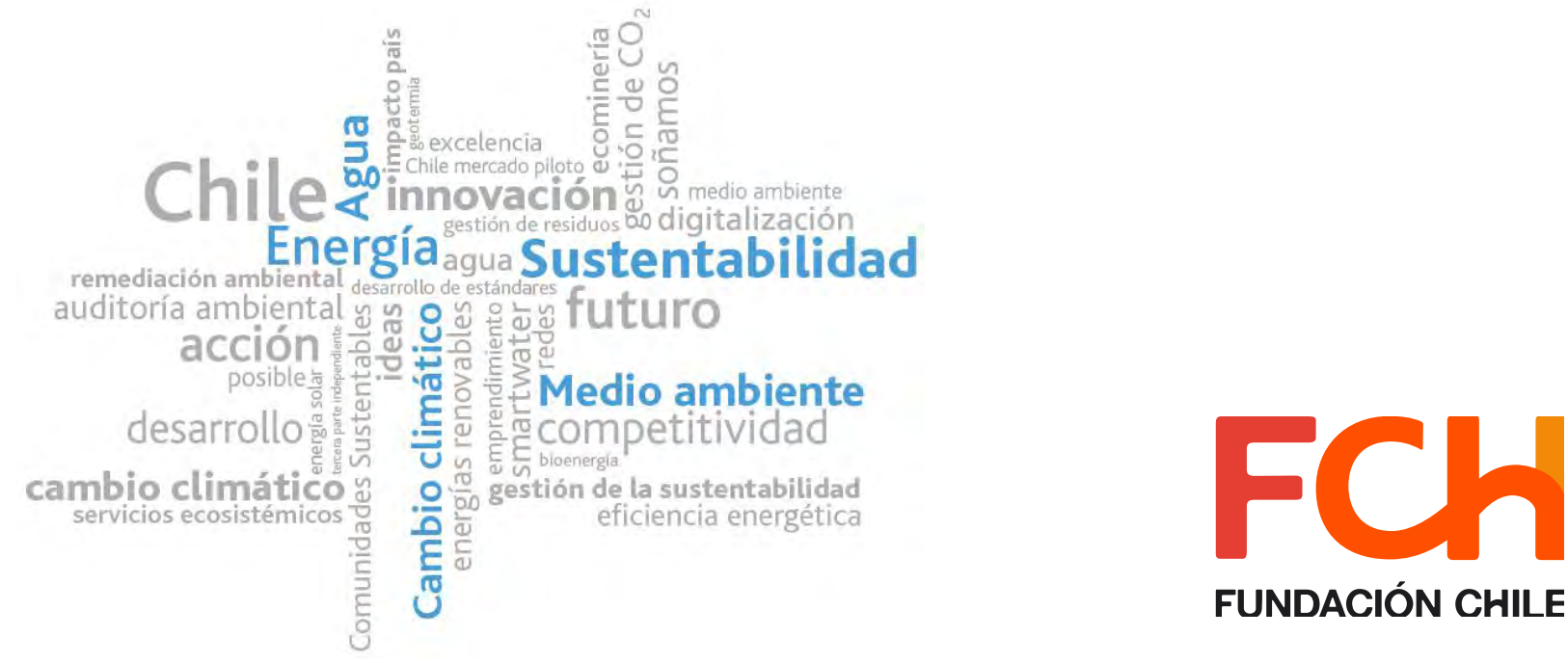

FUNDACIÓN CHILE 


\section{Table of Contents}

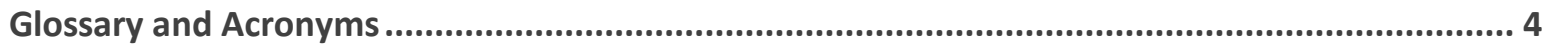

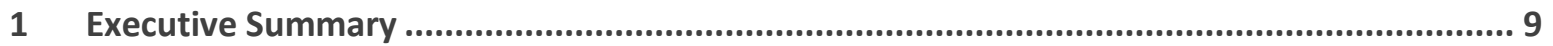

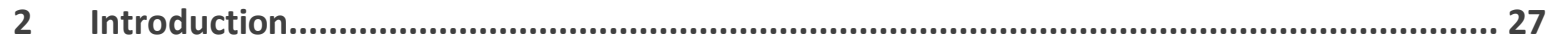

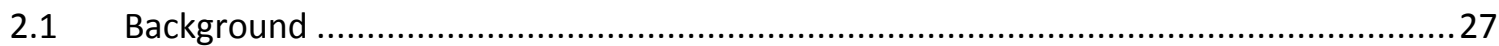

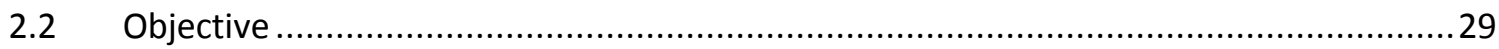

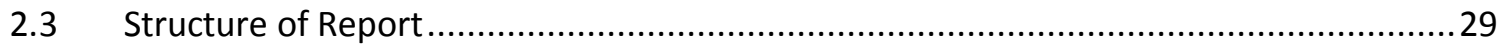

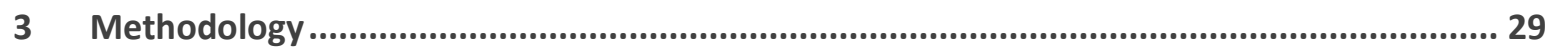

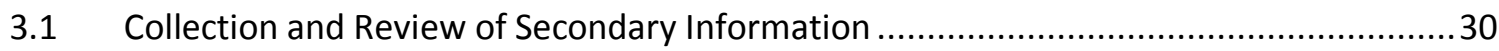

3.2 Collection and Review of Primary Information through Additional Interviews ...............30

3.3 Development of the First Draft of the Report and Internal Review with UNEP and Nordic

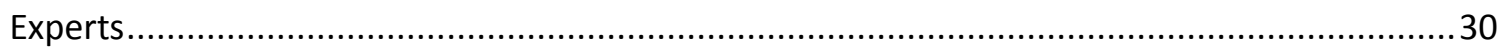

3.4 Discussion of the Preliminary Findings and Recommendations at the Regional Workshop 31

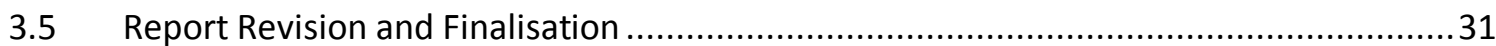

4 Regional Ecolabelling and Sustainable Public Procurement............................................ 31

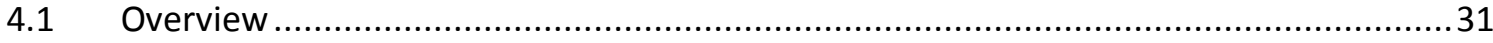

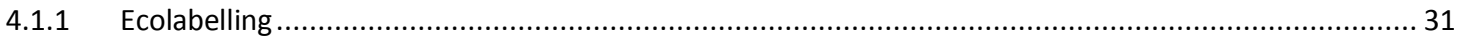

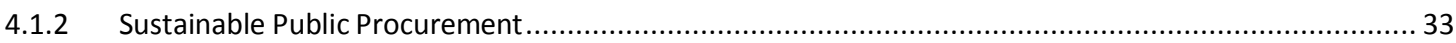

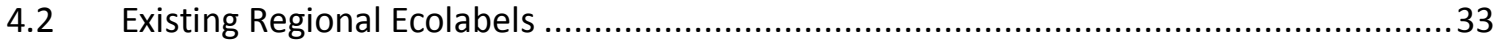

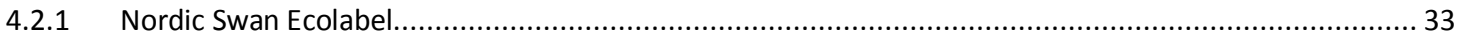

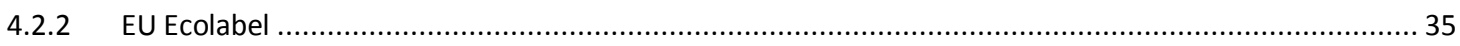

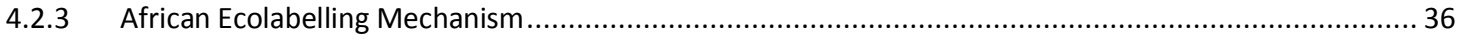

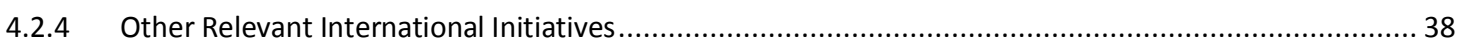

4.3 Existing Regional Ecolabelling Efforts in the Southern Cone ...................................40

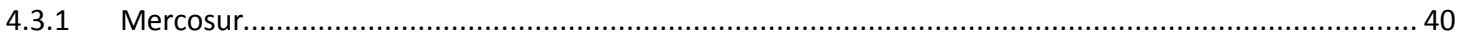

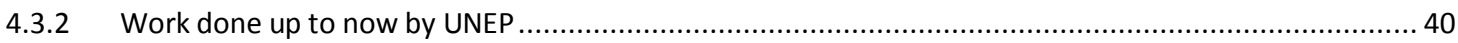

5 Southern Cone Context........................................................................................... 41

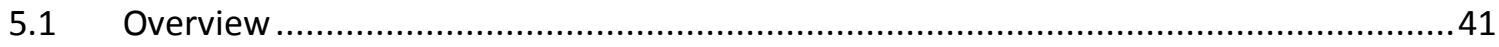

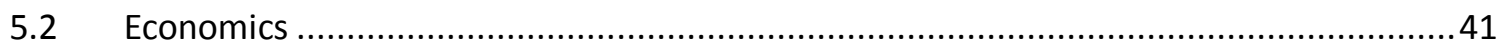

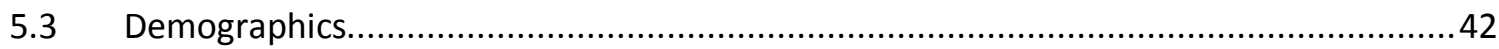

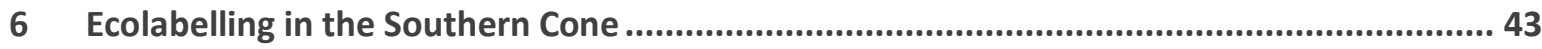




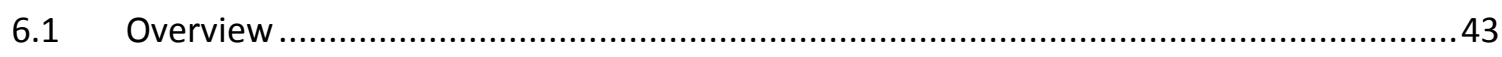

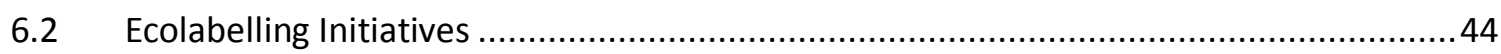

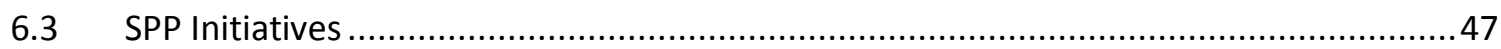

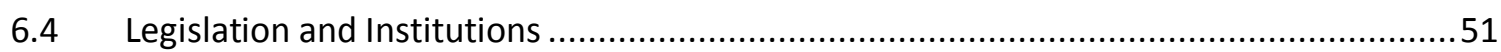

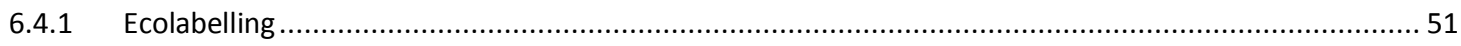

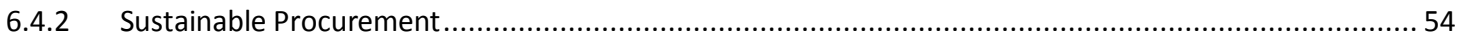

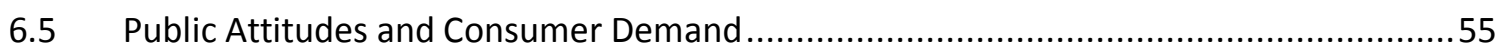

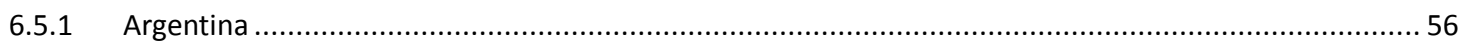

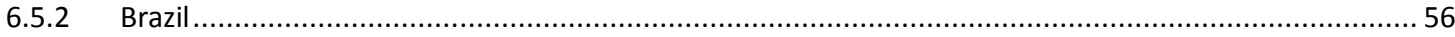

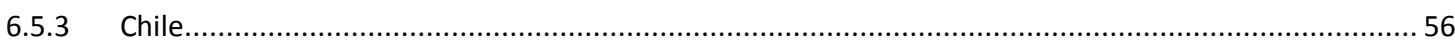

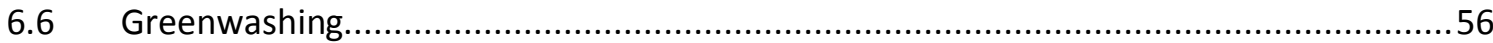

$7 \quad$ Context for Regional Cooperation ............................................................................. 58

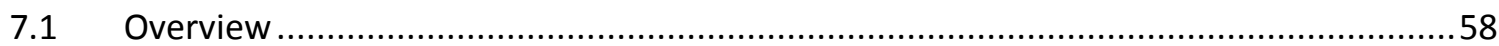

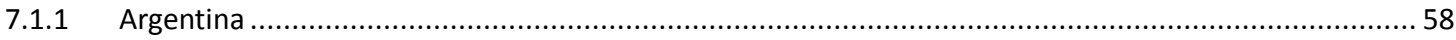

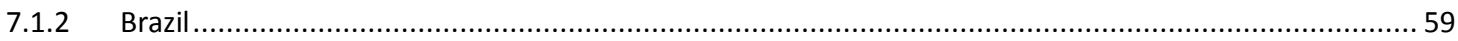

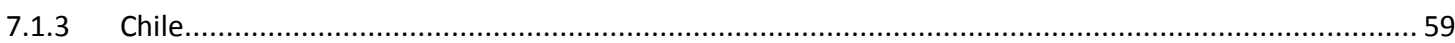

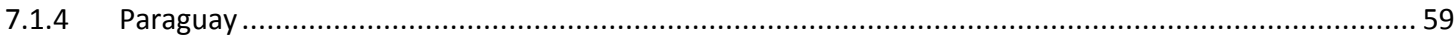

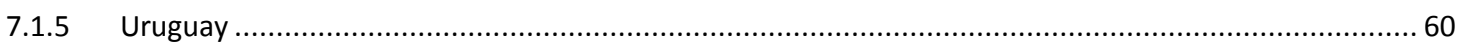

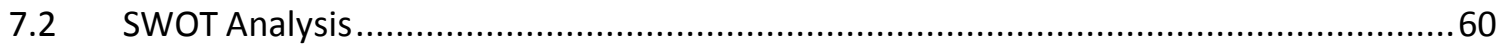

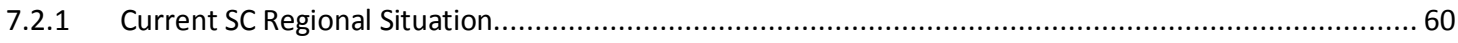

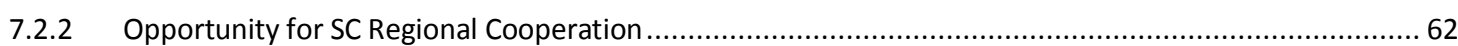

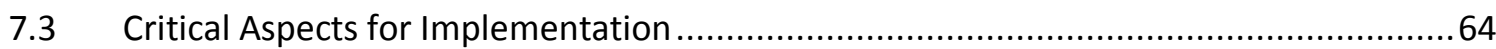

7.4 Technical Capacity for Development of a Regional Cooperation on Ecolabelling ...........65

7.5 Top Industries for Piloting Regional Ecolabelling in the SC ........................................66

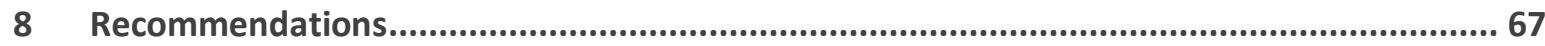

8.1 Feedback from the regional workshop in Rio de Janeiro, November 2012 ..................67

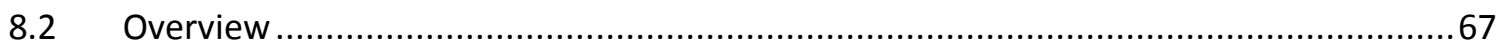

8.3 Fundamentals for initiation of the regional cooperation ..........................................68

8.4 Proposed stages for the regional cooperation initiative on ecolabelling and SPP ..........69

8.5 Proposed roadmap for the implementation of regional cooperation initiative on ecolabelling and SPP in the Southern Cone region of Latin America ........................................................ 72

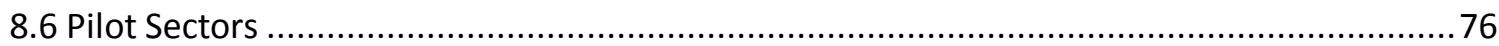

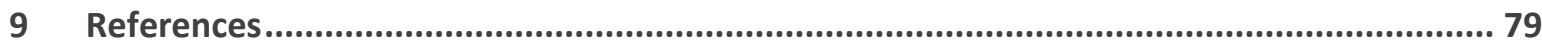

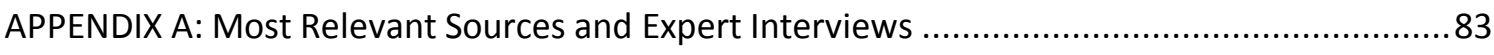

APPENDIX B: Feedback from UNEP Interim Report Presentation ............................................85 


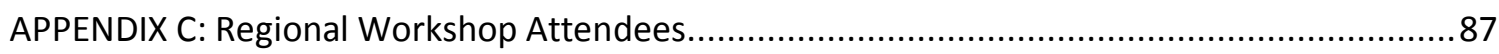

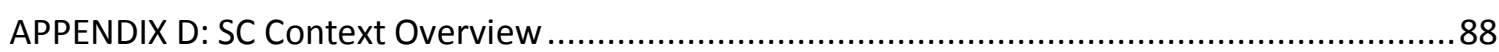

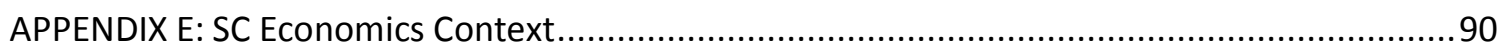

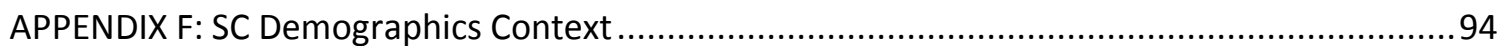

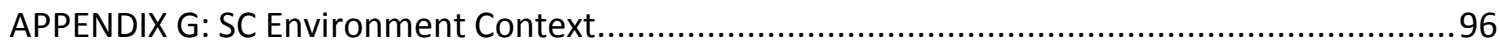

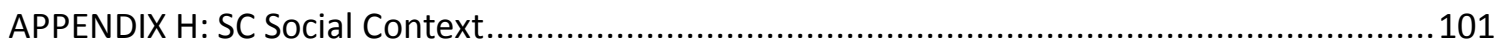

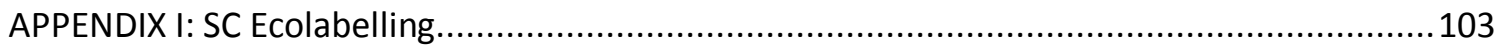

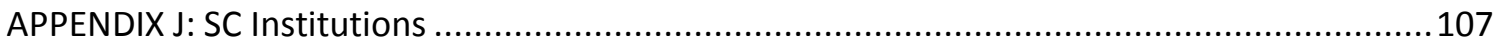




\section{Glossary and Acronyms}

Table 1: Glossary of Terms

\begin{tabular}{|c|c|}
\hline Term & Definition \\
\hline Carbon Footprint & $\begin{array}{l}\text { The total set of greenhouse gas (GHG) emissions caused by a defined system (e.g. } \\
\text { product, service, etc.). }\end{array}$ \\
\hline Certification & $\begin{array}{l}\text { Procedure by which an accredited body gives assurance that a product, process or service } \\
\text { is in conformity with the pertaining standard. }\end{array}$ \\
\hline Consumer Demand & The measure of interest for an everyday purchase of a good or a service. \\
\hline Cradle-to-Grave & $\begin{array}{l}\text { Corresponds to the absolute beginning to end of life for a given product, service or } \\
\text { system. For example, a products life cycle would generally consist of raw material } \\
\text { extraction, manufacturing, transport, use and disposal. }\end{array}$ \\
\hline Delinquency & The tendency to overstep especially legal limits. ${ }^{2}$ \\
\hline Ecolabel & $\begin{array}{l}\text { Environmental and/or social performance labels designating the environmental and/or } \\
\text { social quality of a product or service. }\end{array}$ \\
\hline Energy Efficiency & $\begin{array}{l}\text { All changes that result in a reduction in the energy used for a given energy service } \\
\text { (heating, lighting, etc.) or level of activity. }{ }^{1}\end{array}$ \\
\hline Fair Trade & $\begin{array}{l}\text { Trade operations which strengthen the economic position of small-scale producers and } \\
\text { landowners in order to ensure that they are not marginalised in the world economy. }{ }^{1}\end{array}$ \\
\hline Gross Domestic Product (GDP) & $\begin{array}{l}\text { The market value of all officially recognised final goods and services produced within a } \\
\text { country in a given period. The formula for calculating GDP is private consumption }+ \text { gross } \\
\text { investment + government spending + (exports - imports). }\end{array}$ \\
\hline $\begin{array}{l}\text { International Organisation of } \\
\text { Standards (ISO) }\end{array}$ & World's largest developer and publisher of international standards. ${ }^{2}$ \\
\hline ISO 14020:2000 & $\begin{array}{l}\text { This International Standard establishes guiding principles for the development and use of } \\
\text { environmental labels and declarations. }\end{array}$ \\
\hline ISO 14024:1999 & $\begin{array}{l}\text { The ISO principles and procedures for developing Type I environmental labelling } \\
\text { programmes, including the selection of product categories, product environmental criteria } \\
\text { and product function characteristics; and for assessing and demonstrating compliance. }{ }^{5}\end{array}$ \\
\hline Life Cycle Assessment & $\begin{array}{l}\text { A method for assessing the impacts associated with all the stages of a product's life from } \\
\text { cradle-to-grave. }\end{array}$ \\
\hline Life Cycle Based & Utilising an approach from a cradle-to-grave perspective \\
\hline Regional Ecolabel & $\begin{array}{l}\text { An environmental performance label which operates in a particular geographical area that } \\
\text { consists of more than one country. }\end{array}$ \\
\hline Southern Cone (SC) Region & $\begin{array}{l}\text { Geographic region consisting of the southernmost countries of South America, i.e. } \\
\text { Argentina, Brazil, Chile, Paraguay, and Uruguay. }\end{array}$ \\
\hline Sustainable Public Procurement (SPP) & $\begin{array}{l}\text { The process by which government, regional and local public authorities or bodies } \\
\text { governed by public law obtain goods and services with taxpayer money by accounting for } \\
\text { their environmental, social and economic value. }\end{array}$ \\
\hline Type I Ecolabelling & A voluntary, multiple-criteria based, third party programme that awards a licence which \\
\hline
\end{tabular}

${ }^{1}$ UNEP, 2010. ABC of SCP Clarifying Concepts on Sustainable Consumption and Production.

${ }^{2}$ Montada, L. (2002), Delinquenz, in R. Oerter, \& L. Montada (Ed.), Entwicklungspsychologie (S. 859-873), Weinheim: Beltz

${ }^{3} 2$ degrees, 2012. Labelling 2degrees Sustainability Essentials. http://www.2degreesnetwork.com/groups/supply-

chain/resources/2degrees-essentials-guide-labeling/download/.

${ }^{4}$ ISO, 2000. ISO 14020:2000 Environmental labels and declarations - General Principles.

http://www.iso.org/iso/catalogue detail?csnumber=34425.

${ }^{5}$ ISO, 1999. ISO 14024:1999 Environmental labels and declarations - Type I environmental labelling - principles and procedures.

http://www.techstreet.com/standards/iso/14024_1999?product_id=3516.

${ }^{6}$ CSR Europe, 2009. Sustainable Public Procurement.

http://www.csreurope.org/data/files/20091001 csr europe helpdesk for epson sustainable public procurement final.pdf. 


\begin{tabular}{|l|l|}
\hline & $\begin{array}{l}\text { authorises the use of environmental labels on products indicating overall environmental } \\
\text { preference of a product within a product category based on life cycle considerations (ISO } \\
\text { 14024). }\end{array}$ \\
\hline Type II Ecolabelling & $\begin{array}{l}\text { Informative environmental self-declaration claims on a single issue, and therefore not } \\
\text { based on life cycle considerations. Although type } 2 \text { labels do not require third party } \\
\text { verification it is preferred. (ISO 14021). }\end{array}$ \\
\hline Type III Ecolabelling & $\begin{array}{l}\text { Voluntary programmes that provide quantified environmental data of a product, under } \\
\text { pre-set categories of parameters set by a qualified third party and based on life cycle } \\
\text { assessment, and verified by that or another qualified third party (ISO 14025). }\end{array}$ \\
\hline
\end{tabular}

Table 2: Acronyms

\begin{tabular}{|c|c|}
\hline Acronym & Organisation \\
\hline \multicolumn{2}{|l|}{ General } \\
\hline AMCEN & African Ministerial Conference on Environment \\
\hline ARSO & African Standardisation Organisation \\
\hline AUC & African Union Commission \\
\hline CSP & Category Sustainability Profile \\
\hline FCh & Fundación Chile \\
\hline GEN & Global Ecolabelling Network \\
\hline GENICES & $\begin{array}{l}\text { Global Ecolabelling Network International Coordination Ecolabelling } \\
\text { System }\end{array}$ \\
\hline GDP & Gross Domestic Product \\
\hline GHG & Greenhouse Gas Emissions \\
\hline HDI & Human Development Index \\
\hline ISEAL & International Social Environmental Accreditation and Labelling \\
\hline LCA & Life Cycle Assessment \\
\hline LEED & Leadership in Energy and Environmental Design \\
\hline MDGs & Millennium Development Goals \\
\hline PSI & Product Sustainability Information \\
\hline SC & Southern Cone \\
\hline SCP & Sustainable Consumption and Production \\
\hline SME & Small and Medium Enterprises \\
\hline SMRS & Sustainability Measurement and Reporting System \\
\hline SPP & Sustainable Product Procurement \\
\hline TSC & The Sustainability Consortium \\
\hline UNDP & United Nations Development Programme \\
\hline UNEP & United Nations Environment Programme \\
\hline \multicolumn{2}{|l|}{ Argentina } \\
\hline NOP & Argentinean National Office for Procurement, Argentinacompra \\
\hline MFA & Ministry of Foreign Affairs \\
\hline
\end{tabular}




\begin{tabular}{|c|c|}
\hline MESD & Ministry of Environment and Sustainable Development \\
\hline MFPPISE & $\begin{array}{l}\text { Ministry of Federal Planning, Public Inversions and Services, Secretariat of } \\
\text { Energy }\end{array}$ \\
\hline FAIMA & Argentine Forestry Industry Federation \\
\hline AFoA & Argentine Forestry Association \\
\hline AFCP & Argentinean Manufacturers of Cellulose and Paper Association \\
\hline INTI & Argentinean National Institute of Industrial Technology \\
\hline IRAM & Argentine National Standardisation Body \\
\hline SAGPyA & Secretariat of Agriculture, Livestock, Fishing and Food \\
\hline OAA & Argentine Accreditation Body \\
\hline CTS-UTN & Sustainability Center of Technology - National Technical University \\
\hline \multicolumn{2}{|l|}{ Brazil } \\
\hline ABNT & Brazilian Technical Norm Association (ABNT) \\
\hline IBD & Brazilian IBD Certifying Organisation \\
\hline MDIC & $\begin{array}{l}\text { Ministry of Development, Industry and Foreign Trade, Secretariat of } \\
\text { Foreign Trade }\end{array}$ \\
\hline ComprasNet & Ministry of Planning, Budget and Management, ComprasNet \\
\hline INMETRO & Brazilian National Institute of Metrology, Quality and Technology \\
\hline MAPA & Ministry of Agriculture, Livestock and Food Supply \\
\hline MPA & Ministry of Fisheries and Aquaculture \\
\hline MME & Ministry of Mines and Energy \\
\hline MMA & Ministry of Environment \\
\hline ABIPA & Brazilian Association of Panel Wood Industries \\
\hline SFB & Brazilian Forestry Service \\
\hline IBAMA & Brazilian Institute for Renewable Natural Resources and the Environment \\
\hline CONAMA & Brazilian National Council for the Environment \\
\hline $\mathrm{ABIMCl}$ & Brazilian Association of the Mechanically Processed Wood Industry \\
\hline \multicolumn{2}{|l|}{ Chile } \\
\hline ChileCompra & Chilean National Directorate of Public Procurement Chile \\
\hline CNLP & Chilean National Council of Clean Production \\
\hline AChEE & Chilean Agency for Energy Efficiency \\
\hline CCS & Santiago Chamber of Commerce \\
\hline MINVU & Ministry of Urbanism \& Housing \\
\hline SAG & Livestock and Agricultural Service \\
\hline SERNATUR & Chilean National Tourism Service \\
\hline MMA & Ministry of Environment \\
\hline SERNAC & Chilean National Consumer Service \\
\hline
\end{tabular}




\begin{tabular}{|c|c|}
\hline CGBC & |Chilean Green Building Council \\
\hline INN & Chilean National Institute of Standardisation \\
\hline RNM & Chilean National Network of Metrology \\
\hline MME & Ministry of Energy \\
\hline \multicolumn{2}{|l|}{ Paraguay } \\
\hline DNCP & Paraguayan Direction of Public Procurement \\
\hline MAG & Ministry of Agriculture and Livestock \\
\hline NSPCB & National Sustainable Production and Consumption Board \\
\hline SENAVE & Paraguayan National Service for the Quality of Vegetables and Seeds \\
\hline SEAM & Ministry of Environment \\
\hline UIP & Paraguayan Industrial Union \\
\hline MIC & Ministry of Industry and Trade \\
\hline CPL & Centre for Cleaner Production \\
\hline REDES & Corporate Network for Sustainable Development \\
\hline IICA & Inter-American Institute for Agriculture Cooperation \\
\hline IECE & Investigation and Education Centre for Eco Development \\
\hline \multicolumn{2}{|l|}{ Uruguay } \\
\hline CNCS & Uruguayan National Chamber of Commerce and Services \\
\hline OPP & Uruguayan National Planning and Budget Office \\
\hline NDPP & Uruguayan National Direction for Public Procurement \\
\hline DINAMA & Uruguayan National Direction for the Environment \\
\hline MVOTMA & Ministry of Housing, Urban Planning \& Environment \\
\hline DNE & Uruguayan National Directorate for Energy \\
\hline MIEM & Ministry of Industry, Energy and Mining \\
\hline UTE & $\begin{array}{l}\text { Uruguayan National Management of Power Stations and Electric } \\
\text { Transmission }\end{array}$ \\
\hline UNIT & Uruguayan Institute of Technical Norms \\
\hline
\end{tabular}




\section{Executive Summary}

\section{Background and Objective}

One of the most significant environmental and social problems of the world corresponds to unsustainable patterns of production, distribution, consumption and disposal of products. These unsustainable patterns are the result of choices made by a myriad of actors across the value chain of products. These choices can be influenced by making credible and meaningful information about the products they are producing, trading or consuming more readily available to market actors and decision-makers to enable them to make more informed choices. Such information should be based on the impacts of a product's life cycle to ensure the net improvement and avoid burden shifting ${ }^{7}$.

In this sense, ecolabels and other product information tools have played an important role in advancing more sustainable consumption and production patterns. Their function is to provide information about environmental and/or social aspects of products to all actors of the value chain. Ecolabels not only guide manufacturers towards the right choices of raw materials, production processes, packaging and end-of-life logistics, but also influence the behaviour of consumers so that their choice of product comes with an environmental and/or social conscience (Prasad, 2012). Thus, ecolabels are widely supported as an integral component of comprehensive policy frameworks and initiatives aimed at achieving sustainable consumption and production patterns (DEFRA, 2010).

In this respect, Sustainable Public Procurement (SPP) plays a crucial part in the uptake of ecolabelling. Public procurement constitutes a significant part of domestic consumption. Through specific SPP policies, governments have backed the creation of markets for domestic ecolabelled products (Horne, 2009). Equally, ecolabels are a key element for the widespread and better application of SPP, as they can be used to outline and comply with specifications of tendering processes (AMPHOS 21, 2011). The strong inter-linkage between ecolabelling and SPP is evidenced in the case of the EU Ecolabel, where diverse countries have implemented successful national ecolabelling programmes that have facilitated the development of sound SPP policies (AMPHOS 21, 2011).

Compared to developed regions, Southern Cone (SC) countries (Argentina, Brazil, Chile, Paraguay and Uruguay) have little experience with the use of ecolabelling and SPP for promoting sustainable consumption and production patterns. At the same time, there is a wide range in the levels of activity across the countries in the SC. The following table provides a summary.

Table 3: Summary of Ecolabelling and SPP Activity by SC Country

\begin{tabular}{|l|l|l|}
\hline Country & Ecolabelling Activity Summary & SPP Activity Summary \\
\hline Argentina & $\begin{array}{l}\text { 21 ecolabels currently operating in Argentina and 3 } \\
\text { institutions with the capacity of certifying and } \\
\text { standardising. }\end{array}$ & $\begin{array}{l}\text { Existence of different norms and initiatives to support } \\
\text { SPP, with the current focus mainly on energy efficiency. } \\
\text { Training workshops are also beginning to provide } \\
\text { guidance on how to include SPP criteria in purchases. }\end{array}$ \\
\hline Brazil & $\begin{array}{l}39 \text { ecolabels currently operating in Brazil and 5 institutions } \\
\text { with the capacity of certifying and standardising. }\end{array}$ & $\begin{array}{l}\text { An SPP system is operating through a sustainable product } \\
\text { catalogue backed by an SPP legal body. }\end{array}$ \\
\hline
\end{tabular}

\footnotetext{
${ }^{7}$ Burden Shifting is the process of transferring or minimising the impact or issue brought on at one stage by increasing the impact or problem elsewhere. For example, improving the environmental performance of a product in it operational phase by requiring more energy and resource consumption in the manufacturing stage.
} 


\begin{tabular}{|l|l|l|}
\hline Chile & $\begin{array}{l}\text { 22 ecolabels currently operating in Chile and } 6 \text { institutions } \\
\text { with the capacity of certifying and standardising. }\end{array}$ & $\begin{array}{l}\text { Using a product catalogue which includes several } \\
\text { products with sustainable criteria, with the current focus } \\
\text { mainly on energy efficiency. Different norms and } \\
\text { initiatives to support SPP are in operation, such as } \\
\text { training workshops to provide guidance on how to begin } \\
\text { including more SPP criterion in purchases. }\end{array}$ \\
\hline Paraguay & $\begin{array}{l}11 \text { ecolabels currently operating in Paraguay and } 2 \\
\text { institutions with the capacity of certifying and } \\
\text { standardising. }\end{array}$ & $\begin{array}{l}\text { Begun a SPP plan with short, mid and long-term policies. } \\
\text { Short-term policy (2011-2012) states it will address } \\
\text { forestry products and electronic appliances (energy } \\
\text { efficiency). }\end{array}$ \\
\hline Uruguay & $\begin{array}{l}\text { 9 ecolabels currently operating in Uruguay and 2 } \\
\text { institutions with the capacity of certifying and } \\
\text { standardising. }\end{array}$ & $\begin{array}{l}\text { Established an SPP work plan (2012-2016) that involves } \\
\text { the inclusion of building materials and electronic } \\
\text { appliances (energy efficiency). }\end{array}$ \\
\hline
\end{tabular}

The most common ecolabelling initiatives in the SC relate to energy efficiency of electronic equipment, sustainable forest management and the chain of custody of forest based products. In terms of SPP, common initiatives relate to energy efficiency for electronic appliances and office products such as paper and ink cartridges.

Since there is still much room for growth in these programmes across all SC counties, there is a promising opportunity for progressing towards more sustainable consumption and production patterns through regional cooperation. Rather than each SC country pursuing its own agenda, a regional approach provides a practical solution to the need of providing easy and reliable information about the environmental performance of products. A regional approach does not only save time and resources; it also creates a scope for stronger cooperation on a number of issues related to ecolabelling and SPP, such as trade, resource efficiency and industrial development (AMPHOS 21, 2011). Examples of regional ecolabelling approaches are the EU Flower, the Nordic Ecolabel and the more recent African Ecolabelling Mechanism, which is still under development.

This study, which is part of the project, "Seizing ecolabelling and sustainable public procurement opportunities in the Southern Cone (SC) region," led by UNEP in conjunction with the Nordic Council of Ministers, aims at assessing and advancing the strategies at the level of SC countries towards the development of a regional cooperation on ecolabelling and promoting the role of SPP. More specifically, the study intends to:

- Provide an assessment of the SC context with respect to conditions needed for regional cooperation on ecolabelling;

- Present an overview of various ecolabelling and sustainable public procurement initiatives that exist in the $\mathrm{SC}$ region;

- Identify priority sectors for consideration in terms of their potential for ecolabelling and public procurement;

- Define a strategy and options for cooperation; and

- Describe a recommended way forward for the establishment of regional cooperation.

\section{Methodology}

In order to effectively carry out this study, the following five stages were carried out:

1. Literature Review: Information on ecolabelling and SPP information was collected from internet sources, publicly available reports, and scientific journals. 
2. Expert Interviews: A series of interviews with experts in the areas of ecolabelling and sustainable public procurement both in the Northern Hemisphere and the SC were conducted where a total of 18 experts were interviewed. Following from this, a list of research questions were sent to follow up on the report's proposed recommendations, including a list of strategies for a SC regional cooperation, pilot sectors, and key organisations.

3. Draft Report Production: A draft report presenting the research findings and proposed final recommendations was delivered to the UNEP and the SC regional stakeholder for review and feedback.

4. Regional Workshop: A regional workshop was conducted in order to discuss the report's findings and proposed recommendations in order to provide additional insight from SC stakeholders in a more inclusive arrangement.

5. Report Revision and Finalisation: Based on the feedback from the regional workshop, the draft report was revised with focus on the final recommendations and specific next steps for SC country cooperation on a national level.

\section{Ecolabelling}

Ecolabels are essentially a communication tool to convey certain environmental and social characteristics of a product and/or to differentiate more sustainable products in the marketplace. Globally there exist many policies and programmes aimed at communicating information about products' environmental and social attributes. With the objective of categorising and consolidating ecolabels, the International Organisation for Standardisation (ISO) has published various standards covering different types of environmental labels and declarations, which are described in the following table.

Table 4: Ecolabel Type Summary

\begin{tabular}{|l|l|l|}
\hline Type & Summary & Examples \\
\hline Type I & $\begin{array}{l}\text { Voluntary, multiple-criteria based, multi-product, third party programme that awards a licence } \\
\text { which authorises the use of environmental labels on products indicating overall environmental } \\
\text { preference of a product within a product category based on life cycle considerations (ISO } \\
\text { 14024). }\end{array}$ & $\begin{array}{l}\text { Nordic Swan, EU Flower, } \\
\text { Blue Angel }\end{array}$ \\
\hline Type II & $\begin{array}{l}\text { Environmental self-declaration or claim that does not require third party verification, often } \\
\text { based on a single issue, i.e. not based on life cycle considerations (ISO 14021). }\end{array}$ & \% Recycled Content \\
\hline Type III & $\begin{array}{l}\text { Environmental Product Declarations that provide quantified environmental data of a product, } \\
\text { under pre-set categories defined by a qualified third party and based on life cycle assessment, } \\
\text { which are verified by a qualified third party (ISO 14025). }\end{array}$ & $\begin{array}{l}\text { Japan, Sweden and a } \\
\text { number of other } \\
\text { countries have a EPD } \\
\text { programmes }\end{array}$ \\
\hline
\end{tabular}

In addition to the label types defined by the ISO, there is also a growing number of Type IV or "single issue" labels focusing on a specific life cycle stage, such as agricultural practices and forest management. These types of labels are often referred to as Voluntary Sustainability Standards (VSS). They focus on a specific sector or commodity, and they are granted by third party certification referring to a specific environmental, social or ethical characteristic of a product. Some of the most known Type IV labels include Forest Stewardship Council (FSC), Marine Stewardship Council (MSC), FairTrade and Rainforest Alliance. 


\section{Sustainable Public Procurement}

Public procurement represents a substantial share of the economy in a global frame, reaching between $8-25 \%$ of a country's GDP (OECD, 2006). SPP goes further than the common principles of public procurement (i.e. purchasing products that fulfil the required specifications at the best value), as it also integrates a product or service's performance with respect to sustainability. Therefore, through SPP, the purchase specifications require a product with minimum or lower environmental impact and/or a positive social outcome in relation to another product that fulfils the same purpose. In this manner SPP offers governments an opportunity to lead sustainable development in a country by utilising its acquisition power as an incentive for suppliers to shift towards more sustainable practices. SPP is a considerable channel for the uptake for ecolabels by the markets, as it establishes a frame with specific margins and specifications to satisfy.

\section{Existing Regional Ecolabels and SPP}

The following table provides the most established regional ecolabelling initiatives in the world. The development and design of these labels were explored in order to gain insight on the most effective approach for the SC region.

Table 5: Summary of Existing Regional Eco-labelling Programmes

\begin{tabular}{|c|c|}
\hline Type & Summary \\
\hline Nordic Swan & $\begin{array}{l}\text { - Adopted in } 1989 \text { by the Nordic Council of Ministers, mainly to overcome increasing competition and } \\
\text { confusion resulting from the existence of diverse private ecolabelling schemes claiming good environmental } \\
\text { performance of goods in the region. } \\
\text { - Voluntary ISO Type I ecolabelling scheme currently with } 63 \text { product group categories and over } 5,000 \text { products } \\
\text { that have been awarded the label. } \\
\text { - Funding for the scheme is derived from the member countries and from an annual licence fee charged to } \\
\text { label holders. } \\
\text { - Used not only to enhance the sustainable consumption of private consumers but also as a way to facilitate } \\
\text { SPP in Nordic countries. }\end{array}$ \\
\hline EU Flower & $\begin{array}{l}\text { - Established in } 1992 \text { with the aim of contributing to the efficient use of resources and to environmental } \\
\text { protection through the promotion of products with lowered negative environmental impacts. } \\
\text { - Voluntary, multi-criteria based, third-party scheme (ISO Type I) with criteria for compliance based on life cycle } \\
\text { considerations. Today } 30 \text { countries participate in the scheme, which has } 26 \text { product categories, and more } \\
\text { than } 1,300 \text { licences have been awarded on more than } 17,000 \text { products. } \\
\text { - The programme is sustained through funding from the European Commission and the member states, and } \\
\text { from revenues coming from the annual licence fee for those holding the EU Flower label. }\end{array}$ \\
\hline $\begin{array}{l}\text { African } \\
\text { Ecolabelling } \\
\text { Mechanism } \\
\text { (under dev.) }\end{array}$ & $\begin{array}{l}\text { - Being developed as part of the } 2005 \text { African } 10 \text {-Year Framework Programme on Sustainable Consumption and } \\
\text { Production which was initiated by UNEP with support from the Marrakech Taskforce. } \\
\text { - The main objectives of the scheme are to expand the access for African products to regional and international } \\
\text { markets, stimulate appropriate environmental and health related standards within their design and } \\
\text { production, and to develop a cohesive approach for the region on the effective management of trade (UNEP, } \\
\text { 2007). } \\
\text { - As there is a large number of existing operational ecolabelling initiatives in Africa, one of its main activities } \\
\text { corresponds to validation and harmonisation of existing ecolabels. } \\
\text { - Currently the scheme is working towards the establishment of ecolabels for fisheries, tourism, agriculture and } \\
\text { forestry. }\end{array}$ \\
\hline
\end{tabular}

\section{Early SC Regional Ecolabelling Developments}

The SC countries are integrated in different cooperation frameworks and trade agreements, with the Andes Pact and Mercosur being the most relevant. In the early 1990s, under the Mercosur trade agreement, efforts were made to develop a, "Green Label," for participating countries. Progress on this label has been slower due to two main challenges; the lack of a central certification body capable of operating across the region as well as differences among countries and the impacts it would have on the competitiveness of their industries. With that being said, 
recent efforts have been made to seek out funding for a pilot eco-labelling project to begin establishing the mechanisms necessary to carry forward this initiative.

In 2010, the project, "Seizing ecolabelling and sustainable public procurement opportunities in the Southern Cone region," was put forward by UNEP jointly with the Nordic Council of Ministers. The objective of this project is to assess and advance strategies at the level of SC countries (Argentina, Brazil, Chile, Paraguay and Uruguay) towards the development of a regional cooperation on ecolabelling and promoting the role of SPP. Up to now, two activities have contributed to this project; a consultation workshop that took place in November 2011 in Santiago and this study.

\section{SC Context}

SC countries represent approximately $4 \%$ of both world population and GDP. In terms of land area, they account for $10 \%$ globally (World Bank, 2012). Table 6, provides a summary of the economic, demographic, environmental and social key points for the region.

Table 6: Southern Cone Context Summary

\begin{tabular}{|c|c|}
\hline Area & Key Points \\
\hline Economics & $\begin{array}{l}\text { - Private consumption corresponds to the largest GDP component for all countries, which shows a promising } \\
\text { opportunity for domestic trade, with non-alcoholic beverages, housing expenses and transport representing } \\
\text { key consumption clusters (CEPAL, 2007). } \\
\text { - In terms of exports, while Brazil and Argentina show a good share of manufactures in the SC region (around } \\
\text { 33\%), Paraguay and Chile are close to } 12 \% \text {, which reflects the relevance of natural resources for the SC } \\
\text { economies. } \\
\text { - In terms of imports, SC countries present a much more similar structure than in the case of exports, with } \\
\text { manufactures representing roughly } 70 \% \text { (WTO, 2012). }\end{array}$ \\
\hline Demographics & $\begin{array}{l}\text { - Brazil is by far the most populated country, representing almost } 75 \% \text { of SC population (World Bank, 2012). } \\
\text { - SC population is expected to reach } 303 \text { million by } 2050 \text { and from then on population growth will stop, 21.6\% } \\
\text { will be } 65 \text { years of age or older (UN, 2011). } \\
\text { - Education is continuing to improve overall where the gross enrolment ratio for tertiary education has grown } \\
\text { substantially in SC countries since } 1975 \text {, but with great variation among these countries }{ }^{8} \text {. } \\
\text { - Literacy rate lies above } 90 \% \text { in all SC countries, compared with the world average of } 84 \% \text {. While Argentina, } \\
\text { Chile and Uruguay have rates close to } 98 \% \text { and Paraguay is around } 95 \% \text {, Brazil has the lowest rate of SC } \\
\text { countries with } 90 \% \text { (World Bank, 2012). } \\
\text { - All SC countries have GDP/capita over US\$10,000, except Paraguay, which is significantly behind (US\$3,635) } \\
\text { (World Bank, 2012). }\end{array}$ \\
\hline Environment & $\begin{array}{l}\text { - Three of the Earth's biodiversity hotspots are located in the SC (Myers et. al., 2000). } \\
\text { - More than } 10 \% \text { of threatened amphibians, birds, mammals and reptiles and } 6 \% \text { of plants in the world are } \\
\text { present in the SC (UNEP, 2008). } \\
\text { - Increasing economic activity in the SC region has played a very influential role in the increase of } \\
\text { environmental stressors of the region. } \\
\text { - The abundance of water in the region has provided a high level of hydroelectricity for all countries, ranging } \\
\text { from } 25-100 \% \text { of electricity for each country, which results in a low carbon footprint per country (SEI, 2011). } \\
\text { - There is strong variability in GHG by sector for SC countries; most of the emissions of Brazil are due to } \\
\text { forestry and land use change. Paraguay also owes the majority of its emissions to land use change as well as } \\
\text { agriculture, and the majority of emissions for Argentina and Uruguay is agriculture and a mix of sectors for } \\
\text { Chile. }\end{array}$ \\
\hline Social Context & $\begin{array}{l}\text { - The presence of extreme inequality in income distribution and inequity are the major social challenges in SC } \\
\text { countries, where completely different perspectives and access to opportunities exist between them. } \\
\text { - The structural limits of poverty are rigorous and persistent, which causes many young people to experience } \\
\text { frustration and social exclusion. Therefore, any initiative which has the goal of promoting sustainable } \\
\text { development in the SC region should consider not only environmental aspects, but also include some social } \\
\text { considerations, particularly those concerned with equity and poverty alleviation. } \\
\text { - Countries with a higher level of human development (Argentina, Chile and Uruguay) have a lower percentage } \\
\text { of population living in poverty. } \\
\text { - The increasing urbanisation, cause and effect of urban poverty, is usually associated with a process of } \\
\text { exclusion of large groups of the population, which results in violence, delinquency and insecurity in the cities. }\end{array}$ \\
\hline
\end{tabular}

\footnotetext{
${ }^{8}$ While Argentina is close to $70 \%$ and Chile and Uruguay are close to $60 \%$, Paraguay's ratio is around $35 \%$ and Brazil's is close to $25 \%$.
} 
Because the region's economic activity is centred on primary goods ${ }^{9}$, there has been an overexploitation of natural resources, deforestation, habitat fragmentation and pollution. Even though a large portion of the environmental pressures in the SC comes from the production of these commodities, the limitations of the instruments analysed in this study (regional ecolabelling and SPP) have to be recognised given that their trade is driven by global markets and only partly by intra-regional consumption. At the same time, the global international markets increasingly include sustainability as key factor for the business viability and competitiveness. Therefore regional ecolabelling and national SPP initiatives can make regional companies more ready and adaptive to fast changing terms in the international markets.

\section{SC Eco-labels}

Development of ecolabels, certification systems and sustainability codes in the last decade has become more common in the SC region. Figure 1 provides a summary of the existing ecolabels in the SC by country and product group. The total number of operating ecolabels encountered in the SC region is $51^{10}$. Out of these, Brazil accounts with 39 ecolabels, followed by Argentina and Chile with 21 and 22, Paraguay with 11, and Uruguay with 9 ecolabels ${ }^{11}$.

Various products, presented in Figure 1 below, include either generic labels that integrate multiple sectors or other less common ecolabelled sectors, such as vehicles, textiles and cleaning products. Overall, there were three Type I labels found in the SC, with two of the labels created within the region (ABNT and Falcão Bauer labels from Brazil).

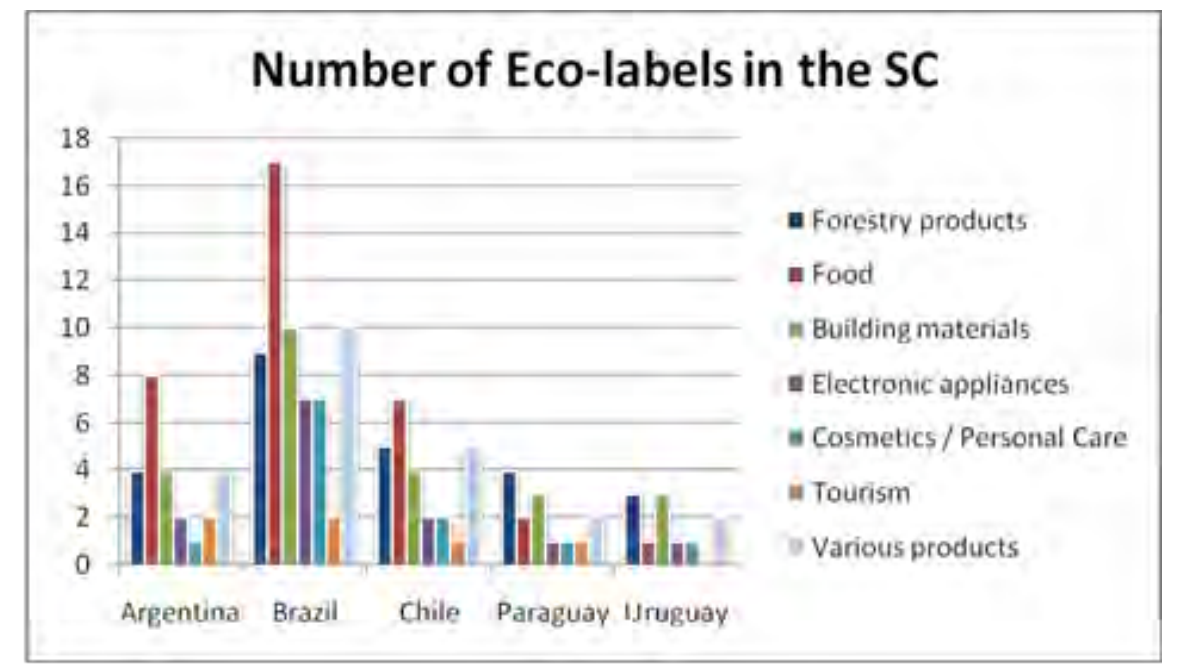

Figure 1: Number of Ecolabels (including Type I, II, III and IV labels) in the SC Region by Sector

\section{Ecolabelling and SPP Initiatives in the SC}

The use of ecolabels and SPP initiatives in SC countries is very uneven, the most common initiatives relate to energy efficiency of electronic equipment and forest stewardship. Brazil has been active in both ecolabel use and development since 1993 when they established the ABNT, "Qualidade Ambiental," ecolabel. Argentina, Chile, Paraguay, and Uruguay began to work in this area during the 1990s through implementing the ISO 14000 series clean production program, with

\footnotetext{
${ }^{9}$ Main Primary Goods Exports: Agriculture, forestry and mining sectors

${ }^{10} \mathrm{~A}$ single ecolabelling scheme can exist in more than one country.

${ }^{11}$ It is important to note that these figures represent the number of ecolabels operating in SC countries, not exclusive ecolabels that have been developed in SC countries. A more detailed classification of the labels is provided in Appendix I, Table I.1
} 
focus on environmental management certification of enterprises. Paraguay's programmes have led to the formation of the National Sustainable Production and Consumption Board in 2006. Uruguay has maintained its focus on the ISO 14000 certifying series since 1998. Since 1994, Argentina's ISO 14000 series approach eventually led to a legal body for the certification of organic products and an organic production programme in 2001. Chile's clean production initiatives finally led to the National Council of Clean Production (CPL) in the year 2000 and the creation of the, "Estrella Azul," Clean production agreement (APL) seal, aimed at enterprises in Chile. Chile and Argentina have developed a strong legislative support for ecolabelling (e.g. energy efficiency).

The national ecolabelling initiatives in the SC region have a special focus on a number of specific sectors. Research shows that initiatives covering sustainable systems and clean production have the most activity (15 initiatives), followed by electronic appliances and energy efficiency (14 initiatives). Behind these sectors comes food with a focus on organic certification labels (10 initiatives). Further back are forestry products ( 9 initiatives) and building materials ( 9 initiatives), which are either in SPP initiatives or in building certification programmes.

National SPP programmes and initiatives are still in an initial stage in the majority of the SC countries. Brazil is the only nation in the SC that has integrated sustainability into their procurement system, making it mandatory through the 2012 Decree on SPP. SPP in Chile and Argentina has taken action through various initiatives, such as online catalogues, that are including information on sustainable products and the certification of sustainable suppliers. Paraguay and Uruguay are beginning to apply SPP policy; Paraguay approved their SPP policy in 2011, which includes a short term (2011-2012), mid-term (2012-2014) and a long term (2015) plan, and Uruguay approved an SPP policy in 2012 for the periods between 2012-2016 with short, mid and long-term aims. Both nations are implementing different pilot sectors for products within the procurement system, with a strong focus on energy efficiency through electronic appliance.

According to the research, the sector with sustainable public procurement initiatives in all SC countries is energy efficiency for electronic appliances. Following this is various office products such as paper (forestry products) and ink cartridges. Other sectors that were commonly addressed within these initiatives were cleaning products and building materials. From the review of these existing initiatives, it can be understood that SC nations are commencing to include regulations, sustainable criteria and programmes that are building a foundation for the application and consolidation of SPP in each nation.

\section{Legislation and Institutions}

A key component for ecolabel and SPP success is a firm support of capable institutions that contribute to the programme's development. In addition, a legal mandate is also of significant importance in order to gain official support and credibility of an ecolabel, seal or SPP system. With the exception of Brazil, there is no specific legislation for ecolabels and SPP in the SC region. However, research shows that there are various legal documents concerning specific sectors and products, which regard sustainability issues. These various laws, regulations and decrees supported by national institutions also assist future initiatives for the integration of SPP into the purchasing system of these nations. For example, the majority of nations in the SC region have a legal document on energy efficiency through appliances and products. Organic agriculture and the control of products that damage the ozone layer are among sectors or products that are also frequently mentioned. Other legal documents focus on various topics such as biodegradable products or vehicle emission control. 
With respect to SPP, Brazil is already in the stage where the use of specific sustainability guidelines is mandatory. Argentina and Chile have a public procurement legislation that supports an upcoming integration of SPP into the public purchasing system. Uruguay holds many regulations and laws for the purchasing in the mentioned products sectors. Paraguay, apart from its public procurement legislation, is advanced in an energy efficiency programme for electronic appliances.

SC Institutions have an important presence throughout many sectors such as forestry, energy efficiency, food, building materials, tourism, and others. It can be observed that among these institutions there is significant government support through various ministries and state institutions. Other important national institutions are those focused on metrology as well as regulations and norms which are present in every $\mathrm{SC}$ nation. Also the industry associations or councils make up an important set of groups from the private sector. Finally, the NGO and not-forprofit community is very active in the sustainability area, with many having sustainability issues as the main focus of their organisation.

\section{Regional Cooperation}

Although SC countries are quite diverse in geographic, demographic and economic terms, as well as in their current involvement in ecolabelling and SPP, interviewees from all SC countries seem to support collaborating at the regional level in ecolabelling. The common driver for this was found to be the opportunity to strengthen the competitiveness of their export and regional trade sectors. However, it was also found that there are some differences between countries in terms of attitudes and emphasis towards cooperation. The following table summarises this information.

Table 7: Attitudes and Incentives of SC Countries towards Regional Ecolabelling Cooperation

\begin{tabular}{|c|c|c|c|c|c|}
\hline & Argentina & Brazil & Chile & Paraguay & Uruguay \\
\hline $\begin{array}{l}\text { General } \\
\text { Attitude }\end{array}$ & Passive & Positive & Positive & Positive & Passive \\
\hline $\begin{array}{l}\text { Main } \\
\text { Feelings }\end{array}$ & $\begin{array}{l}\text { Concerned: } \\
\text { Seen as another } \\
\text { trade barrier }\end{array}$ & $\begin{array}{l}\text { Confident: } \\
\text { Brings negotiation } \\
\text { power in } \\
\text { international markets }\end{array}$ & $\begin{array}{l}\text { Interested but } \\
\text { cautious: } \\
\text { Willing to work } \\
\text { together but first } \\
\text { need to focus on } \\
\text { internal } \\
\text { programmes }\end{array}$ & $\begin{array}{l}\text { Interested: } \\
\text { It might be a way } \\
\text { of gaining more } \\
\text { access to } \\
\text { international } \\
\text { markets }\end{array}$ & $\begin{array}{l}\text { Doubtful: } \\
\text { It is difficult for SC } \\
\text { countries to really } \\
\text { cooperate in } \\
\text { trade issues }\end{array}$ \\
\hline Focus & Exports & $\begin{array}{l}\text { Exports and internal } \\
\text { Market }\end{array}$ & Exports & Exports & Exports \\
\hline $\begin{array}{l}\text { Main } \\
\text { Incentives }\end{array}$ & $\begin{array}{l}\text { Overcoming } \\
\text { lack of internal } \\
\text { governance to } \\
\text { develop } \\
\text { ecolabels }\end{array}$ & $\begin{array}{l}\text { Strengthening its } \\
\text { position in } \\
\text { international markets } \\
\text { and help address } \\
\text { environmental } \\
\text { problems }\end{array}$ & $\begin{array}{l}\text { Strengthening its } \\
\text { position in } \\
\text { international } \\
\text { markets }\end{array}$ & $\begin{array}{l}\text { Learning from } \\
\text { countries with } \\
\text { more } \\
\text { ecolabelling } \\
\text { experience }\end{array}$ & $\begin{array}{l}\text { Strengthening its } \\
\text { position in } \\
\text { international } \\
\text { markets }\end{array}$ \\
\hline
\end{tabular}

Initially, the greater driver for ecolabelling was seen as SPP and regional trade, but as SC countries find themselves at very different stages of ecolabelling development, a common interest they have for regional ecolabelling cooperation was actually found to be the support it would generate for their exports industries. At the same time, these countries also have diverse incentives towards cooperating regionally in this area for reasons not linked to strengthening the export sector.

It is Argentina's need to keep up with other countries' activity which makes them interested in ecolabelling. Argentina has maintained its unfavourable attitude towards ecolabelling initiatives in general. It is more probable that support for regional ecolabelling initiatives has to be looked for in 
the private sector rather than in public bodies. Argentina's interest in participation in regional initiatives is mainly because these generate greater responsibilities and commitments.

Brazil's main incentive for supporting regional ecolabelling initiatives lies in strengthening its position in the processes of mutual recognition of its ABNT ecolabel within international markets (Europe and US). Moreover, it is felt that although the ABNT is a strong ecolabel for participating in international markets, an SC ecolabel would be even stronger due to having a more collective representation and support system. Brazil also showed willingness to provide its experience with the ABNT label for the preparation of a SC label scheme.

Chile seems to have a cautious attitude towards cooperating at the SC regional level on ecolabelling. Although Chile does understand the benefits for the export sectors, and has always had an interest in a permanent cooperation with other SC countries (e.g. exchange in information, workshop participation, etc.), there is a widespread idea that it does not seem to be practical to embark on an official regional ecolabelling initiative in the short term. First of all, Chile recognises the diverse levels of progress in the different countries of the SC. It is also argued that, as it is a relatively recent practice in the country, advances need to be made domestically before a regional initiative should be embarked upon. This means that, prior to regional ecolabelling integration, Chile needs to advance in terms of building up its own institutions and to assess the economic impacts this would bring to its export sectors. At the same time, it seems that Chile is very interested in learning from the Brazilian experience related to the ABNT label.

In Paraguay there is recognition that the country's industries need to include sustainability aspects more actively into their business in which ecolabelling can play an important role, if the country wants to stay competitive in international markets. Thus, the main incentive for cooperating at the $\mathrm{SC}$ level lies in learning, and in being pulled by countries with more ecolabelling experience.

The main incentives Uruguay has for cooperating in ecolabelling at the SC level lie in making their exports sectors more competitive. As current capabilities in this area are insufficient in Uruguay, the country would benefit from sharing information and know-how with other countries.

\section{SWOT Analysis}

In order to summarise the findings from the regional cooperation research and interviews, two SWOT analyses were carried out, one to capture the current regional context and another to assess the opportunity for regional cooperation. The initial analysis, represented in Figure 2 below, shows there to be a common interest in working together across the region where all countries are sharing the same pressures of providing ecolabel recognition to particular export markets. At the same time, the SC countries are at various stages of development in ecolabelling and SPP programmes, which leads to many countries being interested in focusing on internal programmes prior to external collaboration. With that being said, the analysis ultimately found long term regional cooperation to provide a promising opportunity for increasing technical capacity, operational efficiency and programme alignment across countries. 


\section{SWOT- Current SC Regional Situation}

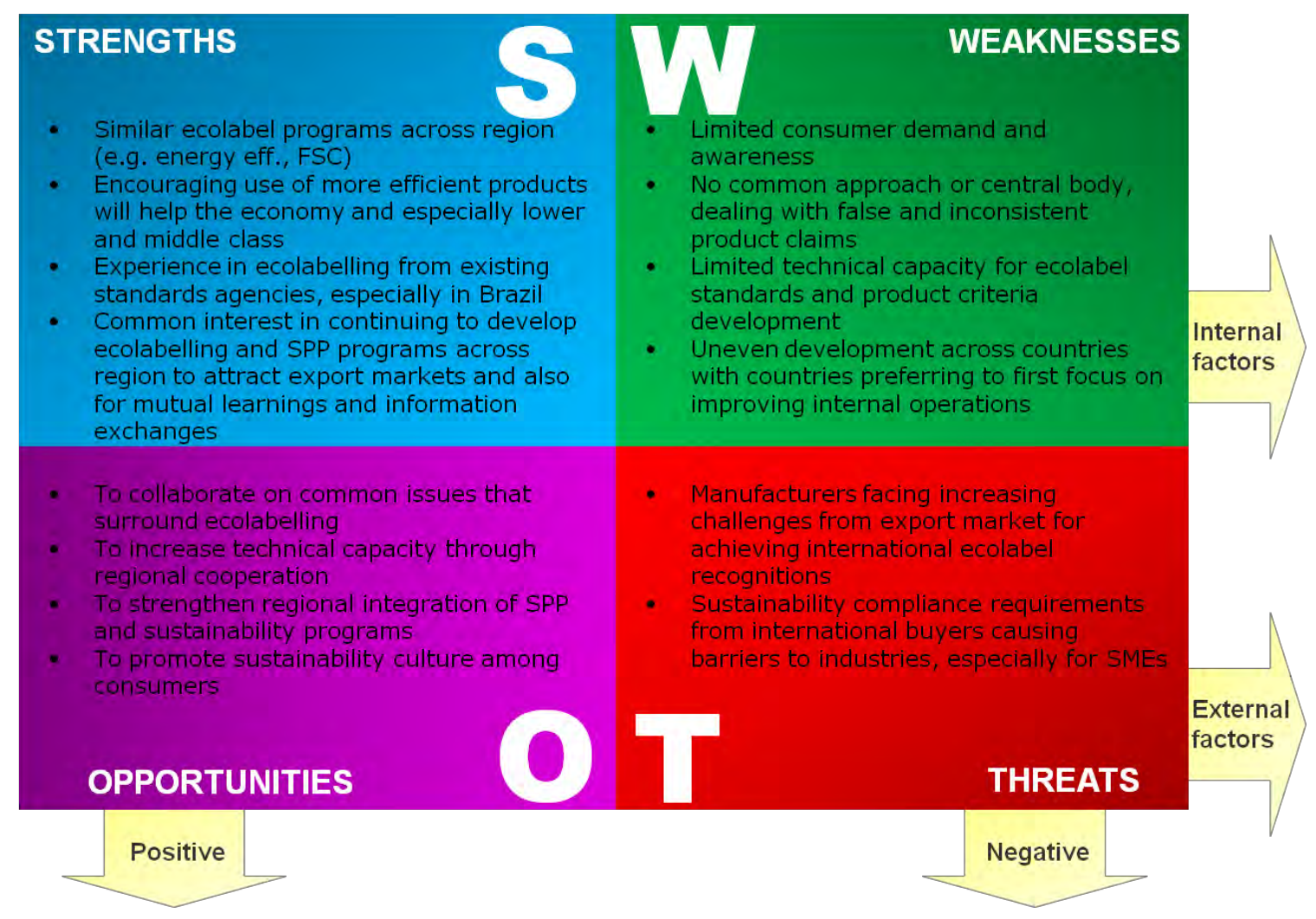

Figure 2: SWOT Analysis for Current SC Regional Situation

Following from the current situation, Figure 3 shows the opportunity for regional cooperation to be good for increasing regional capacity, supporting national SPP, and improving international reputation. One the other hand, there is also a lack of technical capability for ecolabel development, limited consumer awareness and demand, which could be affected by higher prices of goods through additional costs to suppliers. 


\section{SWOT- Opportunity for SC Regional Cooperation}

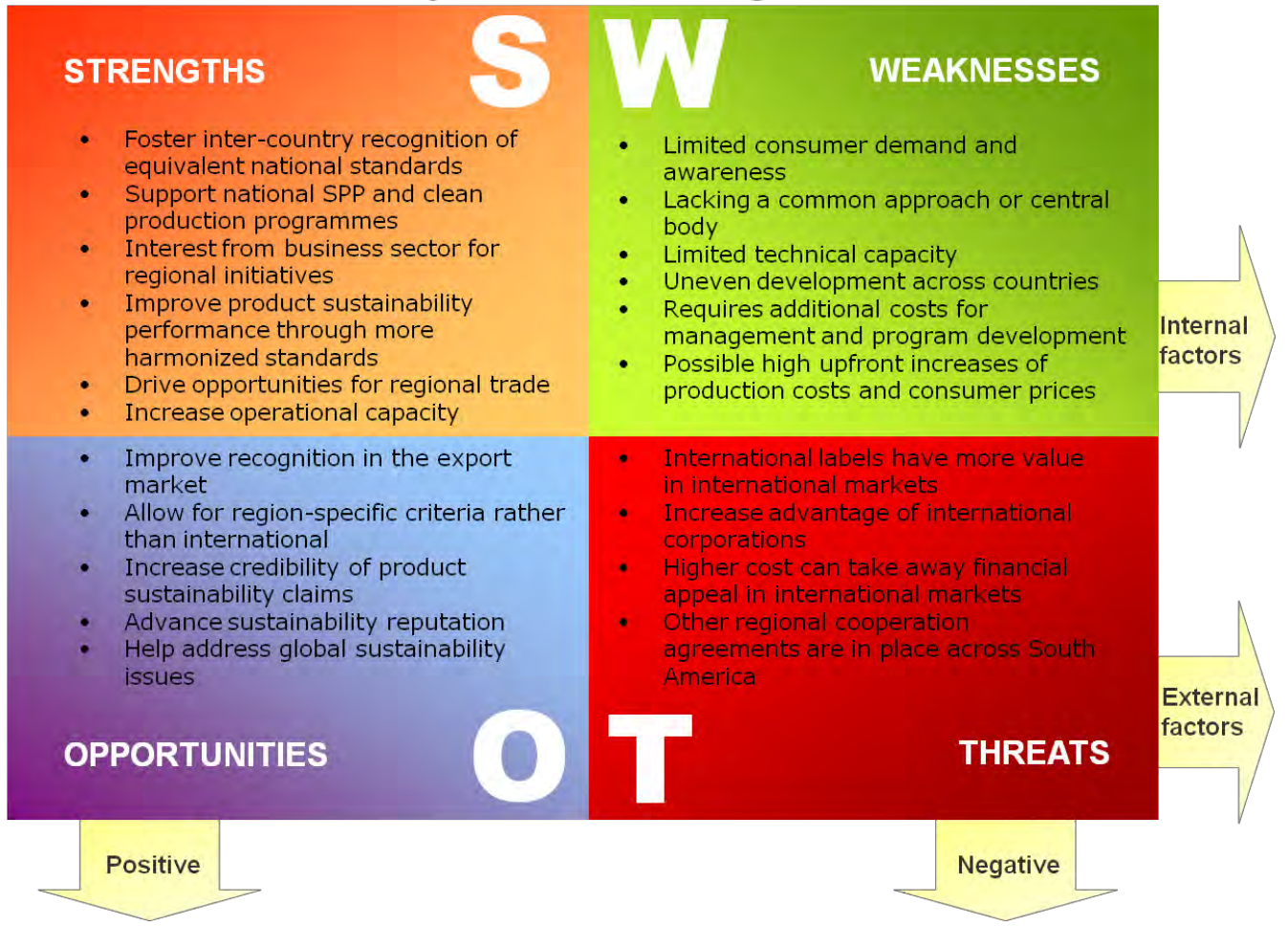

Figure 3: SWOT Analysis for SC Regional Ecolabelling Cooperation

\section{Top pilot Sectors}

In order for a cooperation-label to become successful, a well-selected group of industry sectors should be piloted as a way to provide an initial trial for the label, even for a phase of cooperation on promotion and enablement. The following table proposes the top industries for piloting regional ecolabelling cooperation in the SC. These four sectors were presented due to their ability to meet the key criteria for the region.

Table 8: Summary of Proposed Pilot Sectors with Respect to Key Indicators

\begin{tabular}{|l|l|}
\hline Proposed Pilot Sector & Key Indicator Summary \\
\hline Paper & $\begin{array}{l}\text { Strong Representation: All countries are purchasing pulp and paper products from the } \\
\text { domestic market and all are carrying out logging and production. } \\
\text { Addresses Relevant Issues: Addresses a main threat (logging) for two of the five } \\
\text { biodiversity hotspots that are represented within the SC, the Atlantic Forest and the } \\
\text { Amazon Region }\end{array}$ \\
\hline Timber Building Products & $\begin{array}{l}\text { Aligns with Existing Activity: Transversal product for SPP and private consumption. Priority } \\
\text { product to some governments like Chile and priority product for SPP. }\end{array}$ \\
\hline $\begin{array}{l}\text { Strong Representation: All countries are purchasing timber building products from the } \\
\text { domestic market and all are carrying out logging and production. } \\
\text { Addresses Relevant Issues: Same as previous; addresses a main threat (logging) for two of } \\
\text { the five biodiversity hotspots that are represented within the SC, the Atlantic Forest and } \\
\text { the Amazon Region. } \\
\text { Aligns with Existing Activity: Within the sector, forestry certifications (such as FSC, PEFC }\end{array}$ \\
\hline
\end{tabular}

\footnotetext{
${ }^{12}$ Refer to Report Appendix G, Table G.1 for further details on SC Biodiversity Hotspots
} 


\begin{tabular}{|l|l|}
\hline \multirow{5}{*}{ Electrical Appliances } & $\begin{array}{l}\text { and ABNT) have a reasonable level of implementation in the region. In construction, } \\
\text { building rating tools such as LEED may be good drivers for ecolabelling criteria for building } \\
\text { products. }\end{array}$ \\
\hline $\begin{array}{l}\text { Strong Representation: Energy is produced and consumed in every country in the SC. } \\
\text { Housing, water, electricity and fuels represent 15.8-19.2\% of private consumption in the SC } \\
\text { region }{ }^{13} .\end{array}$ \\
$\begin{array}{l}\text { Addresses Relevant Issues: It addresses an environmental hotspot (energy consumption at } \\
\text { the use phase) and also social issues by reducing cost of living. } \\
\text { Aligns with Existing Activity: Energy efficiency ecolabels for electronic appliances have a } \\
\text { very good penetration in terms of private consumption and SPP for residential and } \\
\text { commercial equipment. }\end{array}$ \\
\hline $\begin{array}{l}\text { Strong Representation: SC region is recognised as a world tourism location. Strong } \\
\text { interest across all SC countries to address this area. } \\
\text { Addresses Relevant Issues: Addresses potential impact tourism industry can put on SC, } \\
\text { which affects some of the most sensitive ecosystems in the region as well as the world. } \\
\text { Aligns with Existing Activity: Although the sector is not at a mature stage, there is still } \\
\text { strong interest in promoting sustainability and eco-tourism. Some activity has occurred } \\
\text { such as the Pão de Açúcar tourism location being certified by the ABNT Type } 1 \text { ecolabel. }\end{array}$ \\
\hline
\end{tabular}

\section{Capacity for Technical Development}

As discussed in the SWOT analysis, the capacity of the SC for a regional ecolabelling programme lies mainly in the standards agencies and other organisations that have developed labels, seals and certifications for products and corporations in the region. Although there is a presence for a range of these types of organisations ${ }^{14}$, the technical rigour behind these labels is limited, with only one organisation within the SC widely recognised as a Type I ecolabel (ABNT in Brazil).

Learning from Mercosur's experiences in developing a regional ecolabel, a critical component for successful development on the technical side was found to be the operations of a credible certification body that is capable of working effectively across all involved countries. As discussed in the previous section, the lack of this body was part of the reason why the label was unable to prosper. Therefore, strong emphasis needs to be placed on this, if a regional ecolabel programme is to be perused.

The limited existence of certification bodies, such as Certfor and Cerflor, and capable experts in the area of life cycle assessment, results in a critical gap in the technical rigour behind some organisations' standards. This leads to, amongst other issues, false green marketing claims, which are just beginning to be policed in the SC.

\section{Case Study: SERNAC Charges Bosch for Misleading, "Green Advertising," Claims}

SERNAC, Chile's National Consumer Service organisation, sued home appliance manufacturer, Bosch, after the company was unable to provide proof for their product marketing claims, which stated their products to be, "100\% sustainable," and using, "green," technology. The lawsuit was triggered by a 'green advertising' study by SERNAC which resulted in issuing official letters to 14 companies demanding a background check on the statements contained in their advertising claims. Bosch was the only company that did not deliver a satisfactory answer. The company said that these messages are an essential part of the, "corporate philosophy," and that the characteristics of their products were constantly working on the issues of environmental care in all areas, from sustainable production methods to the investigation of new efficient technologies. Therefore, Bosch argued that the claim, " $100 \%$ sustainable and Green Technology Inside," was intended exclusively for its users to understand Bosch's commitment to the environment. SERNAC found the response to be inadequate and misleading and a lawsuit has been filed which may result in the maximum penalty established by the Chilean Consumer Law, 750 UTM (SERNAC, 2012).

\footnotetext{
${ }^{13}$ Refer to Report Appendix E, Table E.1 for further details on private consumption in the SC

${ }^{14}$ Refer to Report Appendix I, Table I.1 for a detailed list of SC institutions related to ecolabelling
} 


\section{Critical Aspects for Cooperation}

Based on the primary and secondary research findings and feedback from the regional experts, the study found that there is a strong interest in cooperation on ecolabelling and SPP both at national and regional level. While such cooperation may be challenging to achieve, there are also a number of long-term benefits that can create a strong business case for this effort, such as increasing sales in the export markets. It is important to keep in mind that the following critical aspects for implementation provided in the following table must be met for such cooperation.

Table 9: Critical Aspects for Cooperation

\begin{tabular}{|c|c|}
\hline Critical Aspect & Summary \\
\hline Governing Body & $\begin{array}{l}\text { There needs to be a centralised governing body for regional cooperation. This has shown to be critical } \\
\text { for all existing regional labels (e.g. Nordic Swan and EU Flower). The governing body must be in place } \\
\text { to first define the overall principles, cooperation framework, guidelines and objectives of the label and } \\
\text { then oversee that the management actions are abiding. }\end{array}$ \\
\hline $\begin{array}{l}\text { Stakeholder Engagement } \\
\text { and Buy-In }\end{array}$ & $\begin{array}{l}\text { Commitment of the government, business sector, academic community, and non-governmental } \\
\text { organisations is essential for successful ecolabelling initiatives. Without the engagement of industry } \\
\text { and government, ecolabelling initiatives will simply not materialise. }\end{array}$ \\
\hline $\begin{array}{l}\text { Regional Ecolabelling and } \\
\text { SPP Training Programme }\end{array}$ & $\begin{array}{l}\text { Implementing national level awareness and consultation supported by a regional dialogue and } \\
\text { exchange of information, and training programme are recommended as a minimum requirement for } \\
\text { the implementation of the regional cooperation. }\end{array}$ \\
\hline $\begin{array}{l}\text { Balanced Representation } \\
\text { Amongst the Participating } \\
\text { Countries }\end{array}$ & $\begin{array}{l}\text { Similar to the Nordic Council of Ministers, each regional country should have an equal representation } \\
\text { when critical decisions are made and it must be assured that consideration is made for tailoring } \\
\text { ecolabelling criteria to each country's specific context. In addition, the SC must take a more proactive } \\
\text { step towards ecolabelling and ensuring that the existing schemes and approaches at national level and } \\
\text { regional ecolabelling progress are compliant with international guidelines and practices in a way that } \\
\text { they do not constitute a non-tariff trade barrier. This can enable producers to more effectively } \\
\text { respond to these demands in their own way that would be most suitable for the area. }\end{array}$ \\
\hline $\begin{array}{l}\text { Robust Pilot Sector } \\
\text { Implementation }\end{array}$ & $\begin{array}{l}\text { A well-selected group of industry sectors should be piloted as a way to provide an initial trial for the } \\
\text { programme. These sectors need to be well represented across the region and be aligned with existing } \\
\text { SPP and ecolabelling. }\end{array}$ \\
\hline Consumer Awareness & $\begin{array}{l}\text { A consumer awareness/marketing campaign needs to be put in place to educate the consumers to } \\
\text { understand the concepts behind the ecolabel to hopefully enable them to make more conscious } \\
\text { decisions through the purchasing of ecolabelled products. }\end{array}$ \\
\hline $\begin{array}{l}\text { Methodological Working } \\
\text { Groups, and Roadmap for } \\
\text { Development of Technical } \\
\text { Criteria }\end{array}$ & $\begin{array}{l}\text { Life-cycle based ecolabels which draw from multiple criteria (i.e. Type I ecolabelling schemes) are the } \\
\text { most technically credible and internationally accepted approach for ecolabel standards and therefore } \\
\text { should be intended for the regional ecolabel. With that being said, a collection of industry, scientific } \\
\text { and civil society working groups, run through an effective project road map, must be in place in order } \\
\text { to meet the technical needs of a Type I label. }\end{array}$ \\
\hline
\end{tabular}

\section{Recommendations}

While the research found there to be an overall aspiration for regional cooperation on ecolabelling and SPP in the long term, the conditions in the region for running an effective cooperation programme is still in early stages. In order for the SC region to cooperate effectively, there are several challenges that need to be faced and addressed.

To begin with, it is critical to start engaging multiple stakeholders that have not been sensitised or have not participated in the initial discussions, such as key members from industry, NGOs and the scientific community. This will allow creating an overall baseline understanding of the advantages of tools such ecolabels and credible information about products and their role in advancing more sustainable consumption and production, in addition to providing an overview of the benefits of regional cooperation on these matters. Some of the stakeholders, importantly keeping a multi- 
stakeholder format, can be involved in the overall coordination structure/body that will have to be created to oversee the process of cooperation and eventual establishment of a regional scheme.

At a national level, the following table provides a summary of the fundamental steps needed to be done in order to begin a regional cooperation. The main objective of this stage is to formalise the support from the key stakeholder bodies in each country, and to begin to build the necessary components for the establishment of a regional body.

Table 10: Fundamental national actions for initiation of the regional cooperation

\begin{tabular}{|c|c|}
\hline National Actions & Summary \\
\hline $\begin{array}{l}\text { 1. Establish support from key stakeholder bodies } \\
\text { across SC }\end{array}$ & $\begin{array}{l}\text { Each country must seek out engagement with key } \\
\text { stakeholder bodies in order to present the concepts of the } \\
\text { regional cooperation model and request some formal } \\
\text { statement of support. }\end{array}$ \\
\hline $\begin{array}{l}\text { 2. Nominate representatives for the SC Regional } \\
\text { Cooperation Group }\end{array}$ & $\begin{array}{l}\text { Each country should nominate representatives to a } \\
\text { regional cooperation body. In order to create a balance in } \\
\text { the representation, the group should be made up of } \\
\text { government, industry, and non-governmental } \\
\text { organisations. }\end{array}$ \\
\hline $\begin{array}{l}\text { 3. Contribute to the roadmap for regional } \\
\text { cooperation }\end{array}$ & $\begin{array}{l}\text { Based on the following recommendations, a road map for } \\
\text { regional cooperation will be formulated into a guideline } \\
\text { document. In order to gain complete consensus across the } \\
\text { SC, each country must review these guidelines and } \\
\text { contribute to a final roadmap for regional cooperation. }\end{array}$ \\
\hline
\end{tabular}

An effective way to address action 1 is by drafting a common letter of support in order to provide a general agreement to common objectives for regional cooperation. These objectives will provide the vision for the regional cooperation and the principles for how the programme will operate. By getting the key stakeholder to sign this letter of support, the programme will gain the assurance that there is official support and that it is aligned under these values.

In addition to the following section, developing a guideline for the regional cooperation roadmap could also act as a catalyst for developing the next steps for regional cooperation, by providing the general concepts and a framework for the programme. This would not be a prescriptive guide for how the programme will operate but instead act as a template for the SC representatives to build on.

\section{Proposed Stages for Cooperation}

Three stages of cooperation are proposed for the Southern Cone region:

1. Promote and Enable: establish a firm foundation for the regional cooperation initiative on ecolabelling and SPP through promoting the role of ecolabels and product sustainability information (PSI) in sustainable consumption and production (SCP) and enabling stakeholders to understand and apply ecolabels as voluntary market based tools for advancing SPP.

2. Adapt: have in place a regional recognition system based on benchmarking criteria for existing and new ecolabels and voluntary standards which can serve also as a reference system for provision of credible and substantiated information about products.

3. Establish: establish a new type I ecolabelling programme for the SC region.

\footnotetext{
${ }^{15}$ This task has actually already been achieved at the end of the regional workshop Rio de Janeiro but for the sake of providing a complete structure to this stage of the regional cooperation strategy, it is still included as a fundamental action.
} 
These are called stages of cooperation because they can be selected as one option for a roadmap in a sequential order (stages 1-3) or, as explained further in Table 11, as another roadmap which omits the, "Establish," stage and continues to focus on development of the, "Adapt," stage. The decision for which roadmap to ultimately work with should depend on the needs and views of the stakeholders and the regional coordination group.

Following from the, "Fundamentals," stage (provided in Table 10) the, "Promote and Enable," stage would first focus on setting the regional structure in place, national-level awareness-raising, and developing an information network on ecolabelling and SPP. During this stage, an initial assessment will be conducted to look at international processes and their relevance to the regional initiative and mapping of the selected industry sectors (possibly pulp and paper, timber, electronics and tourism) to analyse the scope for harmonisation.

Subsequent to the, "Promote and Enable," stage, the, "Adapt," stage would run by combining the Nordic Swan's overall governance model and the African Ecolabelling Mechanism's (AEM) ${ }^{16}$ ability to benchmark existing labels and programmes. The, "Adapt," stage would focus on having in place a regional recognition system based on a number of principles/standards to benchmark existing and new ecolabels and voluntary standards towards stronger alignment and harmonisation, which can serve also as a reference system for provision of credible and substantiated information about products. The system can then be tested on pilot industries, selected based on the criteria of relevance for ecolabels and SPP. Anchoring on the recognition system, a central directory of certified products ${ }^{17}$ and information for these types of resources can be established through a website which can be linked with SPP policies. The work would concentrate on the most prominent sectors and labelling schemes.

Lastly, drawing from the EU Flower governance model, the, "Establish," stage would produce a new Type I ecolabel for the entire SC region. This is a long-term strategy which would begin with the establishment of a regional ecolabelling governing body, standards criteria, and the design and implementation of an entire labelling programme.

The proposed roadmap in the table below reports the objectives required in the immediate, short, mid and long-term, which addresses the two road map strategies proposed. Following from the defined objectives, the table outlines the necessary activities to implement and achieve those objectives. It also shows the immediate necessary actions to initiate the cooperation efforts. These immediate, short, mid and long-term objectives and actions are not intended to be followed exclusively but instead are provided as a way to give a better understanding of the requirements for the proposed strategies.

Table 11: Proposed roadmap(s) for SC regional cooperation

\begin{tabular}{|c|c|}
\hline \multirow{3}{*}{ 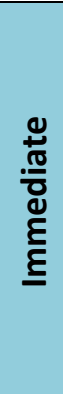 } & I. Fundamentals \\
\hline & $\begin{array}{l}\text { Objective: launch the process and ensure the participation of the relevant stakeholders from } \\
\text { the national level. }\end{array}$ \\
\hline & $\begin{array}{l}\text { The inception phase will include necessary steps to create an agreement among key } \\
\text { stakeholders on the proposed objectives and roadmap, and revise it based on the feedback } \\
\text { received. It will also allow creating an agreement on the implementation process and } \\
\text { governance structure for coordination of the regional initiative. It should include the following } \\
\text { actions: }\end{array}$ \\
\hline
\end{tabular}

\footnotetext{
${ }^{16}$ Refer to Sections 4.2.1 and 4.2.3 for additional information on the Nordic Swan and AEM's governance model

${ }^{17}$ Similar to www.ecospecifier.com
} 
1. Share the results of the roadmap with focal points who form a regional coordination group

2. Organise a webinar to get an agreement and plan start-up meeting

3. Organise a start-up meeting to discuss and agree on roadmap, its objectives, and way of implementation, discuss the workplan, governance structure and its modus operandi

\section{Outputs:}

- Agreement on the roadmap, objectives and way of implementation

\section{Promote and enable}

Objective: establish firm foundation for the regional cooperation initiative on ecolabelling and SPP through promoting the role of ecolabels and product sustainability information (PSI) and its use in SPP, and enabling stakeholders to understand and apply ecolabels as a voluntary market based tools for advancing SCP.

This phase will be an important one to set the stage for further implementation of the initiative. It will focus primary on setting the structure in place, awareness-raising at national level to bring the level of awareness and engagement to a certain level playing field among countries in view of their current differences. During this stage, an initial assessment work will be conducted looking at international processes and their relevance for the initiative, and a mapping of the selected sectors (possibly pulp and paper, timber, electronics and tourism) to analyse the scope for harmonisation. It can include the following actions:

1. Strengthen the regional coordination group

$\circ$ Finalise its composition, define its terms of reference and modus operandi,

- Create conditions for engaging other relevant stakeholders (e.g. signing precompetitive agreements if needed, especially with private sector representatives)

- Conduct regular in person or virtual meetings to coordinate the implementation

2. Carry out awareness-raising and capacity-building activities:

- Conduct regional training of trainers on ecolabelling and SPP

- Engaging the trained experts, conduct national consultation and awareness raising workshops and trainings at national level

3. Mapping and assessment of the selected sectors for the implementation of the next stage of cooperation.

4. Mapping of the international processes and initiative and assess their relevance to the next stage of the regional cooperation initiative: Global Guidance on PSI, 10YFP on Consumer Information and ISEAL Credibility Principles

\section{Outputs:}

- Clearly defined terms of reference and role of each stakeholder in the coordination group,

- Enhanced awareness and understanding about ecolabels, their role and how they can be combined with SPP to create integrated approaches around SCP and sustainable products,

- Clear understanding of the scope for harmonisation in selected industries and relevance of international initiatives and processes to serve as reference to the regional cooperation initiative.

\section{Adapt}

Objective: have in place a regional reference base scheme founded on benchmarking criteria for existing and new ecolabels and voluntary standards which can serve also as a reference system for provision of credible and substantiated information about products. 
Based on the assessments conducted and foundation laid in the previous stage, this stage will focus on developing and agreeing of a regional reference base scheme. It will be based on a set of benchmarking criteria against which existing ecolabels and voluntary standards can be assessed in terms of their effectiveness and contribution to advancing SPP in the region. The scheme can also be used as a reference tool for companies in developing their marketing claims and to encourage the provision of credible and substantiated information about products.

It will be ensured that the scheme is aligned with the international processes looking at the global level and regional level experience feeds into the development of the international processes. The scheme will be also disseminated and validated through a series of consultations. It will be tested in a number of pilot sectors identified based on their relevance for the region and SPP practices. The most valid ecolabels will be promoted for the use in SPP in the region.

The necessary actions can include the following:

1. Create two working groups:

$\bigcirc$ Using the guidelines developed through international processes (eg. PSI Guidance, PCR global Guidance, ISEAL Credibility Principles for standard setting systems, relevant ISO guidelines), develop a reference base scheme for the region.

- Test the reference base scheme for specific sectors towards harmonisation of approaches within the sector (e.g. sector guidelines)

2. Disseminate and validate the reference base scheme in the region

3. Organise capacity building activities for the private sector and public procurement officers to understand and use with the benchmarking

\section{Outputs:}

- Regional recognition of the reference base scheme to be used as a reference for provision of credible product sustainability information, in line with international standards and practices

- Sector guidelines based on the reference base scheme

- Enhanced understanding by private sector of how to provide information about product sustainability and public procurers on how to use the reference base scheme to select more sustainable products

- A structure for an online directory of certified products available for further population and development

\section{Option 1. Continue Adapt}

Objective: continue expanding the reference base scheme to more ecolabels and voluntary standards, while also conducting a review and revision of existing certified products.

If the SC countries find the, "Adapt," stage to be running effectively, then this option will allow them to continue developing the programme and allowing its initial work to be reviewed and improved upon. Also the scheme can then be used to develop an online directory hub for certified products to be used in SPP.

The following areas would be focused on for this option:

1. Continue growth of regional reference base scheme:

- Have working groups expand to additional existing ecolabels and standards that were not addressed in the initial years of the programme

2. Expand and update online directory 
$\circ$ Incorporate additional products to directory that are included in additional ecolabels and standards

- Update existing products upon the occurrence of any changes to their sustainability information

3. Implement identified mechanisms that will drive public procurers to use the reference base scheme

4. Develop an online directory for certified products to be used in SPP practices by countries at the national level.

\section{Outputs:}

- Expanded and revised version of the regional recognition benchmarking scheme and sector guidelines

- Updated online directory with additions and updates to list certified products

- Increased number of public procurers using the reference base scheme

\section{Option 2. Establish}

Objective: establish a new type I ecolabelling programme in the region.

If the countries wish to expand beyond the, "Adapt," stage, then this option will allow them to establish a new type I programme for the region.

This is considered as a long-term objective in the region which may require additional fundraising and strong political support. The following actions will be necessary to implement:

1. Develop programme and business plan for the establishment of the type I ecolabelling programme

2. Start with the pilot sectors selected in the 'Adapt' stage and develop common set of criteria

3. Ensure that the programme is in line with ISO 14024 guidelines

4. Join the Global Ecolabelling Network for information exchange, peer learning and mutual recognition opportunities

5. Develop marketing of the ecolabel

6. Ensure its integration into the SPP policies in the region.

\section{Outputs:}

- ISO type I Ecolabelling programme for the region 


\section{Introduction}

\subsection{Background}

Economic development during the last several decades has reduced poverty and expanded the access to goods and services for billions of people in the world. However, it has been paralleled by diverse negative environmental impacts, some of which are so serious that they threaten to undermine the very basis of current economic development (UNEP, 2012). One of the most significant aspects of this threat corresponds to unsustainable patterns of production, distribution, consumption and disposal of products, which can lead to resource degradation, environmental pollution and ecosystem services disruption.

These unsustainable patterns are the result of choices made by a myriad of actors across the value chain of products. As these choices are greatly conditioned by the information actors have about the products they are producing, trading or consuming. In order to overcome these unsustainable patterns, it is crucial to provide them with transparent, credible and meaningful information about the product's impacts along their life cycle, so that they are able to make informed choices.

In this sense, ecolabels are of great importance, as they provide environmental and/or social information of products that is easy to understand to all actors in the value chain. In effect, ecolabelling has been gaining support during the last decades due to its ability to generate environmental and/or social gains by substituting purchases of conventional products with purchases of more sustainable ones (Rubik et. al., 2008).

Although, demonstrating the environmental and/or social gains of ecolabels has been difficult, related mostly to a lack of empirical studies and to the complexity of separating its effects from other factors that influence the environment and society (Horne, 2009), its application is widely supported as an integral component of comprehensive initiatives aimed at achieving sustainable consumption and production patterns (DEFRA, 2010). The benefit of ecolabels is in their function as independent assurance of environmental and/or social superiority of certain products over others. Especially life-cycle based ecolabels which demonstrate an overall environmental and/or social improvement by taking a cradle-to-grave approach in indentifying and improving product's impacts. More specifically, support for ecolabels lies in their ability to (Prasad, 2012):

- Channel sustainable production and consumption choices in an appealing and flexible way, in comparison to setting regulations or policies;

- Guide manufacturers towards the right choices of raw materials, production processes, packaging and end-of-life logistics; and

- Influence the behaviour of consumers so that their choice of product comes with an environmental and/or social conscience.

Ecolabels are also beneficial for businesses. In a context where sustainability is a key business consideration and companies are progressively held responsible for the entire value chain and life cycle of their products, ecolabels constitute a key way to report and communicate their environmental performance (Lubin and Esty, 2010). This is not only for stakeholders along the supply chain, but also for concerned citizens whose demand for information about the world behind the products is steadily growing. In addition, companies using ecolabels not only enhance their market competitiveness but also increase their social legitimacy (Cañón-de-Francia and Garcés-Ayerbe, 2012). 
The anticipated and observed benefits of ecolabels have prompted many governments to include them into the environmental policy frameworks with support of other diverse policies and initiatives. Among global efforts of various actors to advance more sustainable consumption and production, the retail sector has been particularly influential imposing requirements on their suppliers in order to improve the sustainability of their global supply chains (AMPHOS 21, 2011).

This interest in sustainability and efforts has led to the proliferation of different systems and tools to generate and communicate information about products' environmental attributes (Prasad, 2012). According to Golden (2010), by 2010 there were more than 400 ecolabels in the world marking consumer products in nearly every product category.

Sustainable Public Procurement (SPP) policies play a crucial part in the uptake of ecolabelling. As Horne (2009) argues, through specific public procurement policies governments have backed the creation of markets for domestic labelled products. On the other hand, ecolabels are a key element for the widespread and better application of SPP, as they can be used to outline and verify the compliance with specifications of tendering processes (AMPHOS 21, 2011). The strong inter-linkage between ecolabelling and SPP is evidenced in the case of the EU, where countries like Germany, Austria, Sweden, Denmark, Finland, and the Netherlands implemented national ecolabelling programmes, which facilitated the development of environmentally sound procurement policies (AMPHOS 21, 2011).

In contrast to developed countries, developing countries have generally focused on controlling rather than preventing environmental impacts associated to the value chain of products. In other words, while they have focused on the use of regulations for changing production and consumption patterns, their use of economic instruments and voluntary approaches has not been proactive. Most of developing countries have limited experience in addressing products in an integrated way through a mix of regulatory and voluntary policy approaches such as SPP and ecolabels. This is particularly the case of South American countries (Prasad, 2012).

Nevertheless, as their productive structure and level of environmental performance is different from those developed countries where most of ecolabels have emerged, these schemes need to be tailored to their own requirements and circumstances. However, rather than each developing country pursuing its own ecolabelling scheme, a regional approach provides a practical solution to the need of providing easy and reliable information about environmental performance of products, especially for countries that share close economic ties and social and institutional backgrounds (AMPHOS 21, 2011). Examples of regional ecolabelling approaches are the EU Flower, the Nordic Ecolabel and the more recent African Ecolabelling Mechanism, still under development.

Regional ecolabelling approaches do not only save time, resources and other transaction costs, they also create scope for stronger cooperation on a number of issues that an ecolabel addresses. These include the issues of trade, resource efficiency, and industrial development in addition to the environmental aspects (AMPHOS 21, 2011). They also respond to the current challenge of ecolabels proliferation that confuses both producers and consumers and undermines the intended purpose of ecolabelling.

This study is part of the project "Seizing ecolabelling and sustainable public procurement opportunities in the Southern Cone (SC) region" lead by UNEP in conjunction with the Nordic Council of Ministers. This project has the objective of evaluating and advancing the strategies at 
the level of SC countries (Argentina, Brazil, Chile, Paraguay and Uruguay) towards the development of a regional cooperation on ecolabelling and promoting the role of SPP.

In order to advance towards this objective, a regional consultation meeting took place in Santiago, Chile, in November 2011, which gathered representatives from government ministries, industry associations, consumer groups, and standards agencies of the countries in the region. The purpose of the meeting was to initiate the technical discussions on the possibility of developing a regional cooperation on ecolabelling for the SC. The key outcome of the meeting was the agreement on the need to have more in-depth information sharing of current practices and lessons learned in each country with a long-term goal of developing a regional label.

\subsection{Objective}

The UNEP has commissioned a feasibility study to lay the foundation for the development of a regional cooperation on ecolabelling and promoting the role of sustainable public procurement in the SC. To this end, this study intends to:

- Provide an assessment of the SC context with respect to conditions needed for a regional cooperation on ecolabelling;

- Present an overview of various ecolabelling and sustainable public procurement initiatives that exist in the SC region;

- Identify priority sectors for consideration in terms of their potential for ecolabelling and public procurement;

- Define a strategy and options for cooperation;

- Describe a recommended way forward for the establishment of a regional cooperation.

\subsection{Structure of Report}

The structure of this report is designed to first provide the reader with an introduction to regional ecolabels, sustainable procurement, with international examples. This also includes a summary of the work done on existing regional ecolabels within the SC. Following from this, the context in the SC will be presented by drawing from economic, demographic, environmental and social indicators. From there, the report focuses on specific initiatives that are relevant to regional cooperation. This then leads into recommendations of the report, which intends to bring together the context research, existing programmes and initiatives into a few key recommendations for the regional cooperation in the SC and proposed roadmap for the initiative to go forward.

\section{Methodology}

The methodology for this study consisted of the following five stages:

1) Collection and review of secondary information through literature review

2) Collection and review of primary information through additional interviews

3) Development of the first draft of the report and internal review with UNEP and Nordic experts

4) Discussion of the preliminary findings and recommendations at the regional workshop

5) Report revision and finalisation

Stages one and two were run in parallel and the outcomes were constructed in stage three in order to provide the initial recommendations of the study. Stage four provided the opportunity for 
direct engagement with representatives across the SC in order to review the study's findings and reach a common agreement on the next steps for the region. Following from this, the feedback from the workshop was then incorporated into the draft report, creating the final version of the study.

\subsection{Collection and Review of Secondary Information}

A literature review was conducted in order to gather existing information on the following areas:

- International and regional ecolabelling initiatives;

- The general, economic and demographic context of the SC countries;

- Major environmental and social issues in SC countries

- Ecolabelling initiatives in SC countries; ${ }^{18}$ and

- Public procurement practices in SC countries.

Information was drawn from internet sources, publicly available reports and scientific journals. Appendix A, Table A.1 details those internet sources and documents used during the study. The complete list is provided in the references section at the end of the report.

\subsection{Collection and Review of Primary Information through Additional Interviews}

In addition to the literature review, a series of interviews was conducted with experts in the areas of ecolabelling and sustainable public procurement both in the Northern Hemisphere and the SC. Overall, 18 experts were interviewed. Appendix A provides a complete list of the interviewees and the questions asked to the experts.

The intention of the interviews was not to get a statistically representative sample of the region but instead to gather views and perspectives from direct stakeholders involved in the process across the region. The international experts consisted of persons with strong experiences in developing regional and international ecolabels and sustainable public procurement. Upon completion of the initial interviews, several follow-up interviews were held in order to gain clarification on particular areas, such as governance models and pilot sectors.

\subsection{Development of the First Draft of the Report and Internal Review with UNEP and Nordic Experts}

Once the primary and secondary information was gathered, a preliminary report was prepared for the review by UNEP and Nordic experts involved in this project. The feedback received on the report was translated into a list of actions for further development of the report and its summary. Appendix B provides a record of the meeting notes.

An internal report was then prepared to incorporate these additional actions while also addressing the report's recommendations. In order to gain additional feedback from the SC regional experts, a list of research questions were sent to four experts from Argentina, Brazil, Paraguay and Uruguay. The research questions focused on the report's proposed recommendations, including a

\footnotetext{
${ }^{18}$ It is important to note that the focus of the study was not to provide a full assessment of all existing ecolabels in the SC but instead to provide an overview of various SC ecolabeling and sustainable public procurement initiatives that currently exist. With that being said, the research on existing labels initially drew information from the Ecolabels Index directory due to its reputation for being the largest global directory of ecolabels. Following from this, further investigations were carried out (e.g. researching government websites and expert interviews) for each country to confirm the status of existing labels and to incorporate any additional labels that may have been overlooked in the directory.
} 
list of strategies for a SC regional cooperation, pilot sectors and key organisations. The project's methodology intentionally allocated a set amount of hours for research support from the SC regional experts in order to incorporate their experiences in the areas of ecolabelling and sustainable procurement in the SC region.

The internal report and responses from the research were then reviewed and a final draft report was delivered to the UNEP. Several iterations of the draft report were then carried out until the final version was complete.

\subsection{Discussion of the Preliminary Findings and Recommendations at the Regional Workshop}

A regional workshop was held on November 8-9, 2012, in Rio de Janeiro, Brazil, in order to review the draft report's findings and recommendations, and reach a consensus on the way forward for regional cooperation. More than twenty SC representatives attended, at least two from each country, as well as experts from the European Commission and the Nordic Council of Ministers. A complete list of attendees and a record of the meeting is provided in Appendix C.

\subsection{Report Revision and Finalisation}

Based on the feedback from the regional workshop, the draft report was then revised and finalised upon UNEP's approval. The main revision of the report was focused around the recommendations section, which incorporated key findings from the regional workshop.

\section{Regional Ecolabelling and Sustainable Public Procurement}

\subsection{Overview}

In order to provide an introduction to the report's research, the following section gives an overview on ecolabelling and sustainable public procurement. Examples of existing regional ecolabels (being implemented overseas) and a summary of previous work on regional ecolabelling in the SC then follow.

\subsubsection{Ecolabelling}

Ecolabels are a communication tool to differentiate more sustainable product on the marketplace. More specifically, ecolabels are an instrument for informing consumers or clients about products or services, which have a positive performance according to defined sustainability criteria, especially in terms of a low impact on the environment. Whilst ecolabels are voluntary, they have become a competitive factor for suppliers and manufacturers around the world.

Globally, there are many existing labelling policies and programmes created by governments, nongovernmental organisations (NGOs) and private companies, which cover a range of sectors and address various environmental and social aspects. With the objective of categorising and consolidating ecolabels, the International Organisation for Standardisation (ISO) has set a group of various standards covering different types of environmental labels and declarations:

Table 10: Ecolabel Type Summary

\begin{tabular}{|l|l|l|}
\hline Type & Summary & Examples \\
\hline Type I & $\begin{array}{l}\text { Voluntary, multiple-criteria based, multi-product, third party programme that awards a licence } \\
\text { which authorises the use of environmental labels on products indicating overall environmental } \\
\text { preference of a product within a product category based on life-cycle considerations (ISO }\end{array}$ & $\begin{array}{l}\text { Nordic Swan, EU Flower, } \\
\text { Blue Angel }\end{array}$ \\
\hline
\end{tabular}




\begin{tabular}{|c|l|l|}
\hline Type II & $\begin{array}{l}\text { 14024). } \\
\text { Environmental self-declaration or claim that does not require third party verification, often } \\
\text { based on a single issue, i.e. not based on life-cycle considerations (ISO 14021). }\end{array}$ & \% Recycled Content \\
\hline Type III & $\begin{array}{l}\text { Environmental Product Declarations that provide quantified environmental data of a product, } \\
\text { under pre-set categories defined by a qualified third party and based on life-cycle assessment, } \\
\text { which are verified by a qualified third party (ISO 14025). }\end{array}$ & $\begin{array}{l}\text { Japan, Sweden and a } \\
\text { number of other } \\
\text { countries have a EPD } \\
\text { programmes }\end{array}$ \\
\hline
\end{tabular}

In addition to the label types defined by the ISO, there is also a number of Type IV or "single-issue" labels which are not considered within ISO classification. Type IV labels are sector-focused and granted by a third-party certification referring to a specific environmental, social or ethical characteristic of a product. An important difference of Type IV labels is that they focus on specific key environmental impacts and/or social issues that may occur in the product life cycle (e.g. forest or fishery management, agricultural production, energy consumption, etc.) rather than taking a more holistic view of the product's environmental and/or social performance from a life-cycle perspective. These labels are generally based on a set of 'best practice' criteria or standards that are used to differentiate the product from mainstream products, usually on the basis of the reputation of the organisation issuing the label. For example, the Forest Stewardship Council certifies that labelled products are from forests managed according to a specific set of protocols (DEFRA, 2010).

Taking a life-cycle perspective when identifying and measuring possible impacts of products or services is a practical way of identifying opportunities for reductions and achieving a holistic improvement at a product level. Internationally, the method for assessing the environmental performance of products with respect to its entire life is known as life-cycle assessment (LCA). LCA is a technique to assess environmental and social impacts associated with the product from cradle to grave (e.g. from raw material extraction, manufacturing, distribution, use, to end of life). This enables the estimation of cumulative environmental impacts resulting from all stages in the product life cycle, which often includes impacts that are not considered in more traditional analyses. Additionally, it helps to avoid shifting environmental problems from one place to another, as it addresses the entire product system, hence, avoiding the sub-optimisation that could result if only a single process were the focus of the study (EPA, 2006). Therefore a life-cycle approach for ecolabels can assist in:

- Identifying opportunities to improve the environmental performance of products at various points in their life cycle;

- Informing decision-makers in industry, government or non-government organisations (e.g. for the purpose of strategic planning, priority setting, product or process design or redesign); and

- Marketing (e.g. implementing an ecolabelling scheme, making an environmental claim, or producing an environmental product declaration) (ISO, 2006).

- Differentiating products that have an overall environmental impact lesser than other products.

- Ensuring the credibility of the information and label by running the program through a third-part verification system. 


\subsubsection{Sustainable Public Procurement}

Public procurement is a substantial share of the economy in a global frame, reaching between 8$25 \%$ of a country's GDP in state acquisitions and contracts (OECD, 2006). Sustainable public procurement (SPP) goes further than the common principles of public procurement (i.e. purchasing products that fulfil the required specifications at the best value), as it also integrates a product's performance with respect to sustainability. Therefore, through SPP, the purchase specifications require a product with minimum or lower environmental impact, as well as with a positive social outcome in relation to another product that fulfils the same purpose.

The effects and the influences that SPP has on the environment and society is being recognised and better understood as an instrument to reach objectives in sustainable development (e.g. energy and water efficiency, GHG emissions biodiversity protection, etc.). In this manner SPP offers governments an opportunity to lead sustainable development in the country by utilising their acquisition power as an incentive for suppliers to shift towards more sustainable objectives.

In general, SPP considers sustainability criteria that specify how to evaluate if a product is preferable with respect to its impacts on the environment and society. In this sense a life-cyclebased ecolabel for products is of great assistance for the purchaser, as it would enable a better understanding of a product without having to go through more analysis. Additionally, SPP could be a considerable channel for the uptake for ecolabels by the markets, as it establishes a frame with specific margins and regulations to satisfy.

\subsection{Existing Regional Ecolabels}

Numerous ecolabels that exist in the marketplace can be differentiated based on their scopes (e.g. national, regional, sector- or impact-specific labelling), governance models (e.g. public or private), levels of credibility, and market penetration. In this complex panorama, it is necessary to review their functionality and impacts learned in order to identify the common characteristics of a successful ecolabelling initiative.

The following section provides information about international initiatives considered to be specifically relevant to this study. The main focus is set on the existing and developing regional ecolabelling programmes in the world: the European Union Flower, the Nordic Ecolabel and the African Ecolabelling Mechanism (under development). Additional international programmes that support ecolabelling and other product sustainability information (PSI) were also presented due to the influence they have on international ecolabelling and SPP programmes.

\subsubsection{Nordic Swan Ecolabel}

By the late 1980s, the Nordic market had a collection of diverse private ecolabelling schemes claiming good environmental performance of goods. With this growing activity, there was still yet to be an independent organisation overseeing their practices. This issue resulted in increasing competition and confusion around which scheme to trust and place preference on in the marketplace (Horne, 2009). In order to overcome this issue, the Nordic Council of Ministers, consisting of Norway, Sweden, Finland, Iceland, Denmark and the self governing areas of Åland Islands, Faroe Islands and Greenland, decided to develop an ecolabel for the region that would harmonise existing schemes, be clearly recognisable by Nordic consumers, and concentrate efforts into one single label (AMPHOS 21, 2011). Thus, the Nordic Ecolabel scheme, commonly known as the Swan label, was adopted in 1989 by the Nordic Council of Ministers. By adopting a regional approach, Nordic countries were able to join efforts and make the label recognised both in the region and globally (AMPHOS 21, 2011). 
The Nordic Swan ecolabel is a voluntary ISO Type I ecolabelling scheme. Norway and Sweden took up the label from the start, Finland joined in 1990, Iceland in 1991 and Denmark in 1998. Today there are 63 product group categories and over 5,000 products that have been awarded the Nordic Swan label. Funding for the scheme is derived from the member countries and from an annual licence fee charged to label holders. The share of the management budget comes from the licence fees, which was 77\% in 2006 (Aalto et al., 2008).

The Nordic Ecolabel is used not only to enhance the sustainable consumption of private consumers but also as a way to facilitate Sustainable Public Procurement (SPP) in Nordic countries. It is estimated that approximately $60-70 \%$ of Nordic public purchasers use this ecolabel for the purpose of SPP (Aalto et al., 2008). With respect to procurements that require a competitive bid, suppliers cannot be obligated to make use of a specific label. With that being said, reference can be made to the criteria of the Nordic Ecolabel and the label can be specified as one way of ensuring compliance with the product requirements. In addition, the Nordic Ecolabel criteria documents serve as a useful source of information for public purchasers (Aalto et al., 2008).

The governance structure of the Nordic Swan Ecolabel is provided in Table 13 below. The fundamental rules of procedure for the Nordic Ecolabelling Board (NEB) are governed by decisions of the Nordic Council of Ministers (NCM). The NCM does not deal with details of the system. The NEB manages the general operations of the label, such as drawing up annual work plans and reports, approving product groups and criteria, appointing members to expert groups that draft criteria, and coordinating the communications and marketing strategies.

National Ecolabelling Bodies (or secretariats), which are mandated by national authorities, manage the schemes at the national level. The national bodies administer the costs of criteria development and product licensing by managing the licensing process and co-ordinating the advisory work of National Ecolabelling Boards. The latter consist of authorities and other stakeholders which advise the ecolabelling bodies on appointing members to the NEB.

Table 11: Nordic Ecolabel Governance Structure (Aalto et al., 2008)

\begin{tabular}{|c|c|}
\hline Governance Role & Role and responsibilities \\
\hline Nordic Council of Ministers & $\begin{array}{l}\text { - } \quad \text { Approves goals and principles } \\
\text { Provides funding for the Nordic co-ordination and for the secretariat of } \\
\text { the Nordic Ecolabelling Board }\end{array}$ \\
\hline Nordic Ecolabelling Board & $\begin{array}{l}\text { - Makes decisions of principle and operative decisions concerning } \\
\text { ecolabelling } \\
\text { - } \quad \text { Draws up annual work plans and reports } \\
\text { - } \quad \text { Approves product groups and criteria } \\
\text { - Decides on the principles for communications and marketing strategy }\end{array}$ \\
\hline $\begin{array}{l}\text { National Ecolabelling Bodies } \\
\text { (secretariats) }\end{array}$ & $\begin{array}{l}\text { - Mandated by the national authorities to manage the schemes on a } \\
\text { national level } \\
\text { - Cover the costs of criteria development and licensing (party with } \\
\text { financial contributions from the national authorities for criteria } \\
\text { development) } \\
\text { - Manage the licensing process } \\
\text { - Co-ordinate the advisory work of national ecolabelling boards }\end{array}$ \\
\hline National Ecolabelling Boards & 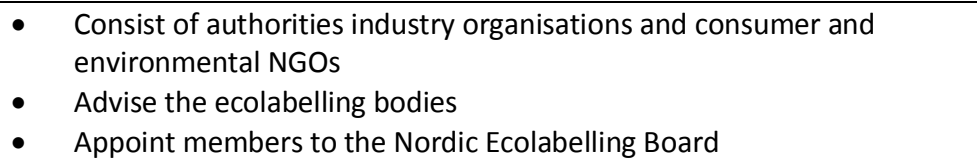 \\
\hline
\end{tabular}




\subsubsection{EU Ecolabel}

The EU Flower ecolabel programme was established in 1992. It is a voluntary, multi-criteria based, third-party scheme (ISO Type I) with criteria for compliance based on life-cycle considerations. Its overall objective is to contribute to the efficient use of resources and to environmental protection through the promotion of products with lowered negative environmental impacts, when compared with similar products.

Today, 30 countries participate in the EU Flower scheme (27 EU countries and three non-EU countries). It currently has 26 product categories and more than 1,300 licences have been awarded on more than 17,000 products. The programme is sustained through funding from the European Commission and the member states, and from revenues coming from the annual licence fee for those holding the EU Flower label. Most of the EU Ecolabel operation is supported by public funding.

The EU Flower's advantage mainly has to do with its multi-country dimension, with the label being used across the entire European Union as well as other European countries (Horne, 2009). It is also the only scheme that has discounts for SMEs, micro enterprises and operators in developing countries. ${ }^{19}$

On the other hand, bureaucracy, complexity, rigidity, delays in setting criteria and costs are often viewed as weaknesses of the scheme. The latter, together with claims that political interests rule over scientific and environmental findings, seems to explain the limited uptake and impact of the label. This is especially the case in states with strong national schemes in place, such as Germany (Horne, 2009).

Similar to the Nordic Ecolabel, the EU Flower Ecolabel is also used to facilitate SPP within the European Union. The EU Ecolabel provides an excellent source for finding environmental criteria for public procurement among EU countries. At the same time, as long as these criteria are the same or lower than those of the EU Ecolabel, public procurers can verify if a product meets the criteria included in the tendering simply by checking that it carries the EU Ecolabel. In fact, following EU procurement law (Directive 2004/18/EC), the EU Ecolabel, together with other ecolabels, can be used as a source for environmental criteria and as a form of verification. However, public procurement cannot demand that a product carries a specific ecolabel; it can only indicate that the criterion sustaining a certain ecolabel is met, and that it may be used as one form of proof for compliance (EC, 2008). The bond between the EU Flower Ecolabel and SPP has recently been strengthened by introducing a process where a common scientific knowledge base for criteria for ecolabelling and public procurement within a product area is established through life-cycle assessment of a selected product. Based on this, specific criteria for the EU Flower Ecolabel and for Green Public Procurement are then developed. This is also done in an attempt to harmonise all the approaches targeting products in the SCP framework and reducing the compliance requirements for industries.

The EU Flower has a complex and multilayered governance structure. Each member state assigns one or more 'competent bodies' in charge of implementing the scheme at the national level. These competent bodies are responsible for receiving applications and for awarding the label.

\footnotetext{
${ }^{19}$ Application fees, in general terms, shall be not lower than EUR 200 and not higher than EUR 1200 . However, in the case of SMEs and operators in developing countries, the maximum application fee shall be not higher than EUR 600. In the case of micro-enterprises, the maximum application fee shall be EUR 350. In the case of annual fees, the competent body may require each applicant who has been awarded the label to pay an annual fee. SMEs and operators in developing countries shall pay a fee not higher than EUR 750. In the case of micro-enterprises, the maximum annual fee shall be EUR 350 .
} 
New criteria are adopted by a vote in the Regulatory Committee and any option requires a qualified majority among the members. Although setting criteria across different national conditions requires compromises, the conformity it offers can be welcomed by manufacturers due to lower transaction costs.

Table 12: EU Flower Governance Structure (Aalto et al., 2008)

\begin{tabular}{|c|c|}
\hline Governance Role & Roles and Responsibilities \\
\hline $\begin{array}{l}\text { European Parliament and } \\
\text { Council of the European Union }\end{array}$ & - Adopt/revise regulation on Community Ecolabel Award Scheme \\
\hline European Commission & $\begin{array}{ll}\text { - } & \text { Provides annual budget and secretariat for the EUEB } \\
\text { - } & \text { Provides funding for criteria development (carried out by DG JRC (IPTS)) } \\
\text { - } & \text { Establishes Community ecolabel working plan (including priority product } \\
\text { groups) } \\
\text { - } \\
\text { - } \\
\text { - } \\
\text { - }\end{array}$ \\
\hline Regulatory Committee & $\begin{array}{l}\text { - } \quad \text { Consists of national authorities represented by their mandated delegates } \\
\text { - } \quad \text { Approves criteria } \\
\text { - } \quad \text { Approves working plans }\end{array}$ \\
\hline $\begin{array}{l}\text { European Ecolabelling Board } \\
\text { (EUEB) }\end{array}$ & $\begin{array}{l}\text { - Consists of representatives of the national competent bodies and } \\
\text { representatives of selected stakeholder organisations. The meetings where } \\
\text { criteria are discussed are open for interested parties. } \\
\text { - } \quad \text { Consulted on the working plan } \\
\text { - } \quad \text { Responsible for drafting criteria }\end{array}$ \\
\hline Ad-hoc Working Groups & $\begin{array}{ll}\text { - } & \text { Open for participation of interested parties } \\
\text { - } & \text { Draft criteria for labelling } \\
\end{array}$ \\
\hline National Competent Bodies & $\begin{array}{l}\text { - Mandated by the national authorities to manage the schemes on a national } \\
\text { level } \\
\text { - Cover the costs of licensing, national marketing efforts, work for EUEB and } \\
\text { commenting on draft criteria (party with financial contributions from the } \\
\text { national authorities) } \\
\text { - } \quad \text { Manage the licensing process } \\
\text { - } \quad \text { Ensure transparency and active involvement of stakeholders } \\
\text { - } \quad \text { Seek opinions of interested parties at national level } \\
\text { - } \quad \text { Promote the use of the EU Ecolabel }\end{array}$ \\
\hline
\end{tabular}

\subsubsection{African Ecolabelling Mechanism}

In March 2005, the African Ministerial Conference on Environment (AMCEN) approved an African 10-Year Framework Programme on Sustainable Consumption and Production. The plan was one of the main undertakings of the Johannesburg Plan of Implementation, which was endorsed by the World Summit on Sustainable Development. One of its key activities within the plan was the expansion of market access and improvement of the environmental profile of African products while also establishing a mechanism that promotes the environmental branding. In an act to meet these set objectives, the UNEP, with support from the Marrakech Taskforce, initiated the process for the development of an African Ecolabelling Mechanism (UNEP, 2007).

The main objectives of the African Ecolabelling Mechanism are the following (UNEP, 2007):

- To contribute towards the fulfilment of AU/NEPAD objectives on expanding the access for African products to regional and international markets;

- To stimulate appropriate environmental and health-related standards within the design and production of African products; and 
- To develop a cohesive approach for the region on the effective management of trade and environment relationship.

In order to meet these objectives, the African Ecolabelling Mechanism operates through the governance structure provided in Table 15. Similar to the Nordic Swan and EU Ecolabel, a main governing body develops and oversees the general policies of the programme (executive board), a technical board addresses and monitors the development of the label's criteria, a secretariat manages the day-to-day coordination, and working groups focus in on the criteria for each specific sector.

Table 13: African Ecolabelling Mechanism Governance Structure (based on UNEP, 2007; UNEP 2008)

\begin{tabular}{|c|c|}
\hline Governance Role & Roles and Responsibilities \\
\hline Executive Board & $\begin{array}{l}\text { - Governing body of the scheme } \\
\text { - Provides the general guidance and policy direction to the development and } \\
\text { operation of the mechanism }\end{array}$ \\
\hline Technical Board & $\begin{array}{l}\text { - Experts from key technical institutions and organisations } \\
\text { - Provides the overall technical advice and input to the activities of the } \\
\text { scheme }\end{array}$ \\
\hline Secretariat & $\begin{array}{l}\text { Manages the day-to-day functions of the scheme under the general } \\
\text { guidance of the Executive Board and the technical guidance of the Technical } \\
\text { Board }\end{array}$ \\
\hline Working Groups & $\begin{array}{l}\text { - Consist of members representing key players and actors in the business and } \\
\text { ecolabelling initiatives in the sector } \\
\text { - } \quad \text { Responsible for all the technical input for each priority sectors }\end{array}$ \\
\hline
\end{tabular}

As there was a large number of existing ecolabelling initiatives that are operational in Africa, the African Ecolabelling Mechanism noted the importance of building upon the experience and structure of existing ecolabelling initiatives. Thus, one of its main activities corresponds to validation and harmonisation of existing ecolabels. This function aims at developing and implementing a system through which current national, regional and international ecolabelling systems that are of importance to the African region, are validated and harmonised (UNEP, 2007). More specifically, the workflow of this scheme would follow two tracks; the Executive Board either decides to further consider the inclusion of a product category identified, or it is submitted by the Secretariat. This would lead to track one following products that have a labelling programme and track two following products under consideration that do not have a labelling programme (UNEP, 2008).

Following UNEP (2008: 13), under track one, "an Expert Review Group will be formed to undertake the validation and harmonisation of the labelling programme and submit its recommendation to the Technical Board. The Technical Board would make its recommendation on the certification by making a submission to the Executive Board. The Secretariat will execute the implementation on the basis of the Executive Board's decision." Under track two, "the Expert Review Group would be mandated to develop a draft criteria and procedures based on latest technology. This would then be taken through a multi-stakeholder validation process before being reviewed by the Technical Boards and submitted to the Executive Board for its final decision."

The African Ecolabelling Mechanism is not yet operational but under development. Nevertheless, up to now considerable progress has been made on the label, including a regional assessment of 
existing ecolabels, establishment of the Secretariat, several regional meetings with key partners and promoters, and secured funding from the German Climate Change Fund through the German Federal Environment Ministry for the launch and development of the mechanism (AMPHOS 21, 2011: 10).

One important feature of the African Ecolabelling Mechanism is its emphasis on existing ecolabels in the African region. Thus, instead of creating yet another, possibly, competing label, regional initiatives can emulate the idea that existing standards can be benchmarked against overall common regional standards. In this sense, validation and harmonisation of existing ecolabels can be an aim of new regional ecolabelling initiatives seeking to harmonise and align what already exists in the market.

\subsubsection{Other Relevant International Initiatives}

In addition to these three regional initiatives, the following sub-sections provide several examples of international programmes related to ecolabelling and product sustainability information worldwide. These programmes do not provide certification of products but instead serve as framework or support systems in areas such as networking and promotion, standards development, and scientific research.

\section{a. The Global Ecolabelling Network and GEN Internationally Coordinated Ecolabelling System}

The Global Ecolabelling Network (GEN) is a global association of Type I ecolabelling organisations which cooperate to develop, promote and harmonise the use of ecolabelling worldwide and see to encourage an increasing supply and demand of more environmentally responsible goods and services. GEN has 27 member organisations, including the European Commission's Environment Directorate-General, the Nordic Ecolabelling Board, and the Assoçiacão Brasileira de Normas Técnicas (ABNT), which is the only GEN member from South America.

GEN focuses on Type I ecolabels of the ISO 14020 series as internationally recognised and the most comprehensive standards for labelling schemes. ISO 14024 (Type I ecolabel) considers labels from a whole of life perspective, using several environmental impact categories to develop multicriteria standards which are accredited independently by a third-party organisation.

GEN Internationally Coordinated Ecolabelling System (GENICES) was established by GEN in 2003 as a mechanism for enhanced cooperation and collaboration in product certification, criteria development and review. GENICES seeks to expedite the start of new programmes and the certification of products already certified elsewhere in order to facilitate the access to export markets and the procurement of multinational companies. This is being achieved through the development of criteria common to different ecolabelling schemes and mutual recognition of verification procedures. These processes aim also to contribute effectively to concerns about ecolabels or voluntary environmental requirements being trade barriers. The overall purpose of GEN and GENICES is thus to provide frameworks for more effective cooperation among ecolabels, reducing the transactions costs for producers looking for compliance with ecolabels in different markets.

Most of GEN members also use Type I ecolabels as primary references for green products in Green or Sustainable Public Procurement policies and practices of their respective governments.

\section{b. ISEAL Alliance}

Founded in 2002 by a group of sustainability standard organisations, ISEAL seeks to define good practice for sustainability standards and promote credible standards among relevant stakeholders 
worldwide. ISEAL covers standards for the following sectors or subjects: agriculture, carbon and climate, forestry, fishing, manufacturing and textiles, mining and minerals and water. Members include Forest Stewardship Council (FSC), Fairtrade International, Marine Stewardship Council (MSC), Rainforest Alliance, UTZ Certified and Social Accountability Accreditation Services, among others $^{20}$. Most of these standards correspond to labels referred to as Type IV ecolabels, described in Section 4.1.1.

ISEAL provides its members with Codes of Good Practices often seen as global references for developing standards and filtering effective and credible ones. The codes cover standard setting, assurance (certification and accreditation) and impact assessment stages of a standard system.

\section{c. The Sustainability Consortium (TSC)}

As sustainability is coming into the mainstream, global companies and retailers are increasing the demand for credible and robust methods for sustainability assessment and communication. Owing to the multi-disciplinary nature of the subject, the complexity of the supply chains involved and the multiple visions and interests from different groups, there is a recognised need to make collaborative efforts to align methods and share information. In response, multi-stakeholder organisations such as The Sustainability Consortium (TSC) have been created.

TSC is a business-oriented organisation which seeks to design and implement a credible, transparent and scalable science-based Sustainability Measurement and Reporting System (SMRS), which can be accessible for producers, retailers and users of consumer products. The SMRS addresses both environmental and social issues, using a life-cycle approach. TSC members include private companies, NGOs, universities and government organisations ${ }^{21}$. The organisation is based in the US, has opened regional hubs in Europe and South America, and has recently announced plans for expanding to China.

The SMRS is divided into two levels:

- Level 1 SMRS: Based on literature review of published studies (life-cycle assessments, empirical studies and others), expert interviews and member input, a Category Sustainability Profile (CSP) is created for each product category. Each CSP summarises the product category's environmental and social hotspots, improvement opportunities and additional stakeholders concerns. Based on the CSP, Key Performance Indicators (KPIs) are created for members (e.g. retailers) to engage with their supply chain for performance tracking and improvement.

- Level 2 SMRS: This model and framework under development seeks to enable scientifically credible comparisons between the life cycles of different products within a product category. The model would use the best available life-cycle assessment methodologies, data and supply chain information to create globally standardised databases and measurement protocols to accurately represent the entire product value chain. This would allow users to enter specific parameters of their products to obtain assessments at a fraction of the time and cost usually involved in performing a life-cycle assessment.

Currently, the main focus of TSC's work is set on the Level 1 SMRS. CSPs and KPIs covering the first 35 product categories were released to members in August of 2012. The number of product categories covered is expected to reach 100 by the end of 2012, including products from the

\footnotetext{
${ }^{20} \mathrm{http}: / /$ www.isealalliance.org

${ }^{21}$ See list of members at http://www.sustainabilityconsortium.org/members/.
} 
apparel; electronics; food, beverage and agriculture; home and personal care; paper, textiles and toys sectors. Retailers, such as Walmart, are piloting the first set of KPIs, by engaging with their supply chains (B2B communication) in order to measure and drive improvements on the most relevant sustainability issues for the products sold in their stores ${ }^{22}$.

TSC's work has set out to not only provide drivers in the retail sector but also in consumer demand. The retail sector will begin to present these KPIs as indicators to help guide their purchasing decision, where they will put preference on suppliers that achieve the KPI sustainability improvements. In addition, TSC is also studying more effective mechanisms for increasing consumer awareness and demand of sustainable products (e.g. how many attributes can be effectively communicated to final consumers, or which visual schemes are more appealing).

\subsection{Existing Regional Ecolabelling Efforts in the Southern Cone}

In the early 1990s, under the Mercosur trade agreement, efforts were made to develop a, "Green Label," for participating countries. However, the work was discarded due to the lack of a central certification body capable of operating across the region, as well as differences among countries and the impacts it would have on the competitiveness of their industries. In 2010, a new effort for SC ecolabelling was put forward by UNEP as part of its Sustainable Consumption and Production Agenda, which this study is contributing to. The following sub-sections provide further details on these initiatives.

\subsubsection{Mercosur}

Mercosur was established in 1991 primarily as a trade agreement that permits the consolidation of a customs union among particular South American member states. Four of the five SC countries (Argentina, Brazil, Paraguay and Uruguay) are member states and Chile is an associate member. It was conceived as an appropriate instrument for the integration of its member states to the outside world, providing tools for improving competitiveness (AMPHOS 21, 2011).

In this context, these countries developed the "Mechanism for Political Consultation and Coordination", which allows the creation of agreed positions on matters of regional scope beyond the economic and commercial issues. As part of this mechanism, Work Sub-group No. 6, "Environment" (Subgrupo de Trabajo No. 6 "MedioAmbiente," SGT6) started working on developing a, "Green Label," for Mercosur. Progress on this label has been slow due to two main challenges; the need of a central certification body and, as Gobby (2006: 121) states, "internal divergences among the countries over the potential repercussions of the competitiveness of their industries." Thus, the Sustainable Development Commission at Mercosur is currently seeking funding for a pilot ecolabel project to take place in the Mercosur countries.

\subsubsection{Work done up to now by UNEP}

UNEP's Sustainable Consumption and Production Agenda focuses on information tools, among other approaches and tools to promote SCP, which address the sustainability of products and services in order to provide a link between sustainable consumption and sustainable production.

The UNEP project, "Enabling developing countries to seize ecolabel opportunities," was completed in 2012. The project focused on increasing the environmental efficiency of key export products in developing countries through the use of life-cycle based ecolabelling. The project worked in selected countries (Brazil, China, India, Kenya, Ethiopia, Mexico and South Africa) with industries

\footnotetext{
${ }^{22}$ http://www.sustainablebrands.com/news_and_views/articles/walmart-sets-2017-target-supply-chain-improvement-takessustainability?utm_source=Twitter\&utm_medium=schtweets\&utm_campaign=editorial
} 
to meet the requirements of Type I ecolabels and with governments to create an enabling policy framework. This was done through activities such as awareness raising, capacity building, technical assistance and consultation activities involving diverse stakeholders.

In addition, this project also aimed at promoting greater cooperation and mutual recognition among ecolabelling programmes including regional approaches. The regional approach creates also scope for stronger cooperation on a number of issues that ecolabelling address, such as environmental protection, trade, resource efficiency and industrial development. Regional efforts that allow harmonisation of ecolabelling initiatives in selected countries are emphasised because they can more efficiently make use of time, resources, and reduce transaction costs. Within this framework, UNEP, jointly with the Nordic Council of Ministers, started the project "Seizing ecolabelling and sustainable public procurement opportunities in the Southern Cone region", whose objective is to assess and advance strategies at the level of SC countries (Argentina, Brazil, Chile, Paraguay and Uruguay) towards the development of a regional cooperation on ecolabelling and promoting the role of SPP.

In order to initiate the discussion around the development of regional ecolabelling cooperation for the SC, a consultation workshop took place on 17-18 November 2011 in Santiago, Chile. Relevant national, regional, and international stakeholders were invited to discuss, share information, and agree on the relevance of such initiative, including representatives of the ministries of trade and industries and environment, industry associations, standard agencies and other technical and civil society institutions of Chile, Argentina, Brazil, Paraguay and Uruguay. With the view of developing a regional ecolabel in the long run, the workshop's main result was an agreement that more thorough information sharing of current practices and lessons learned in each country was needed. This feasibility study is part of this project (AMPHOS 21, 2011).

\section{Southern Cone Context}

An understanding of the SC context is provided in the following section in order to define the perspective for regional cooperation. This section, as well as additional information provided in the appendix, provides a summary of the SC countries with respect to the following areas: economy, demographics, environment and social issues.

\subsection{Overview}

SC countries represent approximately $4 \%$ of both world population and GDP ${ }^{23}$. In terms of land area, they account for $10 \%$ of the world. Brazil accounts for approximately $70 \%$ of population, land area and GDP of the SC. On the other hand, Uruguay represents approximately $1 \%$ of the SC population, land area and GDP ${ }^{24}$. All SC countries have a GDP/capita over US\$10,000, except Paraguay, which is significantly behind (US\$ 3,635) ${ }^{25}$.

\subsection{Economics}

Within the SC, private consumption corresponds to the largest GDP component for all countries, which shows a promising opportunity for domestic trade. Non-alcoholic beverages, housing expenses and transport represent key consumption clusters ${ }^{26}$. While manufactures make up

\footnotetext{
${ }^{23}$ Refer to Appendix D, Table D.1, for further detail on SC and world GDP.

${ }^{24}$ Refer to Appendix D, Table D.2, and Figure D.1 for further detail on SC population and surface area.

${ }^{25}$ Refer to Appendix D, Figure D.2, for further detail on SC GDP per capita.

${ }^{26}$ Refer to Appendix E, Figure E.1, and Table E.1 for further detail on SC GDP and Private Consumption.
} 
approximately $30 \%$ of SC exports, they represent roughly $70 \%$ of SC imports. These figures reflect the relevance of natural resources for the economy of the $\mathrm{SC}$ region.

Small and medium enterprises (SMEs) constitute a heterogeneous universe that ranges from micro subsistence enterprises to medium competitive and firms with exporting capacity. SMEs are important for the economic development of the SC region, representing approximately $27 \%$ of total firms in Argentina, 21\% in Uruguay, 17\% in Chile and 15\% in Brazil. Although they are important in terms of production, their contribution to the employment is greater: $47 \%$ in Uruguay, $44 \%$ in Argentina, $43 \%$ in Brazil and $17 \%$ in Chile $^{27}$.

In terms of exports, while Brazil and Argentina show a good share of manufactures in the SC region (around 33\%), Paraguay and Chile are close to $12 \%$. Agricultural exports present the majority for Paraguay and Uruguay as well as significant sectors for the rest of the SC. In terms of imports, SC countries present a much similar structure than in the case of imports, with manufactures representing the greatest share ${ }^{28}$.

\subsection{Demographics}

The total population of SC countries is 263 million people, representing approximately $45 \%$ of LAC population and $4 \%$ of the World. The population of Argentina, Brazil, Chile, Paraguay and Uruguay is $40.7 \mathrm{M}, 195.5 \mathrm{M}, 17.1 \mathrm{M}, 6.5 \mathrm{M}$ and $3.4 \mathrm{M}$, respectively. Thus, Brazil is by far the most populated country, representing almost $75 \%$ of SC population. In terms of city population, São Paulo is the largest metropolitan area (20.5M) and, Montevideo is the smallest (1.9M).

Additionally, age distribution in SC countries has been varying considerably. As birth rates decline and life expectation grows, population tends to get older. Thus, while in 2000 those under 15 years of age amounted to $29.4 \%$ and those over 64 years of age represented $6.4 \%$, for 2050 these figures are expected to be $15.6 \%$ and $21.6 \%$, respectively. Furthermore, those over 34 in 2000 were $35 \%$ and in 2050 are expected to be $62 \%$, proving a shift in the population distribution ${ }^{29}$.

Since 1950, the SC population has been steadily growing, although at decreasing rates in recent years. It is estimated that SC population growth will jump from 263 million to 303 million by $2050^{30}$. From 2050, population growth is then expected to remain approximately constant. It is estimated that the only countries that by then will continue growing in terms of population are Argentina and Paraguay.

Part of the reason for population increase is due to the fact that life expectancy in the SC has grown substantially during the last decades. Whereas in 1960 the SC region as a whole had a life expectancy of 57.3 years, in 2010 this figure was 73.3 years. The latter figure is greater than the world average of 69.6 years. While Chile has the longest life expectancy with 78.8 years, Paraguay has the shortest with 72.1 years. In between stand Argentina with 75.5, Brazil with 72.8 and Uruguay with $76.1^{31}$.

Currently, only two SC countries have a large middle class (more than half the population in 2005): Argentina (52.9\%) and Uruguay $(55.8 \%)^{32}$. While Chile's middle class is close to these figures

\footnotetext{
${ }^{27}$ Refer to Appendix E, Table E.6 and Table E.7, for further details on SMEs in the SC region.

${ }^{28}$ Refer to Appendix E, Figures E.2-5 and Table E.2, for further detail on SC trade.

${ }^{29}$ Refer to Appendix E, Figure E.1, for further detail on SC Population and Age Distribution.

${ }^{30}$ Refer to Appendix E, Figure E.2, for further detail on SC Population Evolution.

${ }^{31}$ Refer to Appendix E, Figure E.3, for further detail on SC Life Expectancy.

${ }^{32}$ What constitutes the middle class is not straightforward, as there is no common definition on how to measure it. Here we follow Cárdenas, Kharas and Henao (2011: 17) and define it as those "households with daily income between $\$ 10$ and $\$ 100$ per person in
} 
(46.2\%), Brazil's is somehow below (33.8\%), and Paraguay's middle class only represents $18.7 \%$ of the population. However, due to projected economic growth patterns for these countries under a business-as-usual scenario, it is expected that by 2030 all SC countries will have a large middle class, with the exception of Paraguay, which will have a figure close to the current Brazilian one ${ }^{33}$.

As happened during the last decade, where all SC countries experienced substantial growth (CEPAL, 2012), it is projected that by 2030 GDP per capita will grow considerably in all SC countries. In effect, under a business-as-usual scenario, it is expected that by 2030 GDP per capita will more than double in all SC countries if compared to 2005 (Cárdenas et. al., 2011). Thus, under these circumstances, by 2030 all SC countries will exhibit figures higher than US\$10,000, with the exception of Paraguay ${ }^{34}$. This growth in SC middle income countries with growing economies is beginning to lead to a growing number of well-informed consumers that are now beginning to have the power to afford more ethical products which can increase the uptake of ecolabels and certified products (Ariztía et al., 2012).

The literacy rate (that part of the population age 15 and above who can, with understanding, read and write a short, simple statement) is greater than $90 \%$ in all SC countries compared with the world average of $84 \%$. While Argentina, Chile and Uruguay have rates close to $98 \%$ and Paraguay is around $95 \%$, Brazil has the lowest rate of SC countries with $90 \%{ }^{35}$.

Gross enrolment ratio for tertiary education, that which begins at the age of 17 or 18, lasts between 3 and 6 years and leads to both university and non-university degrees, has grown substantially in SC countries since 1975. However, currently it presents great variation among these countries. While Argentina is close to $70 \%$ and Chile and Uruguay are close to $60 \%$, Paraguay's ratio is around $35 \%$ and Brazil's is close to $25 \%$. Brazil's ratio is lower than the world's average of $28.1 \%^{36}$.

\section{Ecolabelling in the Southern Cone}

\subsection{Overview}

The following section provides an overview of the various ecolabelling and SPP programmes that exist in the SC. In addition, the existing national initiatives, legislation and long-term objectives in place to support ecolabelling and SPP programmes are also described which can provide the political and technical basis for working towards regional cooperation.

In effort to identify the most effective pilot sectors for regional cooperation, the primary and secondary research findings, including feedback from the regional experts ${ }^{37}$, found the following key indicators for potential regional ecolabel pilot sectors:

- Strong Representation across the Region: Sector exists across all countries (producing and/or purchasing $)^{38}$ and represents a relevant portion of their economies.

purchasing power parity terms, which implies that we exclude all those individuals who are considered poor in the poorest advanced countries and those who are rich in the richest advanced countries".

${ }^{33}$ Refer to Appendix E, Table E.6, for further details on middle class growth for the SC.

${ }^{34}$ Refer to Appendix E, Table E.7, for further details on income per capita growth for the SC.

${ }^{35}$ Refer to Appendix E, Figure E.4, for further detail on SC Literacy Rate.

${ }^{36}$ Refer to Appendix E, Figure E.5, for further detail on SC Tertiary School Enrolment.

${ }^{37}$ See Appendix A for complete list of interviewees. 
- Relevance of regional environmental and social Issues: Sectors have the potential to address relevant environment and social issues in the SC region.

- Alignment with existing and future regional Ecolabelling and SPP Activity: Sector has been made sufficiently familiar with certification and labelling activities, and is relevant for existing SPP programmes and objectives.

\subsection{Ecolabelling Initiatives}

Development of ecolabels, certification systems and sustainability codes in the last decade has become more common in the SC region. Figure 5 provides a summary of the existing ecolabels in the SC by country and product groups. The total number of ecolabels used in the SC region is $51^{39}$. Out of these, Brazil accounts for 39 ecolabels, followed by Argentina and Chile with 21, Paraguay with 11 , and Uruguay with 9 ecolabels ${ }^{40}$.

The sectors in which labels are mostly used in the SC countries are forestry, food, building materials and electronic appliances (i.e. energy efficiency). Figure 5 below provides an overview of all the existing ecolabels in the SC countries. The figure is categorised by the main types of ecolabels. The category for 'various product groups' represents either generic labels that cover a wide range of sectors or specific labels with less common ecolabelled sectors, such as vehicles, textiles and cleaning products. Overall, there are three Type I labels and, out of these, two labels are from the region: ABNT's label Beija-Flor, a member of the Global Ecolabelling Network, developed in Brazil in 1994 and Falcao Bauer, hybrid and tiered label between type I and type III labels due to the requirement of a partial LCA. . Type I labels cover multiple sectors. For example, the ABNT label includes building materials, cosmetics/personal care as well as forestry products. A complete list of ecolabels in greater detail is provided in Appendix I, Table I.1.

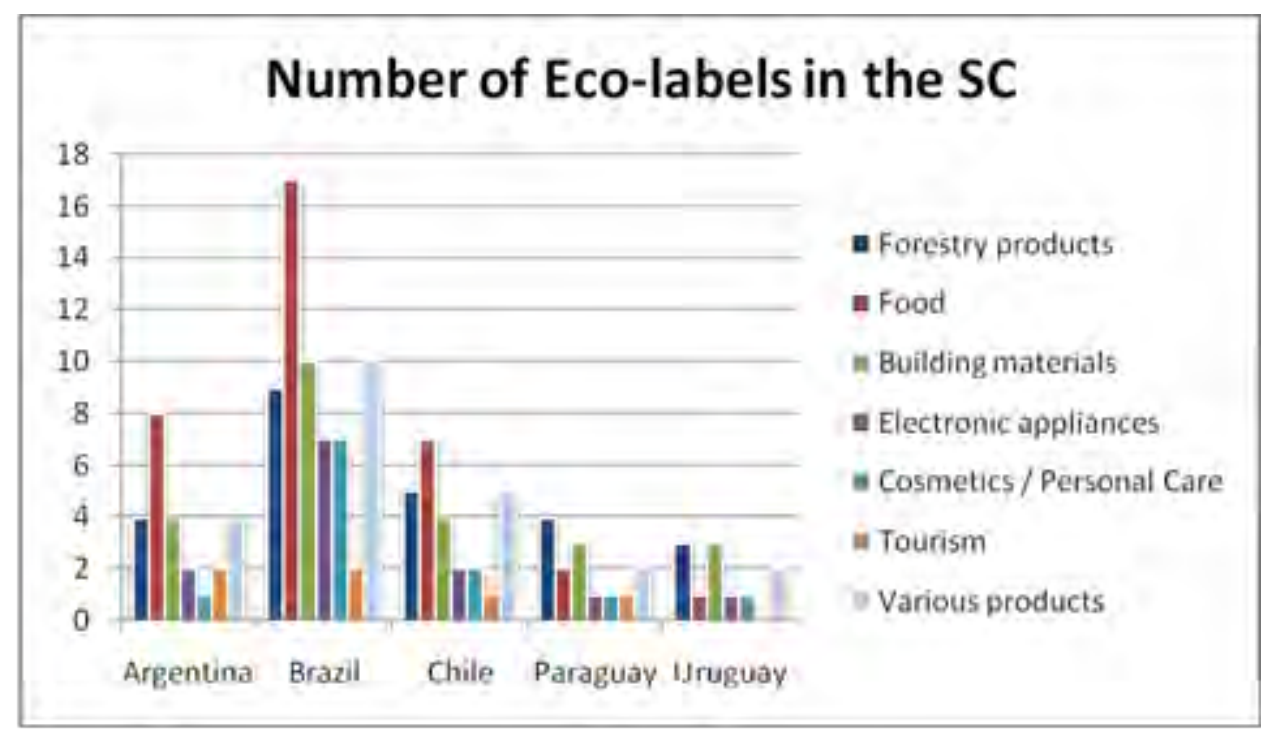

Figure 4: Number of Ecolabels in the SC Region by Sector

\footnotetext{
${ }^{38}$ For the initial projects, the sector has to have reasonable size of production and consumption. If most of the production is exported, then you can't use SPP for reinforcing the initiative. On the other hand, if the product is imported (e.g. electrical appliances), then it would probably be more difficult to engage the industry as they are from another continent.

${ }^{39} \mathrm{~A}$ single ecolabelling scheme can exist in more than one country.

${ }^{40}$ It is important to note that these figures represent the number of ecolabels operating in SC countries, not exclusive ecolabels that have been developed in SC countries. A more detailed classification of the labels is provided in Appendix I, Table I.1.
} 
Table 16 provides the SC ecolabelling initiatives classified by the main industries they are addressing. These initiatives are still in development and therefore are cited in general terms with references to different strategies from energy efficiency to the use of cleaner technologies and materials.

Table 14: SC Eco-labelling Programmes and Initiatives Summary

\begin{tabular}{|c|c|c|c|c|c|c|}
\hline & Initiative & $\begin{array}{l}\text { Forestry } \\
\text { products }\end{array}$ & $\begin{array}{l}\text { Building } \\
\text { materials }\end{array}$ & $\begin{array}{l}\text { Electronic } \\
\text { appliances } \\
\text { (energy } \\
\text { efficiency) }\end{array}$ & Food & Tourism \\
\hline \multirow{13}{*}{ 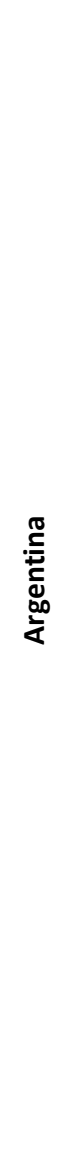 } & $\begin{array}{l}\text { National system for identification of } \\
\text { products and services for public } \\
\text { procurement (catalogue). }\end{array}$ & $\checkmark$ & $\checkmark$ & $\checkmark$ & $\checkmark$ & $\checkmark$ \\
\hline & Buen diseño seal & $\checkmark$ & $\checkmark$ & $\checkmark$ & & \\
\hline & $\begin{array}{l}\text { Forestry certification system for } \\
\text { Argentina (CERFOAR) }\end{array}$ & $\checkmark$ & & & & \\
\hline & $\begin{array}{l}\text { Quality of electronic devices program } \\
\text { (PROCAE) }\end{array}$ & & & $\checkmark$ & & \\
\hline & $\begin{array}{l}\text { Clean production program in the city } \\
\text { of Buenos Aires (Buenos Aires } \\
\text { Produce MásLimpio) }\end{array}$ & & & $\checkmark$ & & \\
\hline & $\begin{array}{l}\text { Salteña Eco-efficient Management } \\
\text { seal (province of Salta) }\end{array}$ & & & & & \\
\hline & $\begin{array}{l}\text { Environmental Management Program } \\
\text { “ECO UIC" (Córdoba) }\end{array}$ & & & $\checkmark$ & & \\
\hline & $\begin{array}{l}\begin{array}{l}\text { Sustainable Industrial Development } \\
\text { project (DIS) }\end{array} \\
\end{array}$ & & & & & \\
\hline & Industrial Strategic Plan 2020 & & & & & \\
\hline & $\begin{array}{l}\text { National program for the } \\
\text { development of organic product } \\
\text { certification (PRONAO) }\end{array}$ & & & & $\checkmark$ & \\
\hline & $\begin{array}{l}\text { Argentinean food seal program (Una } \\
\text { Elección Natural) }\end{array}$ & & & & $\checkmark$ & \\
\hline & \begin{tabular}{|l|} 
Certification of Tourist \\
Accommodation Program (Buenos \\
Aires province) \\
\end{tabular} & & & & & $\checkmark$ \\
\hline & $\begin{array}{l}\text { Environmental Responsible Hotels } \\
\text { Program (Buenos Aires) }\end{array}$ & & & & & $\checkmark$ \\
\hline \multirow{8}{*}{$\underset{\bar{N}}{\bar{D}}$} & ABNT Environmental Quality Program & $\checkmark$ & $\checkmark$ & $\checkmark$ & $\checkmark$ & $\cdot$ \\
\hline & Eco seal Falcão Bauer & $\checkmark$ & $\checkmark$ & $\checkmark$ & $\checkmark$ & \\
\hline & Proconve seal & & & & & \\
\hline & $\begin{array}{l}\text { Eco-labelling program initiative Brasil } \\
\text { Eco-Exportador }\end{array}$ & $\checkmark$ & $\checkmark$ & $\checkmark$ & $\checkmark$ & $\checkmark$ \\
\hline & $\begin{array}{l}\text { Brazilian Energy Efficiency labelling } \\
\text { program }\end{array}$ & & & & $\checkmark$ & \\
\hline & \begin{tabular}{|l|} 
Brazilian Corporate Social \\
Responsibility certification program \\
\end{tabular} & $\checkmark$ & $\checkmark$ & $\checkmark$ & $\checkmark$ & \\
\hline & Integrated Agricultural production & & & & $\checkmark$ & \\
\hline & \begin{tabular}{|l|} 
Certification program for \\
Sustainability management of \\
accommodation
\end{tabular} & & & & & $\checkmark$ \\
\hline
\end{tabular}




\begin{tabular}{|c|c|c|c|c|c|c|}
\hline & Brazilian IBD seals & & & & $\checkmark$ & \\
\hline & Procel seal & & & $\checkmark$ & & \\
\hline \multirow{10}{*}{$\stackrel{\stackrel{0}{\underline{z}}}{\leftrightarrows}$} & Estrella Azul label (CNLP) & & & & & \\
\hline & $\begin{array}{l}\text { National system for the certification } \\
\text { of firewood (SNCL) }\end{array}$ & $\checkmark$ & & & & \\
\hline & $\begin{array}{l}\text { Chilean Agency for Energy Efficiency } \\
\text { (AChEE) }\end{array}$ & & & $\checkmark$ & & \\
\hline & $\begin{array}{l}\text { The Chamber of Commerce of } \\
\text { Santiago (CCS) since } 2010 \text { is leading a } \\
\text { strategy focused on the certification } \\
\text { of the productive sector }\end{array}$ & & & & & \\
\hline & $\begin{array}{l}\text { Protocol Agreement for the } \\
\text { Promotion of Sustainable Building }\end{array}$ & & $\checkmark$ & & & \\
\hline & Energy efficiency label for housing & & $\checkmark$ & $\checkmark$ & & \\
\hline & $\begin{array}{l}\text { National system for the certification } \\
\text { of prganic products }\end{array}$ & & & & $\checkmark$ & \\
\hline & National Tourism Service (SERNATUR) & & & & & $\checkmark$ \\
\hline & $\begin{array}{l}\text { ChileCompra: Through the framework } \\
\text { agreement and its online e-catalogue } \\
\text { ChileCompra express }\end{array}$ & $\checkmark$ & $\checkmark$ & $\checkmark$ & $\checkmark$ & $\checkmark$ \\
\hline & $\begin{array}{l}\text { Wine Consortium: The aim is to } \\
\text { promote a sustainability code for the } \\
\text { Chilean wine industry. }\end{array}$ & & & & $\checkmark$ & \\
\hline \multirow{4}{*}{ 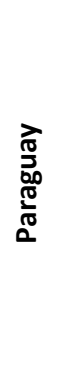 } & $\begin{array}{l}\text { National plan to promote energy } \\
\text { efficiency through eco-labelling in } \\
\text { electronic appliances and products. }\end{array}$ & & & $\checkmark$ & & \\
\hline & $\begin{array}{l}\text { National Council for Sustainable } \\
\text { Production and Consumption }\end{array}$ & $\checkmark$ & $\checkmark$ & $\checkmark$ & $\checkmark$ & \\
\hline & $\begin{array}{l}\text { Eco-labels in wood/furniture/paper, } \\
\text { such as: FSC \& PEFC }\end{array}$ & $\checkmark$ & $\checkmark$ & & & \\
\hline & $\begin{array}{l}\text { Organic products for mainly sugar and } \\
\text { mate herb }\end{array}$ & & & & $\checkmark$ & \\
\hline \multirow{4}{*}{ 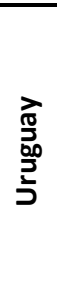 } & $\begin{array}{l}\text { Eco-labels for energy efficiency in } \\
\text { products }\end{array}$ & & & $\checkmark$ & & \\
\hline & $\begin{array}{l}\text { National Action Plan on Sustainable } \\
\text { Production and Consumption (2010- } \\
\text { 2015) }\end{array}$ & $\checkmark$ & $\checkmark$ & $\checkmark$ & $\checkmark$ & $\checkmark$ \\
\hline & Ozono Amigo seal & & & & & \\
\hline & MASlabel & & & & & \\
\hline & & 12 & 12 & 17 & 16 & 8 \\
\hline
\end{tabular}

The ecolabelling initiatives in the SC region show that there are sectors that are being given a special focus. For example, initiatives covering electronic appliances and energy efficiency have the most activity (17), followed by food with a focus on organic certification labels (16). Forestry products and building materials have a similar level of importance in the region (12 for each), which are both involved in SPP initiatives and building certification programmes. Lastly, tourism initiatives are also being developed in the region (8). For more details on the national initiatives supporting ecolabels in the SC refer to Appendix I, Table I.2.

Furthermore, with respect to the private sector, there are a growing number of organisations publishing CSR and sustainability reports. The reports have provided many organisations with their 
first step towards reporting the environmental and social performance of their products and services. The number of sustainability reports by corporations in the SC region has increased from 40\% in 2009 to 47\% in 2011 (Forum Empresa Network, 2011). The following figure below shows the trend of publishing CSRs and sustainability reports by the private sector in Chile. Furthermore, a recent study on what the top 30 corporations in Chile cover in their report shows that 29 corporations reported on the community development, 28 on customer relations, 26 on environmental impacts related to their production, 14 on economic topics, and 14 on the corporate governance (PricewaterhouseCoopers, 2006).

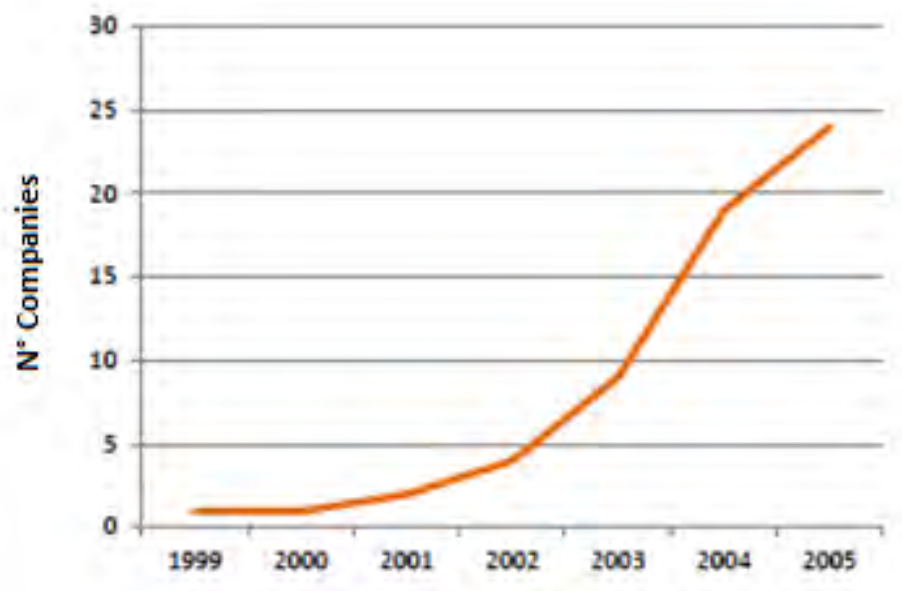

Figure 5: Tendency of corporations that publish CSR reports in Chile (Pricewaterhouse Coopers, 2006)

\subsection{SPP Initiatives}

In recent years, public support towards SPP in the countries of the SC region has increased thanks to various initiatives working towards the inclusion of sustainability in the public procurement system. These initiatives are in different stages in each SC country, with some countries already having a SPP legislation and system in place, such as the Decree 7746/2012 on SPP legislation (Brazil), and others just beginning to explore the possibility (Paraguay and Uruguay). The following table presents the current SPP activity by country and the sectors that they cover. 
Table 15: SC SPP Programmes and Initiatives Summary

\begin{tabular}{|c|c|c|c|c|c|c|c|c|c|}
\hline & Initiative & $\begin{array}{l}\text { Forestry } \\
\text { products }\end{array}$ & $\begin{array}{l}\text { Building } \\
\text { materials }\end{array}$ & $\begin{array}{l}\text { Electronic appliances } \\
\text { (energy efficiency) }\end{array}$ & Food & Tourism & $\begin{array}{l}\text { Personal care/ } \\
\text { cosmetics }\end{array}$ & Vehicles & Other products \\
\hline \multirow{5}{*}{ 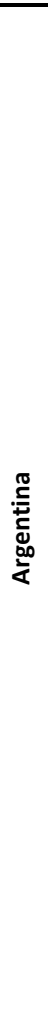 } & $\begin{array}{l}\text { The Balanced and Efficient } \\
\text { use of Energy (PRONUREE) }\end{array}$ & & & $\checkmark$ & & & & & \\
\hline & $\begin{array}{l}\text { The Development of } \\
\text { Capacities for Sustainable } \\
\text { Public Procurement in } \\
\text { Argentina project. }\end{array}$ & $\checkmark$ & $\checkmark$ & $\checkmark$ & $\checkmark$ & $\checkmark$ & $\checkmark$ & $\checkmark$ & $\checkmark$ \\
\hline & $\begin{array}{l}\text { National Programme for } \\
\text { Social Commitment } \\
\text { Certification from the } \\
\text { Institute of Industrial } \\
\text { Technology (INTI). }\end{array}$ & $\checkmark$ & $\checkmark$ & $\checkmark$ & $\checkmark$ & $\checkmark$ & $\checkmark$ & $\checkmark$ & $\checkmark$ \\
\hline & $\begin{array}{l}\text { Guidelines for sustainable } \\
\text { procurement } 2011\end{array}$ & $\checkmark$ & $\checkmark$ & $\checkmark$ & $\checkmark$ & $\checkmark$ & $\checkmark$ & $\checkmark$ & $\checkmark$ \\
\hline & $\begin{array}{l}\text { Sustainable catalogue is } \\
\text { being analysed by } \\
\text { modifying the Product and } \\
\text { Service Identification } \\
\text { System (SIBYS) }\end{array}$ & & & $\checkmark$ & & & & & $\checkmark$ \\
\hline \multirow[b]{2}{*}{ 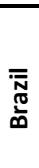 } & Decree $7746 / 2012$ on SPP & $\checkmark$ & $\checkmark$ & $\checkmark$ & $\checkmark$ & $\checkmark$ & $\checkmark$ & $\checkmark$ & $\checkmark$ \\
\hline & $\begin{array}{l}\text { Most purchased products } \\
\text { with sustainable criteria in } \\
\text { procurement catalogue }\end{array}$ & $\checkmark$ & & $\checkmark$ & & & & $\checkmark$ & \\
\hline
\end{tabular}




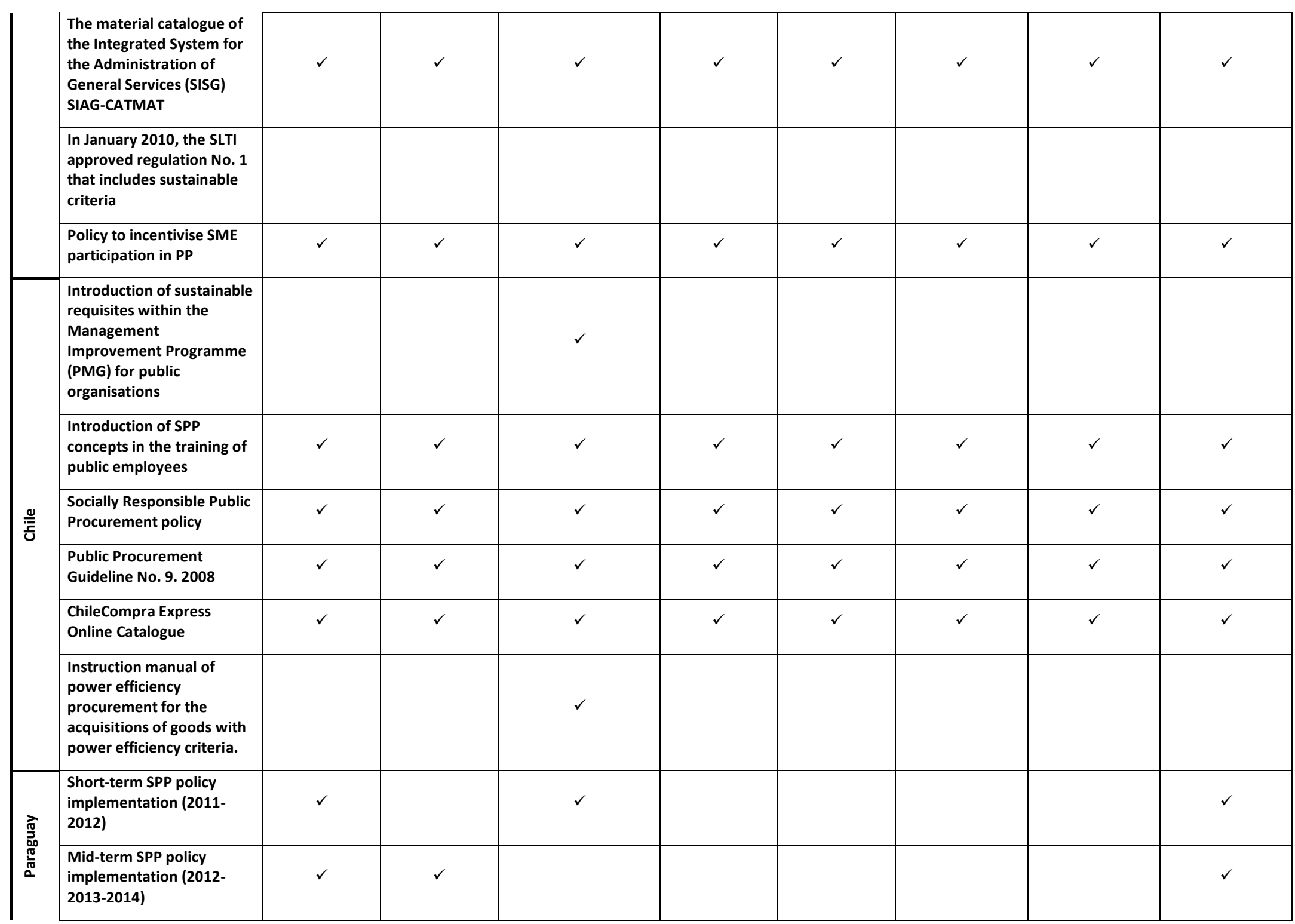




\begin{tabular}{|c|c|c|c|c|c|c|c|c|c|}
\hline & $\begin{array}{l}\text { Long-term SPP policy } \\
\text { implementation (2015) }\end{array}$ & & & & $\checkmark$ & $\checkmark$ & $\checkmark$ & $\checkmark$ & $\checkmark$ \\
\hline \multirow{3}{*}{ 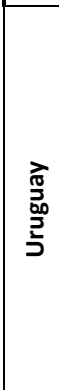 } & $\begin{array}{l}\text { National Plan for } \\
\text { Sustainable Public } \\
\text { Procurement 2012-2016 }\end{array}$ & & $\checkmark$ & $\checkmark$ & & & & & $\checkmark$ \\
\hline & $\begin{array}{l}\text { Sustainability in Building } \\
\text { Sites project for the } \\
\text { Montevideo City Council }\end{array}$ & $\checkmark$ & $\checkmark$ & $\checkmark$ & & & & & $\checkmark$ \\
\hline & $\begin{array}{l}\text { Energy efficiency project } \\
\text { implemented by the } \\
\text { National Directorate for } \\
\text { Energy (DNE) }\end{array}$ & & & $\checkmark$ & & & & & \\
\hline
\end{tabular}


According to this table, the common sectors for public procurement in all five nations are energy efficiency for electronic appliances, office products such as paper (forestry products) and ink cartridges, as well as cleaning and building materials. Brazil is the only nation in the SC that has integrated sustainability into its procurement system, making it mandatory through the 2012 Decree on SPP. The SPP efforts in Chile and Argentina include the development of online catalogues, which provide information on sustainable products and the certification of sustainable suppliers. Paraguay and Uruguay are beginning to apply SPP policies; Paraguay approved its SPP policy in 2011, which includes a short term (2011-2012), mid-term (2012-2013-2014) and a long-term (2015) plan, and Uruguay approved a SPP policy in 2012 for the periods of 2012-2016 with short, mid and long-term objectives. Both nations are working with different pilot sectors within the procurement system, with a strong focus on energy efficiency through electronic appliances.

\subsection{Legislation and Institutions}

\subsubsection{Ecolabelling}

While not all national ecolabelling programmes are government-run, government involvement is seen as an important means of providing credibility and adequate funding, especially during the formative years. Also, government can provide an important support and uptake of ecolabelling through legislative provisions and labelling laws that enforce information disclosure, provide guidance on misleading and deceptive environmental claims, regulate claims through legal definition (e.g. 'organic') and standardise the quality assurance. A key component for ecolabel success is relevant and capable institutions allowing separation of the process of assurance from making the claims.

The following table lists institutions and legislations that provide technical backing to either ecolabels or certification programmes which can potentially support the regional ecolabelling initiative. The institutions are either public or private, with a direct or indirect link to ecolabelling programmes or certification of products.

Table 16: Institutions and Legislation related to Eco-labelling and SPP

\begin{tabular}{|c|c|c|c|}
\hline & Sector & Institutions & Legislation \\
\hline \multirow{7}{*}{ 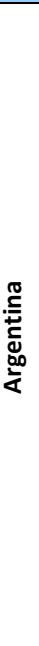 } & \multirow[t]{2}{*}{$\begin{array}{l}\text { Electronics } \\
\text { (Energy Efficiency) }\end{array}$} & \multirow[t]{2}{*}{$\begin{array}{l}\text { Ministry of Federal Planning, Public Investment and } \\
\text { Services, Secretariat of Energy }\end{array}$} & $\begin{array}{l}\text { Law } 86 / 2007 \text { on energy efficiency for } \\
\text { electronic equipment }\end{array}$ \\
\hline & & & $\begin{array}{l}\text { The Law No. } 3246 \text { focuses on the reduction } \\
\text { and consumption optimisation of electricity } \\
\text { in the city of Buenos Aires }\end{array}$ \\
\hline & Forestry & $\begin{array}{l}\text { Argentinean Manufacturers of Cellulose and Paper } \\
\text { Association (AFCP) }\end{array}$ & \\
\hline & $\begin{array}{l}\text { Forestry/Building } \\
\text { Materials }\end{array}$ & Argentinean Forestry Industry Federation (FAIMA) & \\
\hline & $\begin{array}{l}\text { Forestry/Building } \\
\text { Materials }\end{array}$ & Argentinean Forestry Association (AFoA) & \\
\hline & Forestry/Food/Tourism & Ministry of Foreign Affairs & $\begin{array}{l}\text { Decree } 206 / 2001 \text { on the certification of } \\
\text { organic products }\end{array}$ \\
\hline & Food & $\begin{array}{l}\text { Secretariat of Agriculture, Livestock, Fishing, and } \\
\text { Food (SAGPyA) }\end{array}$ & \\
\hline
\end{tabular}




\begin{tabular}{|c|c|c|c|}
\hline & \multirow[t]{2}{*}{ Multi-sectorial $^{41}$} & \multirow[t]{2}{*}{ National Office for Procurement, Argentinacompra } & No legislation that regulates ecolabels. \\
\hline & & & $\begin{array}{l}\text { Decree No. 893/2012 modifies and approves } \\
\text { Decree No. } 1023 / 01 \text { on the new regulations } \\
\text { for SPP. }\end{array}$ \\
\hline & Multi-sectorial & National Institute of Industrial Technology (INTI) & \\
\hline & Multi-sectorial & Argentinian National Standardisation body (IRAM) & \\
\hline & Multi-sectorial & $\begin{array}{l}\text { Centro Tecnológico para la Sustentabilidad -CTS- } \\
\text { UTN (Universidad Tecnológica Nacional) }\end{array}$ & \\
\hline & Multi-sectorial & Deputy Secretary's Office for Consumer Defence & $\begin{array}{l}\text { Law No. } 24240 \text { on Consumer Protection and } \\
\text { Defence. }\end{array}$ \\
\hline \multirow{13}{*}{ 高 } & $\begin{array}{l}\text { Electronics (Energy } \\
\text { Efficiency) }\end{array}$ & $\begin{array}{l}\text { National Institute of Metrology, Quality and } \\
\text { Technology (INMETRO - MDIC) }\end{array}$ & \\
\hline & Multi-sectorial & & National SCP Strategy \\
\hline & $\begin{array}{l}\text { Forestry/Building } \\
\text { Materials }\end{array}$ & $\begin{array}{l}\text { Brazilian Institute for Renewable Natural Resources } \\
\text { and the Environment (IBAMA); National Institute of } \\
\text { Metrology Quality and Technology (INMETRO - } \\
\text { MDIC) }\end{array}$ & \\
\hline & $\begin{array}{l}\text { Forestry/Building } \\
\text { Materials }\end{array}$ & $\begin{array}{l}\text { Brazilian Association of the Mechanically Processed } \\
\text { Wood Industry (ABIMCI) }\end{array}$ & \\
\hline & \multirow[t]{2}{*}{ Food } & \multirow[t]{2}{*}{ Brazilian certifying organisation IBD } & Law No. 10831 on Organic Agriculture \\
\hline & & & $\begin{array}{l}\text { Law No. } 11460 \text { on the Planting of Genetically } \\
\text { Modified Organisms }\end{array}$ \\
\hline & Food & $\begin{array}{l}\text { Ministry of Agriculture, Livestock and Supply } \\
\text { (MAPA) and Ministry of Agrarian Development } \\
\text { (MDA - represents the small scale and family } \\
\text { farmers) }\end{array}$ & \\
\hline & Multi-sectorial & Brazilian Technical Norm Association (ABNT) & $\begin{array}{l}\text { Law No. } 7365 \text { Requiring Detergents to be } \\
\text { Biodegradable }\end{array}$ \\
\hline & Multi-sectorial & Ministry of Environment (MMA) & $\begin{array}{l}\text { Decree } 2783 \text { on the prohibition of products } \\
\text { that contain substances that damage the } \\
\text { ozone layer. }\end{array}$ \\
\hline & Multi-sectorial & $\begin{array}{l}\text { Ministry of Development, Industry and Foreign } \\
\text { Trade (MDIC), Secretariat of Foreign Trade }\end{array}$ & $\begin{array}{l}\text { CONAMA Resolution 15/95 Classification of } \\
\text { imported vehicles for the control of vehicular } \\
\text { emissions. }\end{array}$ \\
\hline & Multi-sectorial & $\begin{array}{l}\text { Institute of Companies and Social Responsibility } \\
\text { (ETHOS) }\end{array}$ & \\
\hline & \multirow[t]{2}{*}{ Multi-sectorial } & \multirow[t]{2}{*}{$\begin{array}{l}\text { Ministry of Planning, Budget and Management, } \\
\text { ComprasNet }\end{array}$} & $\begin{array}{l}\text { MPOG Standard No.1/2010 includes } \\
\text { sustainable criteria focused on the } \\
\text { environment for the acquisition of products } \\
\text { and services for the central government at a } \\
\text { federal level. }\end{array}$ \\
\hline & & & $\begin{array}{l}\text { Decree No. } 7746 \text { Public procurement } \\
\text { institutions must follow the sustainability } \\
\text { guidelines established in the decree }\end{array}$ \\
\hline
\end{tabular}

${ }^{41}$ Multi-sector products include: Forestry products/Food/Building Materials/Electronic/ Cosmetic \&Personal care/ Tourism/Cleaning products/Office products/Vehicles. 


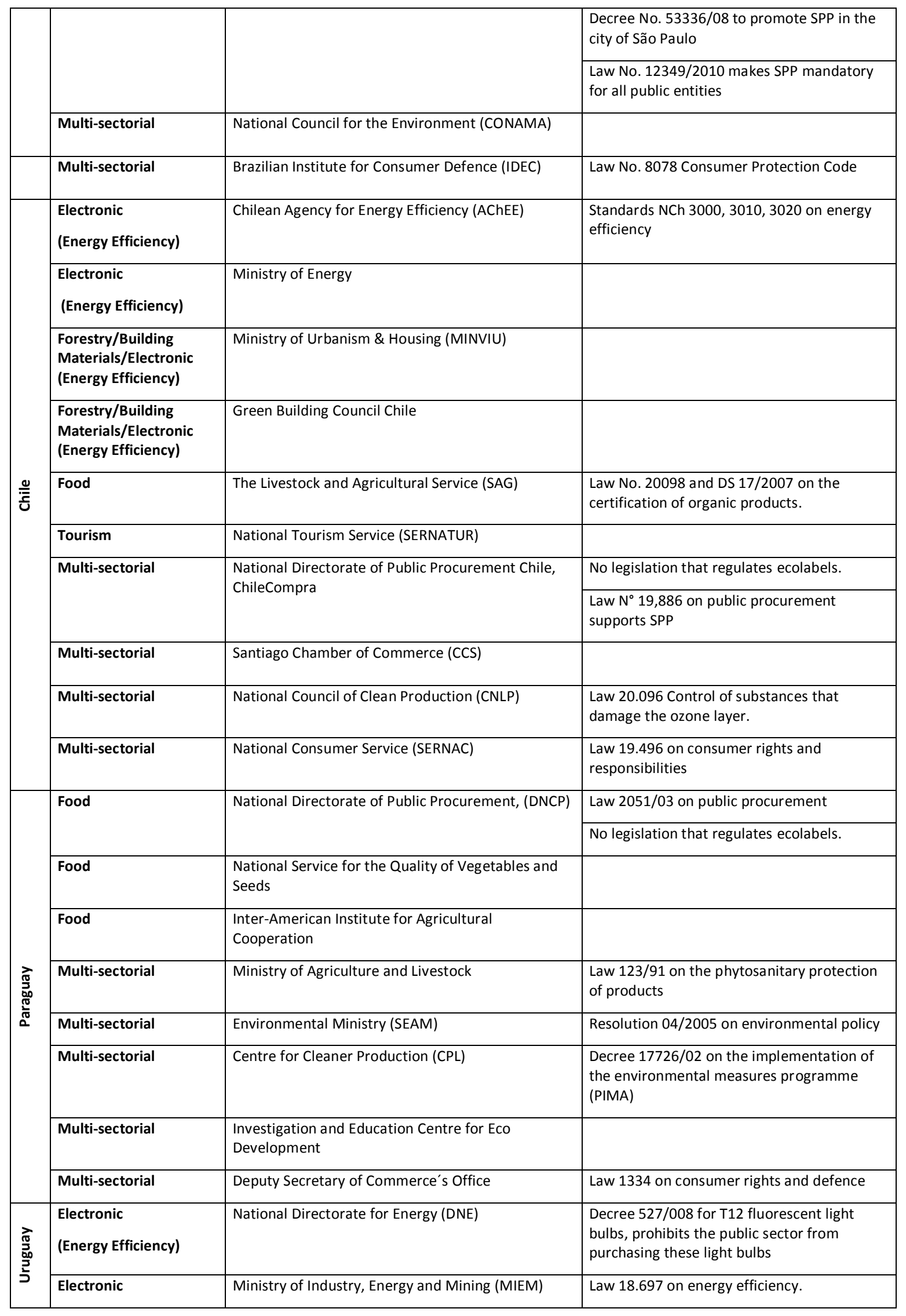




\begin{tabular}{|c|c|c|}
\hline (Energy Efficiency) & & \\
\hline $\begin{array}{l}\text { Electronic } \\
\text { (Energy Efficiency) }\end{array}$ & $\begin{array}{l}\text { National Management of Power Stations and } \\
\text { Electric Transmission (UTE) }\end{array}$ & \\
\hline $\begin{array}{l}\text { Electronic } \\
\text { (Energy Efficiency) }\end{array}$ & Uruguayan Institute of Technical Standards (UNIT) & \\
\hline Forestry & National Directorate for the Environment (DINAMA) & $\begin{array}{l}\text { Law } N^{\circ} 17849 \text { Decree } 315 / 010 \text { on the } \\
\text { inclusion of the management of } \\
\text { recipients/containers }\end{array}$ \\
\hline Forestry & $\begin{array}{l}\text { Ministry of Housing, Urban Planning \& Environment } \\
\text { (MVOTMA) }\end{array}$ & \\
\hline Multi-sectorial & National Directorate for Public Procurement & No legislation that regulates ecolabels. \\
\hline Multi-sectorial & National Chamber of Commerce and Services & \\
\hline Multi-sectorial & National Planning and Budget Office & \\
\hline Multi-sectorial & National Consumer Defence Division & Law 17250 on consumer rights and defence \\
\hline
\end{tabular}

With the exception of Brazil, there is no specific legislation for ecolabels in the SC region. However, it can be observed from the table that there are various legal documents concerning specific sections on products, which regard sustainability issues. For example, almost all nations in the SC region have a legal document on energy efficiency through appliances and products (Paraguay is advancing in the development of a programme and a legal document on energy efficiency). Organic agriculture and the control of products that damage the ozone layer are among the sectors or products that are also frequently mentioned. Other legal documents focus on various topics such as biodegradable detergents or vehicle emission control.

Institutions in the SC region have an important presence throughout many sectors such as forestry, energy efficiency, food, building materials, tourism and others. Among these institutions, it can be observed that there is significant government support through various ministries and state institutions in every sector evaluated, with ministries such as environment, energy, housing and urban planning, agriculture, and finance among others. Other important national institutions are those focused on metrology as well as regulations and standards, such as UNIT, IRAM, INTI, INN and INMETRO (present in every SC nation). Finally, private institutions are represented through industrial associations or councils for specific sectors or products, as well as NGOs from a variety of different areas.

The research found the sector with the largest amount of supporting institutions is energy efficiency through electronic appliances, followed closely by forestry products. Chile, Argentina and Brazil have four to six institutions with initiatives in energy efficiency and Paraguay and Uruguay have two. Brazil also has six institutions with initiatives according to the forestry product sector, Argentina and Chile have four and Paraguay and Uruguay have two.

\subsubsection{Sustainable Procurement}

Legislation supporting the integration of SPP in the SC region is found to some extent in all SC nations. An appropriate legal framework is important for the integration and consolidation of sustainability considerations into the procurement system. Energy efficiency is a common objective in the region and therefore normally included into public purchasing specifications. SPP concerns mostly state institutions which can be important agents in promoting sustainability through their link with the different productive industrial sectors and various national programmes, policies and initiatives. Countries such as Brazil, Chile and Argentina have developed legal and institutional 
frameworks to support their SPP policies and programmes. For example, Brazil's constitution requires public administration bodies to protect the environment. Paraguay has an environmental legal framework and is developing legal bodies in the area of energy efficiency for electric appliances to support cleaner production programmes. Uruguay on the other hand has developed a legal framework for energy efficiency and for electronic appliances and products. Both of these frameworks in Paraguay and Uruguay provide support to SPP, since these legal bodies will provide the resources for identifying the energy efficiency performance of products, which can become a product performance indicator in SPP programmes.

Brazil has made SPP mandatory for all public entities through the Federal Law No. 12.349 enacted in 2010. At the State level, São Paolo adopted the decree to promote SPP back in 2008. Argentina and Chile both have public procurement legislation ${ }^{42}$ that supports the reporting of sustainability performance information for a growing number of products, but public purchasers are still not required to choose products solely on sustainability criteria. In addition, Argentina and Chile also have several certifying and standards institutions which support environmental certifications programmes. These programmes include energy efficiency of electronic appliances, organic food products, and chemical-based products containing ozone-damaging substances.

Uruguay has many regulations and laws for purchasing different products, for example light bulbs and electronic appliances. This is combined with existing certifying and standards institutions, which assists in monitoring a SPP policy. Paraguay, apart from its SPP support in its public procurement policy, does not have a legislative document that would support SPP directly, even though it is well advanced in an energy efficiency programme for electronic appliances. Although Paraguay has no SPP legislation in place, there is indirect support for these types of initiatives from broader environmental policies. For example, Paraguay's National Environmental Policy, established by the CONAM resolution No. 04/2005, has the aim of conservation and management of natural resources to guarantee a sustainable development among other aspects, introducing sustainability principles in the production and service sectors, which are in line with the intentions of SPP program.

\subsection{Public Attitudes and Consumer Demand}

A range of consumer studies, conducted in the SC region, were collected in order to provide a sample of the public attitudes to ecolabels in the $\mathrm{SC}$ region. Although there were some variations in the methodologies used, consumer surveys conducted in Argentina, Brazil and Chile all showed that, on average, at least half of the consumers surveyed were willing to pay more for an eco-friendly product. More specifically, 49\% of Argentineans (Greendex, 2012), 40-77\% of Brazilians (Greendex, 2012 and Green brands, 2011) (3) $^{43}$ and 52\% of Chileans (UDD, 2011) were willing to pay more. In addition, the following table summarises the number of SC consumers which consider themselves environmentally responsible.

The following sub-section provides this information in greater detail. Unfortunately, due to the lack of existing research, little information was found for Paraguay and Uruguay and therefore their subsection were not included.

Table 17: Common Attitudes related to Ecolabels (DECON, 2011)

\begin{tabular}{|c|c|c|c|c|c|}
\hline & Argentina & Brazil & Chile & Paraguay & Uruguay \\
\hline Consider themselves environmentally responsible consumers (\%) & $31.39 \%$ & $31.08 \%$ & $19.33 \%$ & $18.33 \%$ & $14.33 \%$ \\
\hline
\end{tabular}

\footnotetext{
42 Argentina SPP Legislation: Decree No. 893/2012 modifies and approves Decree No. 1023/01 on the new regulations for SPP; Chile SPP Legislation: Law No. 19,886 on public procurement supports SPP

${ }^{43}$ Data taken from different sources: Greendex survey 2012 (40\%) and Green brands, Global insights 2011 (77\%).
} 


\subsubsection{Argentina}

According to the data from latest Greendex surveys, $49 \%$ of Argentineans would choose environmentally friendly products even though these have a higher cost, in comparison to $20 \%$ who wouldn't choose these eco-friendly products and 31\% who did not know or didn't answer. From approximately 1000 surveyed consumers, $46 \%$ buy eco-friendly products. With respect to the energy efficiency of electronic appliances: $29 \%$ of the consumers own an energy saving television, $32 \%$ own an energy saving refrigerator/freezer, $5 \%$ own an energy saving dishwasher and $24 \%$ own an energy saving laundry machine.

\subsubsection{Brazil}

According to research of different surveys, between $40-77 \%$ of Brazilians are willing to purchase and pay more for an eco-friendly product. Furthermore, the Greendex survey shows that $59 \%$ of consumers in Brazil buy environmentally friendly products. In respect to energy efficient electronic appliances, $51 \%$ of the consumers state that they own an energy-saving television, $59 \%$ own an energy-saving refrigerator/freezer, $10 \%$ own an energy-saving dishwasher and 52\% own an energysaving laundry machine.

\subsubsection{Chile}

According to different national surveys and reports on sustainable consumption, it was found that general behaviour and consumption habits in the Chilean society are inclined towards actions that would lead to monetary or resource savings. Results in this report (Ariztía et al., 2012) show that $71 \%$ of the consumer's behaviours are for the reason of saving or optimising their resources, and that $29 \%$ of the consumers are purchasing sustainable products because of responsible or sustainable consumption (Ariztía et al., 2012).

On the other hand, $8.5 \%$ of Chileans say they consider environmental issues when purchasing a product. Furthermore the purchasing of sustainable products is seen to be made by citizens in higher social-economical or educational levels. Among the most common products purchased are organic or natural products (39\%) and products made from recycled material (33\%). Another report states that $82 \%$ of the consumers surveyed consider that environmental impact is of significant or some importance in their purchasing decisions. The results show two completely different figures for the consideration of environmental issues in purchasing, which could be due to a difference in survey methods: in one survey, the price and quality factor were considered while in the other it was not. Concerning the consumer's perception of sustainable products, $67 \%$ of consumers consider sustainable products more expensive, and $52 \%$ of consumers would pay more for an environmentally friendly product (Ariztía et al., 2012).

Finally in the SC regional context, according to the study "Percepción medioambiental de los ciudadanos latinoamericanos," the overall perception of environmental responsible consumers in the SC is above $20 \%$. Argentina and Brazil are among the highest with over $31 \%$. In another section come Chile and Paraguay with $19.33 \%$ and $18.33 \%$, respectively. Uruguay is in the lower section of this study with $14.33 \%$ responsible consumers.

\subsection{Greenwashing}

The term "Greenwashing" refers to the use of false or misleading environmental claims (Feinstein, 2013). A report by Terra Choice (2010) identifies the "Seven Sins of Greenwashing":

- Sin of the hidden trade-off (narrow set of attributes)

- Sin of no proof (unsubstantiated claims) 
- $\quad$ Sin of vagueness (e.g. all-natural claim)

- Sin of irrelevance (e.g. CFC-free claim, considering CFCs are banned by law)

- Sin of lesser of two evils (e.g. organic cigarettes)

- Sin of fibbing (false claims)

- Sin of worshiping false labels (giving the false impression of third-party endorsement)

All countries in the SC region have a specific national institution and legal basis protecting consumer rights. These include the laws regulating the provision by manufacturers of erroneous or false information on products that affect consumer's health, safety and the environment. Depending on each country, the regulations and articles vary in coverage and detail.

In Brazil, a study analysed 887 claims from products across different categories (Neves, 2010) and found that $90 \%$ of the claims committed at least one of the "sins" listed above. The most common were vagueness (46\% of claims), no proof (24\%) and hidden trade-off (15\%).

Both Brazil and Paraguay include, among other specific aspects, the sanctioning of manufacturers of products or services that break or permit the violation in any way of the environmental regulations of the country. Argentina includes in its legal documents, Law 24240 on consumer protection and defence, the training of consumers by the state to enable the consumers to make well-informed decisions in their purchases, with one of the specific focus being the protection of the environment and the efficient use of materials favouring sustainable consumption.

In Chile, the National Consumers' Service (public agency under the Ministry of Economy) recently released a study about environmental marketing claims (SERNAC, 2012). Seventeen marketing claims that were available in the media during June, 2012, were studied for the use of terms such as "natural", "green", "ecologic" and "sustainable". The sector with the most claims was the electronic appliances sector. The companies using these claims were required to provide information to substantiate them. Only one company did not provide a satisfactory reply for their " $100 \%$ sustainable technology" claim, and it is currently being sued for deceiving marketing practices (SERNAC, 2011).

Another manifestation of the growing concern about misleading marketing practices by businesses was the formation of a panel on greenwashing at the Inter-American Association of Intellectual Property meeting held in Uruguay in December 2012, where possible strategies to avoid this type of practices were discussed. The panel is also supposed to analyse the legality and illegality of the adoption of false environmental claims and developing strategies for better enforcement (ASIPI, 2012).

\section{Case Study: SERNAC Charges Bosch for Misleading, "Green Advertising," Claims}

SERNAC, Chile's National Consumer Service organisation, sued home appliance manufacturer, Bosch, after the company was unable to provide proof for their product marketing claims, which stated their products to be, "100\% sustainable," and using, "green," technology. The lawsuit was triggered by a, "green advertising," study by SERNAC which resulted in issuing official letters to 14 companies demanding a background check on the statements contained in their advertising claims. Bosch was the only company that did not deliver a satisfactory answer. The company said that these messages were an essential part of the, "corporate philosophy," and that the characteristics of their products were constantly working on the issues of environmental care in all areas, from sustainable production methods to the investigation of new efficient technologies. Therefore, Bosch argued that the claim, "100\% sustainable and green technology inside," was intended exclusively for its users to understand Bosch's commitment to the environment. SERNAC found the response to be inadequate and misleading and a lawsuit has been filed which may 


\section{Context for Regional Cooperation}

\subsection{Overview}

Although SC countries are quite diverse in geographical, demographic and economic terms, as well as in their current involvement in ecolabelling and SPP, interviewees from all SC countries seem to support collaborating at the regional level in ecolabelling. This is mainly because they believe it can strengthen the competitiveness of their export and regional trade sectors. However, it is also found that there are some differences between countries in terms of attitudes and emphasis towards embarking in an ecolabelling collaboration initiative at the SC level. The following table summarises this information:

Table 18: Attitudes and Incentives of SC Countries towards Ecolabelling Cooperation

\begin{tabular}{|c|c|c|c|c|c|}
\hline & Argentina & Brazil & Chile & Paraguay & Uruguay \\
\hline $\begin{array}{l}\text { General } \\
\text { Attitude }\end{array}$ & Passive & Positive & Positive & Positive & Passive \\
\hline $\begin{array}{l}\text { Main } \\
\text { Feelings }\end{array}$ & $\begin{array}{l}\text { Concerned: } \\
\text { Seen as } \\
\text { another trade } \\
\text { barrier }\end{array}$ & $\begin{array}{l}\text { Confident: } \\
\text { Brings negotiation } \\
\text { power on } \\
\text { international markets }\end{array}$ & $\begin{array}{l}\text { Interested but } \\
\text { cautious: } \\
\text { Willing to work } \\
\text { together but first } \\
\text { needs to focus on } \\
\text { internal } \\
\text { programmes }\end{array}$ & $\begin{array}{l}\text { Interested: } \\
\text { It might be a way } \\
\text { of gaining better } \\
\text { access to } \\
\text { international } \\
\text { markets }\end{array}$ & $\begin{array}{l}\text { Doubtful: } \\
\text { It is difficult for SC } \\
\text { countries to really } \\
\text { cooperate in } \\
\text { trade issues }\end{array}$ \\
\hline Focus & Exports & $\begin{array}{l}\text { Exports and internal } \\
\text { market }\end{array}$ & Exports & Exports & Exports \\
\hline $\begin{array}{l}\text { Main } \\
\text { Incentives }\end{array}$ & $\begin{array}{l}\text { Overcoming } \\
\text { lack of } \\
\text { internal } \\
\text { governance } \\
\text { to develop } \\
\text { ecolabels }\end{array}$ & $\begin{array}{l}\text { Strengthening its } \\
\text { position on } \\
\text { international markets } \\
\text { and help address } \\
\text { environmental } \\
\text { problems }\end{array}$ & $\begin{array}{l}\text { Strengthening its } \\
\text { position on } \\
\text { international } \\
\text { markets }\end{array}$ & $\begin{array}{l}\text { Learning from } \\
\text { countries with } \\
\text { more } \\
\text { ecolabelling } \\
\text { experience }\end{array}$ & $\begin{array}{l}\text { Strengthening its } \\
\text { position on } \\
\text { international } \\
\text { markets }\end{array}$ \\
\hline
\end{tabular}

Initially at the beginning of this project's investigation, in May 2012, it was assumed that SPP and regional trade would be the key drivers for ecolabelling cooperation. However, through the development of this study, all SC countries were found to have a common interest in a regional cooperation project that would support their international exports as opposed to regional trade. At the same time, since the SC countries find themselves at very different stages of ecolabelling development, they have diverse attitudes towards cooperating regionally which are captured in greater detail in the following sub-section.

\subsubsection{Argentina}

The interviews showed that there is a widespread view of ecolabels as a non-tariff trade barrier in Argentina. This seems to have been reflected by the Argentinean position in international forums, where it has maintained its unfavourable attitude towards ecolabelling initiatives in general. While this view is most common in the public sector, it has also been expressed by some private sector actors. Thus, it is more probable that support for regional ecolabelling initiatives has to be looked for in the private sector rather than in public bodies. 
Nevertheless, some respondents stressed that it is very important for Argentina to participate in a regional cooperation initiative, if it is to commit itself to advancing in ecolabelling. This is basically due to the Argentinean government's more reactive response to ecolabelling, where it has not permitted the country to develop an effective, internationally recognised ecolabel scheme on its own. Its interest in participating in regional initiatives is mainly because this will generate greater responsibilities and commitments towards the other parties. As put by one respondent,

"without the need to comply with deadlines, standards and processes driven externally, Argentina would lag behind."

In summary, it is Argentina's need to keep up with the activities in other countries which make them interested in ecolabelling, and the best way to achieve this is by working directly with the region.

\subsubsection{Brazil}

As previously discussed, Brazil has already been very active in terms of ecolabelling and SPP. In fact, it is already looking for the mutual recognition of its ABNT ecolabel with international markets (Europe and US) as a way of increasing its participation in these markets. Thus, the main incentive Brazil has for supporting regional ecolabelling initiatives lies in strengthening its position in these processes.

Brazilian respondents stressed that participating as a region in these negotiating processes of export products is more powerful than going forward on its own. This would mean greater representation of its products on international markets. Moreover, it is felt that although the ABNT is a strong ecolabel for participating in international markets, an SC ecolabel would be even stronger due to having a more collective representation and support system. Brazil has also showed willingness to provide its experience with the ABNT label for the preparation of a SC label scheme.

\subsubsection{Chile}

Chile seems to have a cautious attitude towards cooperating on ecolabelling at the SC regional level. Although Chile does understand the benefits for the export sectors, and has always had an interest in a permanent cooperation with other SC countries (e.g. exchange in information, workshop participation, etc.), there is a widespread idea that it does not seem to be practical to embark on an official regional ecolabelling initiative in the short term. First of all, Chile recognises the diverse levels of progress in the different countries of the SC. It is also argued that, as it is a relatively recent practice in the country, advances need to be made domestically before a regional initiative should be embarked upon. This means that, prior to regional ecolabelling integration, Chile needs to advance in terms of building up its own institutions and to assess the economic impacts this would bring to its export sectors. At the same time, it seems that Chile is very interested in learning from the Brazilian experience related to the ABNT label.

\subsubsection{Paraguay}

Although there are many Paraguayan ISO 14000 certified companies and some certifications for organic products (sugar, cotton, yerba mate and others) are used, there are few certified products on the domestic market. There is not much ecolabelling information available in the country and, therefore, it remains relatively unknown to the market. As expressed by one interviewee,

"we attended the Santiago meeting last year in order to learn about ecolabelling."

This reflects that interest is growing in Paraguay, both at public and private level. There is recognition that the country's industries need to include sustainability aspects more actively into their business and that ecolabelling can play an important role if the country wants to stay competitive on international markets. Thus, the main incentive for cooperating at the SC level lies in learning, and in 
being pulled by countries with more ecolabelling experience, especially Brazil. As put by one interviewee,

"we are interested in cooperating at the SC level basically because we are lagging behind."

\subsubsection{Uruguay}

Uruguay has a feeling of scepticism towards the success of regional SC ecolabelling initiatives, basically due to the perception of recent increases in non-tariff trade barriers for Uruguayan exports in Argentina and Brazil. Nevertheless, interviewees were very clear that the main incentives Uruguay has for cooperating in ecolabelling at the SC level lie in making their exports sectors more competitive. As current capabilities in this area are low in Uruguay, the country would benefit from sharing information and know-how with countries such as Brazil and Chile.

\subsection{SWOT Analysis}

In order to summarise the findings from the regional cooperation research and interviews, two SWOT analyses were carried out, one to capture the current regional context and another to assess the opportunity for regional cooperation.

\subsubsection{Current SC Regional Situation}

The initial analysis summarised in Figure 7 below, shows a common interest across the region to work together addressing the pressures from export markets for greater sustainability of the industries through tools such as ecolabelling. At the same time, the SC countries are at various stages of development in ecolabelling and SPP programmes, which leads many countries to be interested in focusing on internal programmes prior to external collaboration. With that being said, the analysis ultimately found that the long-term regional cooperation could provide a promising opportunity for increasing technical capacity, operational efficiency and programme alignment across countries. 


\section{SWOT- Current SC Regional Situation}

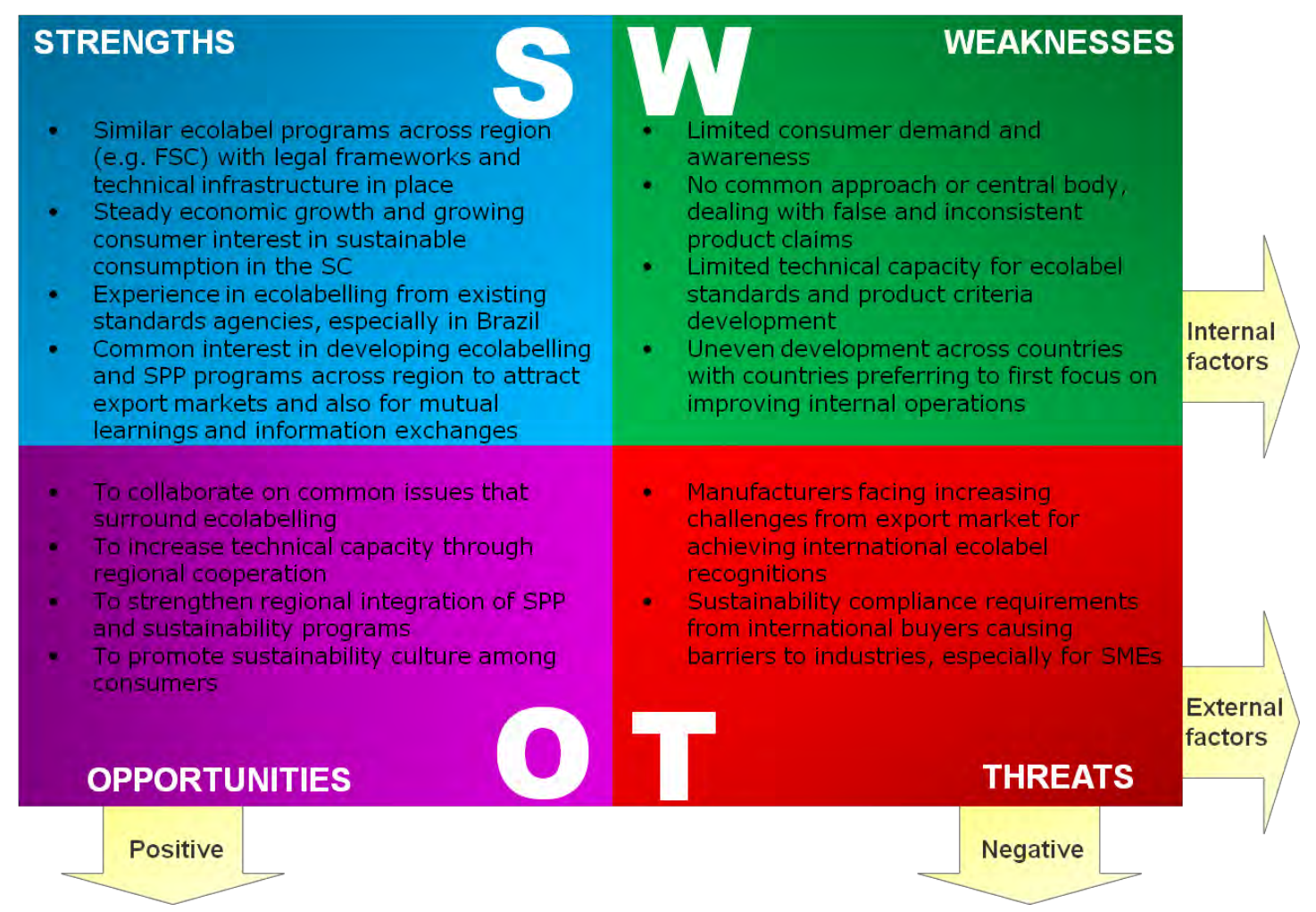

Figure 6: SWOT Analysis for Current SC Regional Situation

Expanding on the point of regional and international competitiveness for SC countries, the global proliferation of ecolabelling creates the need of adapting and implementing them at the local level. As expressed by one interviewee,

"we have more and more global ecolabels. How we implement global ecolabels regionally and nationally is the greatest challenge. We need simplification and harmonisation. We have to adapt these global ecolabels at the local level."

Considering the strengths that SC countries can derive from similar product information systems, and the amount of time, expertise and financial investment required to develop such systems, the opportunity for SC regional cooperation on ecolabelling also lies in economies of scale. If countries cooperate, they can use the needed resources more efficiently and effectively for establishing the organisational structures, developing expertise in establishing criteria and building quality-assurance infrastructure. As expressed by one European interviewee:

"If you want to develop environmental criteria that are unique to a product together with mutual recognition agreements with export markets, it is much easier to deal from a single point than from multiple points. If you have five programmes instead of one, it means five times the amount of staff, money and resources. It would also mean five times the amount of criteria and ecolabels, and as there would surely be not much difference between them, it doesn't make sense to develop them separately. It is much easier to negotiate an agreement with foreign organisations for a single proposal than for five proposals."

These economies of scale are also relevant at the internal consumption level of SC countries. Currently, SC consumers are not well prepared for ecolabelling. Although the consumer surveys, 
presented in Section 6.5, have found some demand for sustainable products, a large proportion of the $\mathrm{SC}$ is still not willing to pay more for them. If the ecolabelling programmes were to be run in a collaborative manner across the SC region, the costs for development could potentially be lower, since the expense would be spread across five countries as opposed to one and larger customer base could be developed. This could potentially make the ecolabelling process cheaper and, in turn, provide ecolabelled products at a lower cost for SC costumers.

\subsubsection{Opportunity for SC Regional Cooperation}

The SWOT analysis summarised in Figure 8 shows how the current regional situation translates into opportunities for regional cooperation in terms of increasing regional capacity, supporting national SPP, and improving international reputation, and into challenges due to the lack of technical capability for ecolabel development, limited consumer awareness and demand, which could be affected by higher prices of goods through additional costs to suppliers.

\section{SWOT- Opportunity for SC Regional Cooperation}

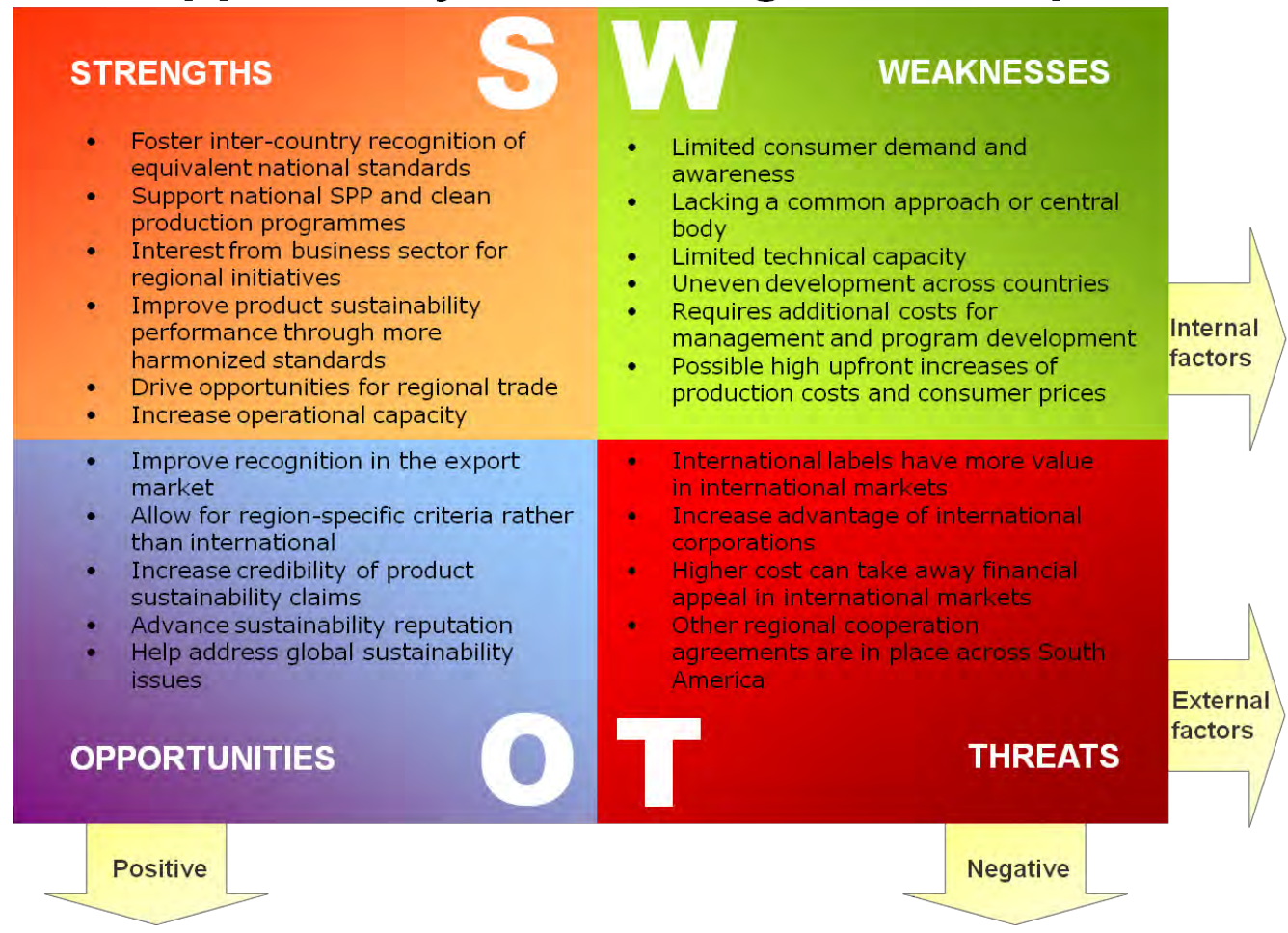

Figure 7: SWOT Analysis for SC Regional Ecolabelling Cooperation

Another important strength attributable to SC regional cooperation on ecolabelling is stronger preference of the private sector for a regional rather than a country-specific initiative. As the markets of single countries are smaller, companies are more willing to go for ecolabels, if they are valid in more than one country. In this regard, it was mentioned during the expert interviews that global companies operating in Brazil and other SC countries would like to have ecolabels that work on a regional basis, because dealing with national ones creates additional transaction costs. As a good part of their supply comes from the region, working with one system would simplify certification issues along the value chain of their products.

With respect to the weaknesses and threats, many regional stakeholders feel that sustainability demands in general impose not only additional costs but can also require expensive technology 
adaptations. More specifically, in view of the costs and capabilities needed to participate in the definition and enforcement of standards, ecolabels are criticised for limiting market access for developing country producers and therefore are, in some cases, considered as representing nontariff barriers to trade (Prasad, 2012).

Following from the internal costs barrier, the perception of ecolabels as something that imposes extra costs to the productive sector can, in turn, act as a barrier to trade within the SC region, the concern especially mentioned in the feedback from Argentina and Uruguay. In effect, some perceive regional ecolabelling as another non-tariff trade barrier that favours more advanced countries in this area over those less advanced. This is specially the case for economic sectors that compete for the same export markets. As expressed by one interviewee:

"as we fiercely compete with other SC countries for the European soy market, it is very difficult to reach an agreement in terms of ecolabelling. It seems very utopic."

Expanding on the points regarding cost, ecolabelling can cause concern for SMEs due to disproportionate costs that they have to incur for ecolabelling certification and management in comparison to larger companies (DEFRA, 2010). As multinational companies ask their suppliers to report on their environmental performance in areas such as energy and water consumption, the capacity for complying can require specific technical capabilities, expertise, financing and capital. This task is very difficult to fulfill by many SMEs, especially in the developing world (Prasad, 2012).

Due to SME's limited capacity in their operations budget, the concern is that voluntary standards and ecolabels can only be afforded by large corporations. In turn, this has the potential of creating even greater inequality between large firms and SMEs. This is a worry brought forward by diverse SC interviewees. As put by one interviewee:

"it is very important that SMEs are not damaged by regional ecolabelling initiatives. These processes are not free and SMEs generally don't have the resources needed to participate. They need special support to get involved, especially those SMEs oriented towards export markets."

Inequality in SC countries is very high in global terms. In effect, Paraguay, Brazil and Chile are among the fifteen most unequal countries in the world, according to diverse Gini coefficient rankings. Thus, for many relevant stakeholders in these countries, any suspicion that ecolabels might bring further inequalities is a cause of significant opposition.

Another weakness of SC cooperation on ecolabelling mentioned repeatedly during the interviews is linked to more structural characteristics of SC countries. These relate to general socio-economic differences, divergent specific environmental objectives, differences in the exporting structure of countries and clearly different interests in ecolabelling matters, where more advanced countries are interested in the expansion of their existing programmes, and less advanced countries are simply trying to learn more from existing programmes. As put by a respondent,

"I am very sceptic about reaching ecolabelling agreements between SC countries. Although superficially they appear as having common interests, in reality their interests part away."

Overall, the underlying barrier in SC countries goes back to the lack of institutional and technical capacity to deal with voluntary standards and labels. Similarly, at an international level, the emphasis has been shifting away from legal arguments against ecolabels towards dealing with the technical and institutional capacity in using ecolabels and how to improve the capacity of their users. It is expected that there will be a growing importance for SC countries to build such capacity and pay more attention in their cooperation efforts on issues such as the rule-making procedures of 
standards based on transparency and openness; increasing information and reducing barriers; increasing the affordability of conformity assessment; clear rules about accreditation; greater involvement of different actors including the business sector; local appropriateness and global consistency; and increasing the opportunities for SMEs to benefit from ecolabelling.

\subsection{Critical Aspects for Implementation}

Based on the SWOT analyses findings and feedback from the regional experts, the study found that there is a strong scope for cooperation on ecolabelling both at national and regional level, and linking it with the implementation of national sustainable public procurement in the SC countries. While such cooperation may be challenging to achieve, it has a number of benefits that can create a strong business case for it. It is important to keep in mind the following critical aspects for implementation for such cooperation:

Table 19: Critical Aspects for Cooperation

\begin{tabular}{|c|c|}
\hline Critical Aspect & Summary \\
\hline Governing Body & $\begin{array}{l}\text { There needs to be a centralised governing body for such a cooperation and eventual } \\
\text { ecolabelling scheme. This has shown to be critical for all existing regional labels (e.g. } \\
\text { Nordic Swan and EU Flower). The governing body must be in place to first define the } \\
\text { overall principles, cooperation framework, guidelines and objectives of the label, and to } \\
\text { then oversee that the management actions are abiding. }\end{array}$ \\
\hline $\begin{array}{l}\text { Stakeholder Engagement } \\
\text { and Buy-In }\end{array}$ & $\begin{array}{l}\text { Commitment of government, business sector and non-governmental organisations, } \\
\text { academic community is essential for successful ecolabelling initiatives. Without the } \\
\text { engagement of industry and government, ecolabelling initiatives will simply not } \\
\text { materialise. }\end{array}$ \\
\hline $\begin{array}{l}\text { Regional Ecolabelling and } \\
\text { SPP Training Programme }\end{array}$ & $\begin{array}{l}\text { Implementing national level awareness and consultation supported by a regional } \\
\text { dialogue and exchange of information, and by training programmes are recommended } \\
\text { as a minimum requirement for the implementation of the regional cooperation. }\end{array}$ \\
\hline $\begin{array}{l}\text { Balanced Representation } \\
\text { among the Participating } \\
\text { Countries }\end{array}$ & $\begin{array}{l}\text { Similar to the Nordic Council of Ministers, each regional country should have an equal } \\
\text { representation when critical decisions are made, and consideration must be made for } \\
\text { tailoring ecolabelling criteria to each country's specific context. In addition, the SC must } \\
\text { take a more proactive attitude towards ecolabelling and ensuring that the existing } \\
\text { schemes and approaches at national level and regional ecolabelling progress are } \\
\text { compliant with international guidelines and practices in a way that they do not } \\
\text { constitute a non-tariff trade barrier. This can enable producers to more effectively } \\
\text { respond to these demands in their own way that would be most suitable for the area. }\end{array}$ \\
\hline $\begin{array}{l}\text { Robust Pilot Sector } \\
\text { Implementation }\end{array}$ & $\begin{array}{l}\text { A well-selected limited group of industry sectors should be piloted as a way to provide an } \\
\text { initial trial for the programme. These sectors need to be well represented across the } \\
\text { region and be aligned with existing SPP and ecolabelling. }\end{array}$ \\
\hline Consumer Awareness & $\begin{array}{l}\text { A consumer awareness/marketing campaign needs to be put in place to educate the } \\
\text { consumers to understand the concepts behind the ecolabel to hopefully enable them to } \\
\text { make more conscious decisions through the purchasing of ecolabelled products. }\end{array}$ \\
\hline $\begin{array}{l}\text { Methodological Working } \\
\text { Groups and Roadmap for } \\
\text { Development of } \\
\text { Technical Criteria }\end{array}$ & $\begin{array}{l}\text { Life-cycle based ecolabels which draw from multiple criteria across the life cycle of goods } \\
\text { and services (i.e. Type I ecolabelling schemes) are the most technically credible and } \\
\text { internationally accepted approach for ecolabel standards. Therefore, they should be } \\
\text { intended for the regional cooperation and eventual ecolabel. Such label should also } \\
\text { consider the three pillars of sustainability to make a meaningful contribution to } \\
\text { sustainability objectives in the region where social aspects are of extreme importance to } \\
\text { national policies. With that being said, a collection of industry, scientific and civil society } \\
\text { working groups, run through an effective project road map, must be in place in order to } \\
\text { meet the technical needs of a Type I label. }\end{array}$ \\
\hline
\end{tabular}




\subsection{Technical Capacity for Development of a Regional Cooperation on Ecolabelling}

The SC's current technical capacity available for the development of a regional ecolabelling programme is through existing SC standards agencies and product certification organisations. In spite of the presence of a wide range of these organisations ${ }^{44}$, the technical rigour behind these labels appears to be limited. In order for the SC region to effectively utilise ecolabels and SPP as sustainability decision-making tools, it is critical that they are developed using strong technical basis and capability. The following case study provides an example of how a government procurement programme is beginning to incorporate ecolabelling criteria, which shows a significant need for increasing capacity for technical rigour.

Case Study: ChileCompra Express
ChileCompra Express is an online electronic catalogue for public procurement in Chile. It provides a
directory of available product and service options for purchase and streamlines the process for
procurement for all government departments across the country. In September 2010, in order to support
Chile's SPP policies, after a market and legal study of the market readiness to respond to SPP, aimed at
incorporating sustainability criteria, ChileCompra Express began incorporating sustainability labels in the
product and service catalogue. In total, it has eight labels related to products and three to suppliers. One
of them is "Eco-Producto (eco-product)," which has been listed as recognising products that in its
manufacturing process, use and final disposition within their life-cycle have a minimum impact on the
environment, compared to other similar goods, or that because of its characteristics is beneficial for the
environment (DCCP, 2011). After further investigation, it was found that there is currently no formalised
process for certifying, "Eco-producto," claims that are listed in the catalogue. Therefore, there is no
common way to substantiate that these products actually have minimum impact on the environment in
respect to other similar goods. Although this may be seen as an issue in the catalogue's current label
criteria, it also certainly shows an important opportunity for developing a reference system for ecolabels
that could serve the purpose of providing recognition for credible claims and labels not only in Chile but
for the entire region.

In order to create a technically rigorous label that considers the key characteristics of products along their life-cycles and is based on three pillars of sustainability (i.e. Type I ecolabelling schemes which also include social considerations), the label must be based on a robust technical assessment using life-cycle approach and data that is representative of the region. To that respect, the SC currently has very limited regional life-cycle inventory data, and the effort for acquiring this data can require a great deal of additional capacity and funding. With that being said, there are alternatives to developing these criteria, such as drawing from existing international data and tailoring them to be appropriate for the region, but there is still concern that this may not adequately capture the true impacts regionally.

Learning from Mercosur's experience in developing a regional ecolabel as discussed in the previous section, a critical component for successful technical development is the need to have in place a credible certification body capable of working effectively across all involved countries. The lack of this body led to the failure of the Mercosur's attempt to build a regional environmental label. Any future initiatives in this respect should put a strong emphasis on this.

In summary, the physical capacity for the technical development is present through existing standards agencies and product certification bodies, but there is still a need for alignment and additional expertise in a life-cycle based approach for developing regionally relevant criteria.

\footnotetext{
${ }^{44}$ Refer to Appendix F, Table F.1, for a detailed list of SC institutions related to ecolabelling.
} 


\subsection{Top Industries for Piloting Regional Ecolabelling in the SC}

In order for an ecolabel to become successful, a well-selected group of industry sectors should be piloted as a way to provide an initial trial for the label. Based on the key indicators defined in the opening of this section and by drawing from the research conducted in the study, the following table proposes the top industries for piloting regional ecolabelling in the SC.

Table 20: Summary of Proposed Pilot Sectors with Respect to the Key Indicators

\begin{tabular}{|c|c|}
\hline Proposed Pilot Sector & Key Indicator Summary \\
\hline Pulp and Paper & $\begin{array}{l}\text { Strong Representation: All countries are purchasing pulp and paper products } \\
\text { from the domestic market and all are carrying out logging and production. } \\
\text { Addresses Relevant Issues: Addresses a main threat (logging) for two of the five } \\
\text { biodiversity hotspots that are represented within the SC, the Atlantic Forest and } \\
\text { the Amazon Region }{ }^{45} \text {. } \\
\text { Aligns with Existing Activity: Transversal product for SPP and private } \\
\text { consumption. Priority product to some governments like Chile, and priority } \\
\text { product for SPP. }\end{array}$ \\
\hline Timber Building Products & $\begin{array}{l}\text { Strong Representation: All countries are purchasing timber building products } \\
\text { from the domestic market, and all are carrying out logging and production. } \\
\text { Addresses Relevant Issues: Same as previous; addresses a main threat (logging) } \\
\text { for two of the five biodiversity hotspots that are represented within the SC, the } \\
\text { Atlantic Forest and the Amazon Region. } \\
\text { Aligns with Existing Activity: Within the sector, forestry certifications (such as } \\
\text { FSC, PEFC and ABNT) have a reasonable level of implementation in the region. In } \\
\text { construction, building rating tools such as LEED may be good drivers for } \\
\text { ecolabelling criteria for wood based building products. }\end{array}$ \\
\hline Electrical Appliances & $\begin{array}{l}\text { Strong Representation: Energy is produced and consumed in every country in } \\
\text { the SC. Housing, water, electricity and fuels represent 15.8-19.2\% of private } \\
\text { consumption in the SC region } 46 \text {. } \\
\text { Addresses Relevant Issues: It addresses an environmental hotspot (energy } \\
\text { consumption at the use phase) and also social issues, by reducing cost of living. } \\
\text { Aligns with Existing Activity: Energy efficiency ecolabels for electronic appliances } \\
\text { have a very good penetration in terms of private consumption and SPP for } \\
\text { residential and commercial equipment. }\end{array}$ \\
\hline Tourism & $\begin{array}{l}\text { Strong Representation: SC region is recognised as a world tourism location. Strong } \\
\text { interest across all SC countries to address this area. } \\
\text { Addresses Relevant Issues: Addresses potential impact tourism industry can have on } \\
\text { the SC, which affects some of the most sensitive ecosystems in the region as well as the } \\
\text { world. } \\
\text { Aligns with Existing Activity: With Pão de Açúcar to receive the first Type I ecolabel } \\
\text { recognition for a tourism location in 2012, the tourism industry ecolabelling activity is still } \\
\text { at an early stage, but there is still strong interest in promoting sustainability and eco- } \\
\text { tourism. }\end{array}$ \\
\hline
\end{tabular}

These four sectors were presented due to their ability to meet the key criteria for the region. Further detail on how these pilot sectors should be implemented is provided in Section 8.4 of the report. This

\footnotetext{
${ }^{45}$ Refer to Appendix F, Table F.1 for further details on SC Biodiversity Hotspots

${ }^{46}$ Refer to Appendix D, Table D.1 for further details on Private Consumption in the SC
} 
section not only outlines a proposed approach for these sectors but also the case for implementing an additional three sectors in the long-term development of the programme.

\section{Recommendations}

As described in the methodology, the final recommendations for the regional cooperation initiative on ecolabelling and SPP in the Southern Cone countries were developed from the discussion paper for the first consultation workshop (Santiago, Chile, November 2011), research findings, expert interviews, and feedback from the regional workshop (Rio de Janeiro, November 2012).

\subsection{Feedback from the regional workshop in Rio de Janeiro, November 2012}

At this meeting in Rio de Janeiro, the draft proposal for the regional cooperation was presented for discussion. The participants made the following observations and recommendations:

- Ecolabelling and public procurement are important tools and policy approaches that complement each other with a common objective of promoting the production and consumption of more sustainable products;

- There is strong overall support for regional cooperation on ecolabelling and public procurement across the SC countries;

- It is critical to engage multiple stakeholders to open and transparent dialogue, on a sectoral, national and regional level;

- An emphasis needs to be placed on awareness raising and education for relevant stakeholders and consumers;

- Regional discussions should give input, alignment, support and inspiration for the work on the national level and vice versa (e.g. national consultation workshops);

- Development towards a regional cooperation can follow the specific stages: Promote \& Enable, Adapt and Establish (explained in the following section);

- The first necessary step is to establish a regional coordination group in order to enable efficient communication and coordination of activities under each proposed stage of cooperation;

- Regional cooperation should be based on a clear structure, without too much bureaucracy, with strong national representation across each SC country.

Based on this additional feedback from the meeting, the final recommendations have been revised and are presented in the following sections.

\subsection{Overview}

While the research found there is an overall aspiration for the development of a regional ecolabelling programme based on the ISO type I ecolabel and example of the Nordic Swan in the long term, the current conditions in the region for running an effective ecolabelling programme are still in early stages. However, cooperation in general is seen as positive for the region mostly because it would allow sharing experience, building necessary capacities and expertise, and catching up with what has become a mainstream in the international markets. In order for the SC region to reach the level where they can cooperate on these issues more effectively, there are several considerations to take into account and conditions that need to be met: 
- It is critical to start engaging multiple stakeholders that have not been sensitised or have not participated in the initial discussions, such as key members from industry, existing ecolabels in the SC, NGO's, and the scientific community. This will allow the creation of a level playing field in understanding among key stakeholder groups of the advantages ecolabels can provide for products and their role in advancing more sustainable consumption and production as well as the benefits of regional cooperation.

- When engaging these stakeholders, it is important to create an effective and balanced decision-making structure that does not limit the ability for decisions to be executed efficiently as well as ensuring inclusiveness and transparency of the decision-making process. Therefore, it is recommended that a well designed governing body, with strong representation for each country, selected sector and key stakeholder group (e.g. NGO, government, industry), must be established as early as possible.

- The focus of the regional cooperation on ecolabelling should be ultimately on consumers as the users and target group for provision of credible product information. The consumers in such case can also include governments in their capacity as public procurers of goods and services and businesses.

- Awareness raising and education for consumers is thus an important condition. Consumers have ability to drive the demand for more sustainable and certified products. Currently the demand is limited due to general lack of sustainability culture in the region and restricted purchasing power for more sustainable, which are often assumed more expensive, products.

- Therefore, SPP as well as the exporting sectors are beginning to be seeing, through the clients in the importing countries, how they can play an important role in creating the green market.

- At the same time, for the local private market, retailers may be a key industry that drives sustainable production and consumption, with entities such as the Latin American regional hub of The Sustainability Consortium.

- Equally, given that most of the countries in the region are at the initial stages of SPP development, the existence of credible robust and harmonised ecolabels can support technical work on the implementation of SPP. Given the attention and political support that the SPP approach is receiving in the region, this can be an opportune moment to engage the two approaches of ecolabelling and SPP.

Following this, it is relevant to start the cooperation with an initial phase that would aim at establishing a cooperation framework to create a general understanding of the issues in regional countries through awareness raising and consultation workshops, and establishing a governance structure with two way channels of communication from regional to national and vice versa. The overall cooperation should be based on a robust implementation designed in consultation with all relevant stakeholders. The subsequent stages of cooperation can be also then defined and agreed upon. The entire proposal for the cooperation is outlined in the following section.

\subsection{Fundamentals for initiation of the regional cooperation}

The following section provides a summary of the fundamental steps needed to be done at a national level in order to begin a regional cooperation. These points are identified as part of the fundamental stage for regional cooperation. The main objective of this stage is to formalise the support from the key stakeholder bodies in each country, and to begin to build the necessary components for the 
establishment of a regional body. Table 23 below presents three actions that need to be considered in the fundamental stage.

Additional support should be considered to set up the infrastructure for regional cooperation. This will assist in the coordination across national activities as well as the establishment of some form of a regional office. The regional office does not necessarily need to be a specific location but instead be assigned to an organisation that will be held accountable for regional activity.

Table 23: Fundamental national actions for initiation of the regional cooperation

\begin{tabular}{|c|c|}
\hline National Actions & Summary \\
\hline $\begin{array}{l}\text { 1. Establish support from key stakeholder bodies } \\
\text { across SC }\end{array}$ & $\begin{array}{l}\text { Each country must seek out engagement with key } \\
\text { stakeholder bodies in order to present the concepts of the } \\
\text { regional cooperation model and request some formal } \\
\text { statement of support. }\end{array}$ \\
\hline $\begin{array}{l}\text { 2. Nominate representatives for the SC Regional } \\
\text { Cooperation Group }{ }^{47}\end{array}$ & $\begin{array}{l}\text { Each country should nominate representatives to a } \\
\text { regional cooperation body. To create a balance in the } \\
\text { representation, the group should be made up of } \\
\text { government, industry, and non-governmental } \\
\text { organisations. }\end{array}$ \\
\hline $\begin{array}{l}\text { 3. Contribute to the roadmap for regional } \\
\text { cooperation }\end{array}$ & $\begin{array}{l}\text { Based on the following recommendations, a road map for } \\
\text { regional cooperation will be formulated into a guideline } \\
\text { document. In order to gain complete consensus across the } \\
\text { SC, each country must review these guidelines and } \\
\text { contribute to a final roadmap for regional cooperation. }\end{array}$ \\
\hline
\end{tabular}

An effective way to address action 1 is by drafting a common letter of support in order to provide a general agreement to common objectives for regional cooperation. These objectives will provide the vision for the regional cooperation and the principles for how the programme will operate. By getting the key stakeholder to sign this letter of support, the programme will gain the assurance that there is official support and that it is aligned under these values.

In addition to the following section, developing a guideline for the regional cooperation roadmap could also act as a catalyst for developing the next steps for regional cooperation, by providing the general concepts and a framework for the programme. This would not be a prescriptive guide for how the programme will operate but instead act as a template for the SC representatives to build on.

\subsection{Proposed stages for the regional cooperation initiative on ecolabelling and SPP}

Three stages of cooperation are proposed for the Southern Cone region:

1. Promote and Enable: establish a firm foundation for the regional cooperation initiative on ecolabelling and SPP through promoting the role of ecolabels and product sustainability information (PSI) in sustainable consumption and production (SCP) and enabling stakeholders to understand and apply ecolabels as voluntary market based tools for advancing SPP.

2. Adapt: have in place a regional recognition system based on benchmarking criteria for existing and new ecolabels and voluntary standards which can serve also as a reference system for provision of credible and substantiated information about products.

3. Establish: establish a new type I ecolabelling programme for the SC region.

\footnotetext{
${ }^{47}$ This task has actually already been achieved at the end of the regional workshop Rio de Janeiro but for the sake of providing a complete structure to this stage of the regional cooperation strategy, it is still included as a fundamental action.
} 
These are called stages of cooperation because they can be selected as one option for a roadmap in a sequential order (stages 1-3) or, as shown in Figure 9, as another roadmap which omits the, "Establish," stage and continues to focus on development of the, "Adapt," stage. The decision for which roadmap to ultimately work with should depend on the needs and views of the stakeholders and the regional coordination group.

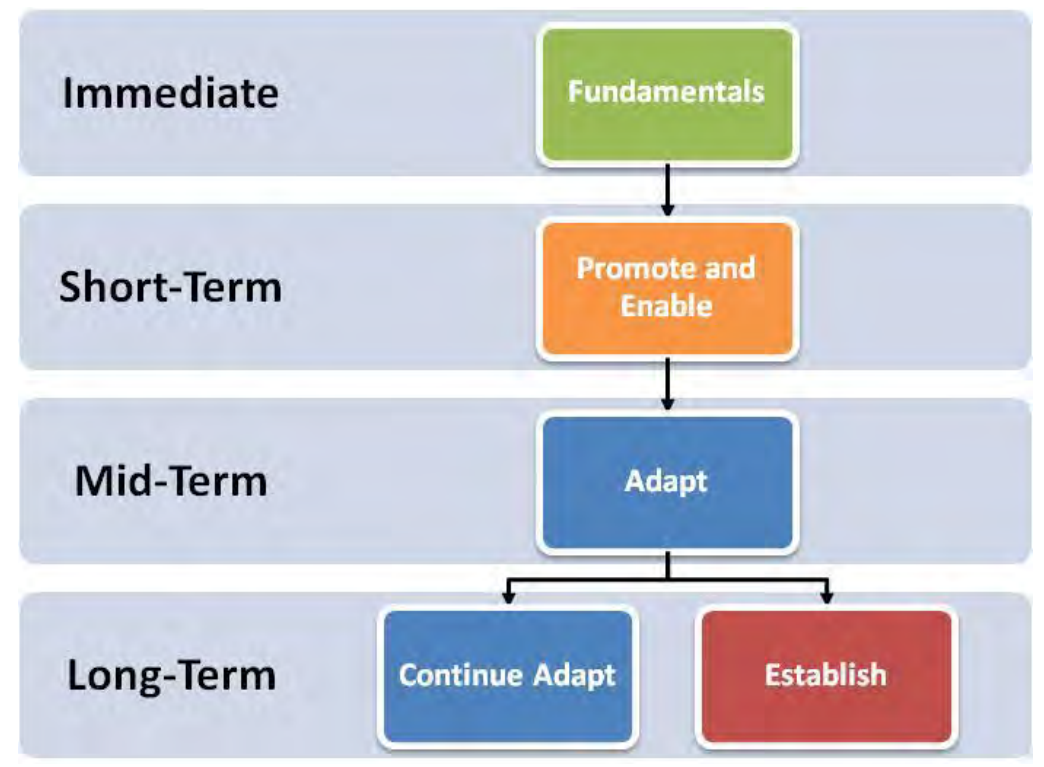

Figure 9: Proposed Roadmaps for Regional Cooperation

Figure 10 presents the proposed governance model for operations. The diagram shows the SC regional coordination group as the regional level centrepiece for all proposed strategies. Following from this, there would be ongoing engagement on a national level through national bodies, which would be made up of representatives from key stakeholder groups. Similar to the Nordic Swan governance model, this design will allow for overarching decisions to be made efficiently through a single SC regional coordination group while still gaining direct feedback and engagement through the national bodies.

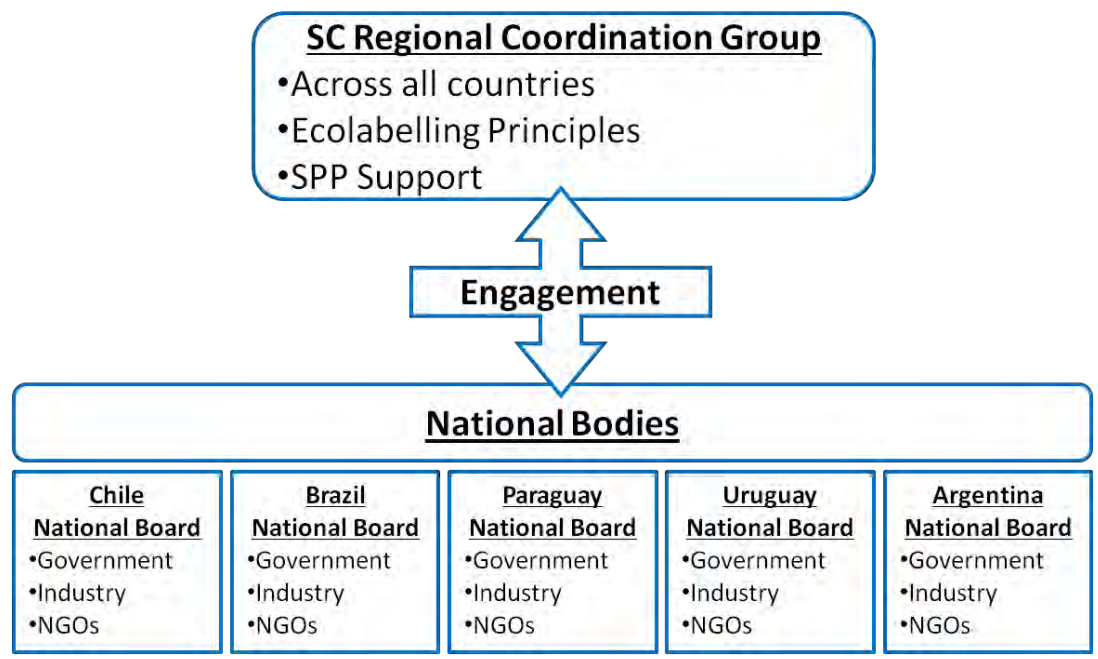

Figure 10: Overview of Proposed SC Ecolabelling and SPP Regional Cooperation Governance Model 
Following from the, "Fundamentals," described in section 1.3, the, "Promote and Enable," stage would first focus on setting the regional structure in place, national-level awareness-raising, and developing an information network on ecolabelling and SPP. During this stage, an initial assessment will be conducted to look at international processes and their relevance to the regional initiative and mapping of the selected industry sectors (possibly pulp and paper, timber, electronics and tourism) to analyse the scope for harmonisation.

Following from the, "Promote and Enable," stage, the, "Adapt," stage would run by combining the Nordic Swan's overall governance model and the African Ecolabelling Mechanism's (AEM) ${ }^{48}$ ability to benchmark existing labels and programmes. The, "Adapt," stage would focus on having in place a regional recognition system based on a number of principles/standards to benchmark existing and new ecolabels and voluntary standards towards stronger alignment and harmonisation, which can serve also as a reference system for provision of credible and substantiated information about products. The system can then be tested on pilot industries, selected based on the criteria of relevance for ecolabels and SPP. Anchoring on the recognition system, a central directory of certified products $^{49}$ and information for these types of resources can be established through a website which can be linked with SPP policies. The work would concentrate on the most prominent sectors and labelling schemes.

Lastly, drawing from the EU Flower governance model, the, "Establish," stage would produce a new Type I ecolabel for the entire SC region. This is a long-term strategy which would begin with the establishment of a regional ecolabelling governing body, standards criteria, and the design and implementation of an entire labelling programme.

The following table provides a summary of the two proposed long-term strategies' pros and cons. The, "Adapt," strategy would provide greater support to existing ecolabelling programmes but still lacks strong harmonisation across initiatives while the, "Establish," strategy would be the most challenging but more comprehensive and regionally representative.

Table 214: Pros and Cons of the Proposed Strategies for SC Regional Cooperation

\begin{tabular}{|c|c|c|}
\hline Strategy & Pros & Cons \\
\hline Adapt: & $\begin{array}{l}(+) \text { Strengthens understanding of various actors } \\
\text { and builds their capacities } \\
(+) \text { Creates alignment across the region while } \\
\text { also supporting existing programmes } \\
(+) \text { Filters out credible labels that can be used in } \\
\text { SPP } \\
\text { (+) Provides a reference system for developing } \\
\text { and providing credible product information for } \\
\text { business sector and public procurers }\end{array}$ & $\begin{array}{l}\text { (-) Countries would still be working with } \\
\text { separate ecolabels and criteria, which } \\
\text { could inherently result in a lack of } \\
\text { harmonisation and stronger alignment } \\
\text { across programmes } \\
\text { (-) Still may require businesses to go } \\
\text { through several labelling requirements } \\
\text { in order to achieve regional recognition } \\
\text { (-) Existing labels may not agree to } \\
\text { participate due to vested interests and } \\
\text { competition }\end{array}$ \\
\hline Adapt and Establish & $\begin{array}{l}(+) \text { Creates regional cooperation across a range } \\
\text { of issues, which will align criteria across all } \\
\text { countries } \\
(+) \text { Can result in more stream-lined and cost- } \\
\text { effective processes for businesses that wish to } \\
\text { achieve recognition (since they would only }\end{array}$ & $\begin{array}{l}\text { (-) Much effort required to gain buy-in } \\
\text { from all key stakeholders and credibility } \\
\text { in export market } \\
\text { (-) Substantial funding needed. } \\
\text { (-) Does not support existing labels in the }\end{array}$ \\
\hline
\end{tabular}

\footnotetext{
${ }^{48}$ Refer to Sections 4.2.1 and 4.2.3 for additional information on the Nordic Swan and AEM's governance model

${ }^{49}$ Similar to www.ecospecifier.com
} 


\begin{tabular}{|l|l|l|}
\hline Strategy & Pros & Cons \\
\hline & $\begin{array}{l}\text { need to apply to a single label rather than } \\
\text { several) } \\
(+) \text { Potentially better regional trade and SPP } \\
\text { (since they would all be drawing products } \\
\text { from the same recognition scheme) } \\
(+) \text { Life cycle coverage of product impact could } \\
\text { allow a holistic approach to environmental } \\
\text { improvement and avoid burden shifting }\end{array}$ & $\begin{array}{l}\text { region } \\
(-) \text { May require businesses with exting } \\
\text { ecolabel recognition to go through the } \\
\text { process all over again } \\
(-) \text { Can potentially compete with existing } \\
\text { labels }\end{array}$ \\
\hline
\end{tabular}

\subsection{Proposed roadmap for the implementation of regional cooperation initiative on ecolabelling and SPP in the Southern Cone region of Latin America}

The proposed roadmap in Table 25 reports the objectives required in the immediate, short, mid and long-term, which addresses the two road map strategies proposed. Following from the defined objectives, the table outlines the necessary activities to implement and achieve those objectives. It also shows the immediate necessary actions to initiate the cooperation efforts. These immediate, short, mid and long-term objectives and actions are not intended to be followed exclusively but instead are provided as a way to give a better understanding of the requirements for the proposed strategies.

Table 25: Proposed roadmap(s) for SC regional cooperation

\section{Fundamentals}

Objective: launch the process and ensure the participation of the relevant stakeholders from the national level.

The inception phase will include necessary steps to create an agreement among key stakeholders on the proposed objectives and roadmap, and revise it based on the feedback received. It will also allow creating an agreement on the implementation process and governance structure for coordination of the regional initiative. It should include the following actions:

1. Share the results of the roadmap with focal points who form a regional coordination group

2. Organise a webinar to get an agreement and plan start-up meeting

3. Organise a start-up meeting to discuss and agree on roadmap, its objectives, and way of implementation, discuss the workplan, governance structure and its modus operandi

\section{Outputs:}

- $\quad$ Agreement on the roadmap, objectives and way of implementation

\section{Promote and enable}

Objective: establish firm foundation for the regional cooperation initiative on ecolabelling and SPP through promoting the role of ecolabels and product sustainability information (PSI) and its use in SPP, and enabling stakeholders to understand and apply ecolabels as a voluntary market based tools for advancing SCP.

This phase will be an important one to set the stage for further implementation of the initiative. It will focus primary on setting the structure in place, awareness-raising at national level to bring the level of awareness and engagement to a certain level playing field among countries in view of their current differences. During this stage, an initial assessment work will be conducted looking at international processes and their relevance for the initiative, and a 
mapping of the selected sectors (possibly pulp and paper, timber, electronics and tourism) to analyse the scope for harmonisation. It can include the following actions:

1. Strengthen the regional coordination group

- Finalise its composition, define its terms of reference and modus operandi,

- Create conditions for engaging other relevant stakeholders (e.g. signing precompetitive agreements if needed, especially with private sector representatives)

- Conduct regular in person or virtual meetings to coordinate the implementation

2. Carry out awareness-raising and capacity-building activities:

- Conduct regional training of trainers on ecolabelling and SPP

- Engaging the trained experts, conduct national consultation and awareness raising workshops and trainings at national level

3. Mapping and assessment of the selected sectors for the implementation of the next stage of cooperation.

4. Mapping of the international processes and initiative and assess their relevance to the next stage of the regional cooperation initiative: Global Guidance on PSI, 10YFP on Consumer Information and ISEAL Credibility Principles

\section{Outputs:}

- Clearly defined terms of reference and role of each stakeholder in the coordination group,

- Enhanced awareness and understanding about ecolabels, their role and how they can be combined with SPP to create integrated approaches around SCP and sustainable products,

- Clear understanding of the scope for harmonisation in selected industries and relevance of international initiatives and processes to serve as reference to the regional cooperation initiative.

\section{Adapt}

Objective: have in place a regional reference base scheme founded on benchmarking criteria for existing and new ecolabels and voluntary standards which can serve also as a reference system for provision of credible and substantiated information about products.

Based on the assessments conducted and foundation laid in the previous stage, this stage will focus on developing and agreeing of a regional reference base scheme. It will be based on a set of benchmarking criteria against which existing ecolabels and voluntary standards can be assessed in terms of their effectiveness and contribution to advancing SPP in the region. The scheme can also be used as a reference tool for companies in developing their marketing claims and to encourage the provision of credible and substantiated information about products.

It will be ensured that the scheme is aligned with the international processes looking at the global level and regional level experience feeds into the development of the international processes. The scheme will be also disseminated and validated through a series of consultations. It will be tested in a number of pilot sectors identified based on their relevance for the region and SPP practices. The most valid ecolabels will be promoted for the use in SPP in the region.

The necessary actions can include the following:

1. Create two working groups:

○ Using the guidelines developed through international processes (eg. PSI Guidance, PCR global Guidance, ISEAL Credibility Principles for standard setting systems, relevant ISO guidelines), develop a reference base scheme for the region. 
$\circ$ Test the reference base scheme for specific sectors towards harmonisation of approaches within the sector (e.g. sector guidelines)

2. Disseminate and validate the reference base scheme in the region

3. Organise capacity building activities for the private sector and public procurement officers to understand and use with the benchmarking

\section{Outputs:}

- Regional recognition of the reference base scheme to be used as a reference for provision of credible product sustainability information, in line with international standards and practices

- Sector guidelines based on the reference base scheme

- Enhanced understanding by private sector of how to provide information about product sustainability and public procurers on how to use the reference base scheme to select more sustainable products

- A structure for an online directory of certified products available for further population and development

\section{Option 1. Continue Adapt}

Objective: continue expanding the reference base scheme to more ecolabels and voluntary standards, while also conducting a review and revision of existing certified products.

If the SC countries find the, "Adapt," stage to be running effectively, then this option will allow them to continue developing the programme and allowing its initial work to be reviewed and improved upon. Also the scheme can then be used to develop an online directory hub for certified products to be used in SPP.

The following areas would be focused on for this option:

1. Continue growth of regional reference base scheme:

- Have working groups expand to additional existing ecolabels and standards that were not addressed in the initial years of the programme

2. Expand and update online directory

- Incorporate additional products to directory that are included in additional ecolabels and standards

- Update existing products upon the occurrence of any changes to their sustainability information

3. Implement identified mechanisms that will drive public procurers to use the reference base scheme

4. Develop an online directory for certified products to be used in SPP practices by countries at the national level.

\section{Outputs:}

- Expanded and revised version of the regional recognition benchmarking scheme and sector guidelines

- Updated online directory with additions and updates to list certified products

- Increased number of public procurers using the reference base scheme

IV. Option 2. Establish

Objective: establish a new type I ecolabelling programme in the region. 
If the countries wish to expand beyond the, "Adapt," stage, then this option will allow them to establish a new type I programme for the region.

This is considered as a long-term objective in the region which may require additional fundraising and strong political support. The following actions will be necessary to implement:

1. Develop programme and business plan for the establishment of the type I ecolabelling programme

2. Start with the pilot sectors selected in the 'Adapt' stage and develop common set of criteria

3. Ensure that the programme is in line with ISO 14024 guidelines

4. Join the Global Ecolabelling Network for information exchange, peer learning and mutual recognition opportunities

5. Develop marketing of the ecolabel

6. Ensure its integration into the SPP policies in the region.

Outputs:

- ISO type I Ecolabelling programme for the region 


\subsection{Pilot Sectors}

The following table summarises the pilot sectors recommended. As discussed in Section 7.5, these sectors were chosen according to interviews, research and feedback from the regional workshop. There is a set of pilot projects (paper, forestry building products, electrical appliances and tourism) recommended for the short term, a second (food, beverage \& agriculture \& cleaning products) for the mid-term and a third (steel building products and leather) for the long-term in both, "Adapt," and, "Establish," long-term strategies. The reason for the short, mid and long term selection of each sector is provided in the second column of the table. For each pilot sector to succeed, industry engagement is essential. In addition to this, key benefits, challenges and considerations need to be addressed, which are presented in the following table.

\section{Table 26: Proposed Pilot Sector Summary}

\begin{tabular}{|c|c|c|c|c|}
\hline Pilot sectors & Main reasons & Key Benefits & Key Challenges & Key Considerations \\
\hline \multicolumn{5}{|c|}{$\begin{array}{ll}\text { S HOR T } & \text { TER M } \\
\end{array}$} \\
\hline Paper and pulp & $\begin{array}{l}\text { - Good progress (implementation and } \\
\text { existing certifications) in the value } \\
\text { chain for forestry stages thanks to } \\
\text { FSC and PEFC certification. } \\
\text { - Go beyond the current included } \\
\text { stages in forestry certification and } \\
\text { complement them with processing } \\
\text { and manufacturing stages. } \\
\text { - Transversal product for SPP and } \\
\text { private consumption. Priority product } \\
\text { to some governments like Chile and } \\
\text { priority product for SPP. }\end{array}$ & $\begin{array}{l}\text { (+) Easier for a step by step } \\
\text { implementation of continuous } \\
\text { improvement. } \\
(+) \text { Additional value to existing powerful } \\
\text { ecolabels could give strength to the } \\
\text { initiative. } \\
(+) \text { Product consumed by public and } \\
\text { private (including exports) markets. }\end{array}$ & $\begin{array}{l}\text { (-) Stakeholder engagement (industry } \\
\text { and current ecolabels governance) } \\
\text { and technical feasibility of including } \\
\text { aspects beyond current schemes. } \\
\text { (-) Matching production, consumption, } \\
\text { SPP and private consumption } \\
\text { (retailers?) and coordinate the } \\
\text { different actors. }\end{array}$ & $\begin{array}{l}\text { - Should meet criteria and requirements by } \\
\text { clients such as retailers, regional } \\
\text { governments and international markets. } \\
\text { - As per being a common product and } \\
\text { having same or similar types of end user } \\
\text { regardless of the market and type of } \\
\text { client (most people uses paper for similar } \\
\text { purposes), technical criteria should be } \\
\text { developed similarly for the different } \\
\text { destination of consumption. } \\
\text { - Most suitable for, "Adapt," strategy. }\end{array}$ \\
\hline $\begin{array}{l}\text { Timber Building } \\
\text { products }\end{array}$ & $\begin{array}{l}\text { - Building rating tools such as LEED } \\
\text { may be good drivers for ecolabelling } \\
\text { criteria for building products. } \\
\text { - There are several international } \\
\text { initiatives that could serve as a good } \\
\text { basis for a SC project. } \\
\text { - Within the sector, forestry } \\
\text { certifications (such as FSC, PEFC and } \\
\text { ABNT) have a reasonable level of } \\
\text { implementation in the region. }\end{array}$ & $\begin{array}{l}\text { (+) Globally, building rating tools are } \\
\text { good drivers for the incorporation of } \\
\text { sustainability criteria to procurement } \\
\text { practices. } \\
(+) \text { Adapting or replicating existing } \\
\text { models reduces the efforts of } \\
\text { implementation. } \\
\text { (+) Incorporating (and evaluating) } \\
\text { existing initiatives to become part of a } \\
\text { broader scope reduces the efforts of } \\
\text { implementation. }\end{array}$ & $\begin{array}{l}\text { (-) Formally incorporating a SC } \\
\text { ecolabelling programme as valid } \\
\text { criteria for assessing building } \\
\text { products into an existing building } \\
\text { rating tool. } \\
\text { (-) Developing a level playing field } \\
\text { methodology across sub-sectors and } \\
\text { countries that allow fair } \\
\text { comparisons between products. }\end{array}$ & $\begin{array}{l}\text { - Developing from a new Type I label } \\
\text { approach will require more } \\
\text { comprehensive life cycle data for the } \\
\text { region. } \\
\text { - Regional impacts may vary and therefore } \\
\text { the criteria for recognition should be } \\
\text { considered on a national level. } \\
\text { - Most suitable for, "Adapt," or, "Establish," } \\
\text { strategies. }\end{array}$ \\
\hline $\begin{array}{l}\text { Electronic } \\
\text { appliances }\end{array}$ & $\begin{array}{l}\text { Energy efficiency ecolabels for } \\
\text { electronic appliances have a very } \\
\text { good penetration in terms of private } \\
\text { consumption and SPP for residential } \\
\text { and commercial equipment. }\end{array}$ & $\begin{array}{l}(+) \text { Less effort needed for raising } \\
\text { awareness and educating about the } \\
\text { ecolabel. } \\
(+) \text { By addressing a life cycle hotspot, it } \\
\text { gives a life cycle perspective to the }\end{array}$ & $\begin{array}{l}\text { (-) Levels of awareness not being } \\
\text { enough. } \\
\text { (-) Incorporating new criteria such as } \\
\text { toxic materials or chemicals. } \\
(-) \text { Agreement and validation of }\end{array}$ & $\begin{array}{l}\text { - Electronic appliances sector could } \\
\text { possibly be a standalone sector. } \\
\text { - Should meet criteria and requirements by } \\
\text { clients such as retailers, and SPP policies. } \\
\text { - Most suitable for, "Adapt," strategies. }\end{array}$ \\
\hline
\end{tabular}




\begin{tabular}{|c|c|c|c|c|}
\hline & $\begin{array}{l}\text { - It addresses an environmental } \\
\text { hotspot (energy consumption at the } \\
\text { use phase). } \\
\text { - Technical aspects for a regional } \\
\text { methodology shouldn't be too } \\
\text { complex. }\end{array}$ & $\begin{array}{l}\text { ecolabel. } \\
(+) \text { Less effort and resources needed to } \\
\text { develop a regionally agreed } \\
\text { methodology. }\end{array}$ & $\begin{array}{l}\text { benchmarks. } \\
(-) \text { Not having strong influence from } \\
\text { manufacturing countries. }\end{array}$ & \\
\hline Tourism & $\begin{array}{l}\text { - Region as a world tourism destiny } \\
\text { facilitates regional cooperation. }\end{array}$ & $\begin{array}{l}(+) \text { Incentive for integration in a SC } \\
\text { region tourism destination. } \\
(+) \text { Promotion and added value of } \\
\text { tourism through sustainability and eco- } \\
\text { tourism. }\end{array}$ & $\begin{array}{l}(-) \text { The sector is still not in a mature } \\
\text { stage for standardised certification. } \\
(-) \text { There are many aspects to be } \\
\text { measured as tourism is considered a } \\
\text { service that also includes products. }\end{array}$ & $\begin{array}{l}\text { - Development of a standardised } \\
\text { assessment structure that specifies what } \\
\text { will be included for the certification or } \\
\text { labelling of this sector. } \\
\text { - Most suitable for, "Establish," strategy. }\end{array}$ \\
\hline $\begin{array}{l}\text { Food, beverage \& } \\
\text { agriculture }\end{array}$ & $\begin{array}{l}\text { - General interest. } \\
\text { - Even though there are no initiatives in } \\
\text { place, there are strong international } \\
\text { initiatives from government and } \\
\text { private. } \\
\text { - Production across the region. }\end{array}$ & $\begin{array}{l}\text { (+) Address increasing global concern on } \\
\text { impacts from food's life-cycles. } \\
(+) \text { Important environmental and social } \\
\text { issues in the region are within this } \\
\text { sector. }\end{array}$ & $\begin{array}{l}\text { (-) Multiplicity of sustainability issues } \\
\text { may cause disagreements and } \\
\text { consumer confusion (e.g. organic is } \\
\text { not necessarily better from a life- } \\
\text { cycle perspective). } \\
\text { (-) Complexity of supply chains and } \\
\text { production practices. } \\
\text { (-) Risk of excluding SMEs }\end{array}$ & $\begin{array}{l}\text { Most suitable for the 'Adapt' strategy, } \\
\text { recognising existing labels and } \\
\text { incorporating life-cycle approach, } \\
\text { compatible with demands from relevant } \\
\text { markets. }\end{array}$ \\
\hline Cleaning Products & $\begin{array}{l}\text { - Progress in international schemes. } \\
\text { - Retailers driving consumer } \\
\text { information. }\end{array}$ & $\begin{array}{l}(+) \text { A common sector for industries, } \\
\text { public institutions and homes, making it a } \\
\text { key sector, as it integrates all these areas. } \\
(+) \text { Through an environmental focus } \\
\text { health aspects are dealt with as the } \\
\text { products are in direct contact with the } \\
\text { consumer, therefore more consumer } \\
\text { concern. }\end{array}$ & $\begin{array}{l}\text { (-) Coordinating different products or } \\
\text { existing labels under the same criteria. } \\
(-) \text { Incorporating a SC ecolabelling } \\
\text { programme as valid a criterion that is } \\
\text { recognised by international } \\
\text { corporations in this sector. }\end{array}$ & $\begin{array}{l}\text { - There are different existing labels in the } \\
\text { sector. } \\
\text { - Criteria in this section must aim to } \\
\text { international standards as there are } \\
\text { many international corporations } \\
\text { integrating this sector. } \\
\text { - Most suitable for, "Adapt," strategy. }\end{array}$ \\
\hline \multicolumn{5}{|c|}{ L O N G TER M } \\
\hline $\begin{array}{l}\text { Steel Building } \\
\text { products }\end{array}$ & $\begin{array}{l}\text { - Building rating tools such as LEED may } \\
\text { be good drivers for ecolabelling } \\
\text { criteria for building products. } \\
\text { - There are several international } \\
\text { initiatives that could serve as a good } \\
\text { basis for a SC project. } \\
\text { - ABNT is the only SC region } \\
\text { programme that is developing the } \\
\text { sector for steel products at the } \\
\text { moment. As an ecolabel category in } \\
\text { steel products for civil construction. }\end{array}$ & $\begin{array}{l}(+) \text { Globally, building rating tools are } \\
\text { good drivers for the incorporation of } \\
\text { sustainability criteria to procurement } \\
\text { practices. } \\
(+) \text { Adapting or replicating existing } \\
\text { models reduces the efforts of } \\
\text { implementation. } \\
(+) \text { Incorporating (and evaluating) } \\
\text { existing initiatives to become part of a } \\
\text { broader scope reduces the efforts of } \\
\text { implementation. }\end{array}$ & $\begin{array}{l}\text { (-) Formally incorporating a SC } \\
\text { ecolabelling programme as valid } \\
\text { criteria for assessing building } \\
\text { products into an existing building } \\
\text { rating tool. } \\
\text { (-) Developing a level playing field } \\
\text { methodology across sub-sectors and } \\
\text { countries that allow fair } \\
\text { comparisons between products. }\end{array}$ & $\begin{array}{l}\text { Developing from a new Type I label } \\
\text { approach will require more } \\
\text { comprehensive life cycle data for the } \\
\text { region. } \\
\text { - Regional impacts may vary and therefore } \\
\text { the criteria for recognition should be } \\
\text { considered on a national level. } \\
\text { - Most suitable for, "Establish," strategy. }\end{array}$ \\
\hline Leather & $\begin{array}{l}\text { - Progress in international schemes for } \\
\text { leather apparel. } \\
\text { - Retailers driving consumer }\end{array}$ & $\begin{array}{l}\text { (+) A common sector that exists in all SC } \\
\text { countries. } \\
(+) \text { Can connect to a range of consumer }\end{array}$ & $\begin{array}{l}\text { (-) Currently very little ecolabelling } \\
\text { activity for leather in the SC. } \\
\text { (-) Not a strong opportunity for uptake }\end{array}$ & $\begin{array}{l}\text { - Industry exists in all five countries. } \\
\text { - Achieved agreement across all five } \\
\text { countries in regional workshop but }\end{array}$ \\
\hline
\end{tabular}




\section{References}

- Aalto, K., Heiskanen, E., Leire, C. and Thidell, A. (2008). The Nordic Swan - From past experiences to future possibilities: The third evaluation of the Nordic ecolabelling scheme. Nordic Council of Ministers, TemaNord 2008:529. Retrieved from http://www.norden.org/en/publications/publikationer/2008-529.

- (2009). A guide to environmental labels for procurement practitioners of the United Nations. Retrieved from https://www.ungm.org/SustainableProcurement/toolsUN/Env Labels Guide.pdf.

- (2013). All Ecolabels. Ecolabels Index. Retrieved from http://www.ecolabelindex.com/ecolabels/.

- (2011). Anuario estadístico de América Latina y el Caribe (Statistical Yearbook for Latin America and the Carribean). United Nations (UN). Retrieved from http://www.redhum.org/archivos/pdf/ID 10656 IC Redhum-LACAnuario estadistico de americalatina y el carive-CEPAL-20120106.pdf.

- Ariztía, T., Kleine, D., Brightwell, G., Agloni, N. and Afonso, R. (2012). Ethical consumption in Brazil and Chile, Institutional context and path of developments. Proceedings: Global Research Forum on Sustainable Consumption and Production. Retrieved from http://grfscp.files.wordpress.com/2012/05/grf-2012-rio-ariztia-etal.pdf.

- Buitelaar, R. (2010). La situación de las PYMES en América Latina. El enfoque y el aporte de CEPAL. Sistema Económico Latinoamericano y del Caribe (SELA). Retrieved from http://www.sela.org/attach/258/EDOCS/SRed/2010/07/T023600004285-0Di 9 Situacion PYMES en America Latina Enfoque aporte CEPAL.pdf.

- Cañón-de-Francia, J. and Garcés-Ayerbe, C. (2012). ISO 14001 environmental certification: a sign valued by the market? Environmental and Resource Economic, 44(2): 245-262. Retrieved from http://econpapers.repec.org/article/kapenreec/v 3a44 3ay 3a2009 3ai 3a2 3ap 3a 245-262.htm.

- Cárdenas, M., Henao, C., and Kharas, H. (2011). Latin America's Global Middle Class. Global Economy and Development at Brookings, Brookings Institution. Retrieved from http://www.brookings.edu/ /media/research/files/papers/2011/4/27\%20global\%20m iddle\%20class\%20cardenas\%20kharas/0427 global middle class cardenas kharas.

- (2012). CEPALSTAT Bases de Datos y Publicaciones Estadísticas. Comisión Econónmica para América Latina y el Caribe (CEPAL). Retrieved from http://estadisticas.cepal.org/cepalstat/WEB CEPALSTAT/Portada.asp.

- Cordoba, N. (2012). Snapshot of MERCOSUR and the EU. University of Wuppertal, European Economy and International Economic Relation. Retrieved from http://www.eiiw.eu/fileadmin/eiiw/Daten/Publikationen/Sonstiges/MERCOSUR EUTRADE.pdf.

- (2012). Consumo y Producción Sustentable (CPS) Estado de Avances en América Latina y el Caribe, Global Outlook on SCP Policies: Latin America and the Caribbean. UNEP. Retrieved from http://www.slideshare.net/robsonqsmsrs/global-outlook-on-scppolicies-lac-chapter.

- (2007). Ecolabelling as a Potential Marketing Tool for African Products. UNEP/ARSCP. Retrieved from http://www.unep.org/roa/docs/pdf/Eco-labelling-Brochure.pdf. 
- (2010). Effective Approaches to Environmental Labelling of Food Products. Department for Environment, Food and Rural Affairs (DEFRA). Retrieved from http://randd.defra.gov.uk/Default.aspx?Menu=Menu\&Module=More\&Location=None \&Completed $=0 \&$ Project $\mid \mathrm{D}=17104$.

- (2011). Eficiencia en el uso de los recursos en América Latina: Perspectivas e implicancias económicas. Estudios de caso: Mercosur, Chile y México. UNEP \& Red Mercosur. Retrieved from http://www.pnuma.org/reeo/Documentos/REEO\%20WEB\%20FINAL.pdf.

- (2006). Environmental management - Life Cycle Assessment - Principles and framework. International Standards Organisation, ISO 14040:2006. Retrieved from http://www.iso.org/iso/catalogue detail.htm?csnumber=37456.

- (2006). Environmental management - Life Cycle Assessment - Requirements and Guidelines. International Standards Organisation, ISO 14044:2006. Retrieved from http://www.iso.org/iso/catalogue detail?csnumber=38498.

- (2012). Estudio Publicidad Medioambiental. SERNAC. Retrieved from http://www.sernac.cl/estudio-sobre-publicidad-medioambiental-en-chile/.

- (2011). Estudio Sustentaqué: El Impacto de la Sustentabilidad en el Consumo. Universidad del Desarrollo (UDD). Retrieved from http://www.udd.cl/noticias/2011/10/05/estudio-sustentaque-el-impacto-de-lasustentabilidad-en-el-consumo-2/.

- Feinstein, N. (2013). Learning from Past Mistakes: Future Regulation to Prevent Greenwashing. Boston College, Envtl. Aff. L. Rev. 229. Retrieved from http://lawdigitalcommons.bc.edu/ealr/vol40/iss1/6/.

- Ferraro, C. and Stumpo, G. (2010). Políticas de apoyo a las pymes en América Latina, Entre avances innovadores y desafíos institucionales. CEPAL. Retrieved from http://www.eclac.cl/cgibin/getProd.asp?xml=/publicaciones/xml/7/41837/P41837.xml\&xsl=/ddpe/tpl/p9f.xsl.

- (2012). GlobalOutlook on SCP Policies: taking action together. UNEP. Retrieved from http://www.unep.fr/shared/publications/pdf/DTIx1387xPAGlobalOutlookonSCPPolicies.pdf.

- Gobby, J. A. (2006). Environmental effects of implementing Mercosur in Argentina: an integrated assessment. A dissertation presented to the Graduate School of the University of Florida In partial fulfilment of the requirements for the degree of Doctor of Philosophy, University Of Florida. Retrieved from http://ufdcimages.uflib.ufl.edu/UF/EO/01/57/42/00001/gobbi j.pdf.

- Golden, J. S. (2010). An Overview of Ecolabels and Sustainability Certifications in the Global Marketplace. Corporate Sustainability Initiative, Nicholas Institute for Environmental Policy Solutions, Duke University. Retrieved from http://center.sustainability.duke.edu/sites/default/files/documents/ecolabelsreport.p df.

- (2008). Green Public Procurement and the European Ecolabel: Fact sheet. European Commission (EC). Retrieved from http://ec.europa.eu/environment/gpp/pdf/toolkit/module1 factsheet ecolabels.pdf.

- (2012). Greenwashing. Congreso de la Asociación Interamericana de la Propiedad Intelectual (ASIPI). Retrieved from http://www.asipiuruguay2012.com/greenwashing/. 
- Horne, R. E. (2009). Limits to labels: The role of ecolabels in the assessment of product sustainability and routes to sustainable consumption. International Journal of Consumer Studies, 33:175-182. Retrieved from http://www.econbiz.de/en/search/detailed-view/doc/all/limits-to-labels-the-role-ofeco-labels-in-the-assessment-of-product-sustainability-and-routes-to-sustainableconsumption-horne-ralph/10003834238/?no cache=1.

- (2012). Informativosustentável: Contratações Governamentais com Critérios de Sustentabilidade. Brasilia, Ministério do Planejamento, Orçamento e Gestão, Governo Federal do Brasil (MPOG). Retrieved from http://www.comprasnet.gov.br/ajuda/resultados e dados estatisticossustentaveis.pdf.

- (2008). Integración, Comercio y Ambiente en el Mercosur. UNEP. Retrieved from http://www.ambiental.net/geomercosur/GeoMercosurCompleto.pdf.

- (2012). International trade and market access data. World Trade Organization (WTO). Retrieved from http://www.wto.org/english/res e/statis e/statis e.htm.

- Ladvocat, G. (2011). Programa ABNT de eco-etiquetado. Presentation made during the Consultation Workshop of the Regional Cooperation on Ecolabelling in SC Countries Project held in Santiago, 17-18 November 2011. Retrieved from www.estis.net\%2Fincludes\%2Ffile.asp\%3Fsite\%3Deco-label\%26file\%3D1F6CA939F8E0-438B-BB6F-D7C121BF2CC8\&ei=aJhxUamsN4Kg8QTi4AY\&usg=AFQjCNFt0O2 CZjOFZO6RC1Lyrg7WG4NA\&sig2=ZsbO4SoNJEHrJFtxBpV9Ig\&bvm=bv.45373924,d.eWU\&cad= ria.

- (2006). Life Cycle Assessment: Principles and Practice. Environmental Protection Agency (EPA), EPA/600/R-06/060. Retrieved from http://www.epa.gov/nrmrl/std/lca/pdfs/chapter1 frontmatter Ica101.pdf.

- Lubin, D. A. and Esty, D. C. (2010). The sustainability imperative. Harvard Business Review, 88(5): 42-50. Retrieved from http://hbr.org/2010/05/the-sustainabilityimperative.

- (2012). Ministério do Planejamento, Orçamento e Gestão, Governo Federal do Brasil. Contratações Públicas Sustentáveis.

- Myers, N., Mittermeler, R., Mittermeler, C., da Fonseca, G., Kent, J. (2000). Biodiversity hotspots for conservation priorities. Nature, Volume 403. Retrieved from http://seserver.ethz.ch/staff/af/Fi159/M/My042.pdf.

- Neves, T. (2010). Greenwahing no Brasil: um estudo sobreos apelos ambientais nos rótulos dos productos. Market Analysis. Retrieved from http://www.marketanalysis.com.br/biblioteca/Relatorio Greenwashing FINAL.pdf.

- 2006. OECD Stat Extracts. Organisation for Economic Co-operation and Development (OECD). http://stats.oecd.org/.

- (2011). Política de Compras Públicas Sustentables. Decreto 893/12. 2012. Aprobación de la Reglamentación del Decreto Delegado N 1023/01 y sus modificaciones. DCCP, Buenos Aires, Boletín Oficial de la República Argentina.

- Prasad, M. (2012). Communicating Product Sustainability: Focus on Emerging Economies and Developing Countries. Discussion Paper, International Workshop on Product Sustainability Information. Retrieved from 
http://www.emcentre.com/NewsAttach/590de5ed-aa6a-4785-83ad-

528eea64a66f.pdf.

- (2011). Regional Ecolabelling Cooperation in the SC Countries. Discussion paper prepared for the Consultation Workshop of the Regional Cooperation on Ecolabelling in SC Countries Project held in Santiago, 17-18 November 2011. AMPHOS 21.

- (2010). Regional training workshop on ecolabelling for Latin American countries, with focus on MERCOSUR members and associates. UNEP, Rio de Janeiro, August 19-20.

Retrieved from Fej!! Hyperlinkreferencen er ugyldig..

- (2007). Resultados del Programa de Comparación Internacional de América del Sur. Coordinadores regionales de América del Sur, CEPAL. Retrieved from http://www.eclac.org/cgibin/getProd.asp?xml=/publicaciones/xml/2/28872/P28872.xml\&xsl=/deype/tpl/p9f.xsl \&base $=/ \mathrm{dds} / \mathrm{tpl} / \mathrm{top}-$ bottom.xslt.

- Rubik, F., Scheer, D. and Iraldo, F. (2008). Ecolabelling and product development: potentials and experiences. International Journal of Product Development 6(3/4): 393 419. Retrieved from http://web1.sssup.it/pubblicazioni/ugov files/302930 Ecolabel\%202008.pdf.

- Sengstschmid, H., Sprong, N., Schmid, O., Stockebrand, N., Stolz, H. and Spiller, A. (2011). EU Ecolabel for food and feed products - feasibility study (ENV.C.1/ETU/2010/0025). Report for DG Environment, European Commission, October 201, Aylesbury, Oakdene Hollins Research \& Consulting. Retrieved from http://ec.europa.eu/environment/ecolabel/documents/Ecolabel for food final repor t.pdf.

- (2012). Sistema de Información de las Contrataciones Públicas de la República del Paraguay. Dirección Nacional de Contrataciones Públicas (DNCP). Retrieved from http://m.dncp.gov.py/.

- (2006). AcciónRSE. Pricewaterhouse Coopers. Retrieved from http://www.pwc.com/en GX/gx/sustainability/assets/sbsmarkets.pdf.

- (2008). Strategy Document of the African Ecolabelling Mechanism (AEM). UNEP. Retrieved from http://www.unep.org/roa/docs/pdf/Africa 10YFP March05.pdf.

- (2007). Structure and functions of The African Ecolabelling Mechanism. UNEP. Retrieved from http://www.unep.org/roa/docs/pdf/StructureEcoLabelling\%20Mechanism.pdf.

- (2010). The Sins of Greenwashing, Home and Family Edition. Terra Choice. Retrieved from http://sinsofgreenwashing.org/index35c6.pdf.

- (2011). The State of Corporate Social Responsibility in Latin America. Forum Empresa Network. Retrieved from http://www.empresa.org/doc/Estado-RSE2011/estado-rse2011-brochure-ingles.pdf.

- (2012). The World Bank: Data. World Bank. Retrieved from http://data.worldbank.org/. 


\section{APPENDIX A: Most Relevant Sources and Expert Interviews}

Table A.1: Internet Sources and Documents Most Relevant for the Study

\begin{tabular}{|c|c|}
\hline Source Type & Most Relevant Studies \\
\hline Internet sites & $\begin{array}{l}\text { - } \text { CEPAL, Anuario estadístico de América Latina y el Caribe, } 2011 . \\
\text { http://websie.eclac.cl/anuario_estadistico/anuario_2011/esp/content_es.asp } \\
\text { - } \quad \text { Ecolabel Index. http://www.ecolabelindex.com } \\
\text { - } \quad \text { World Bank Data. http://data.worldbank.org } \\
\text { - World Trade Organisation International Trade and Tariff Data. } \\
\text { http://www.wto.org/english/res_e/statis_e/statis_e.htm }\end{array}$ \\
\hline Documents & $\begin{array}{l}\text { - Aalto, K., Heiskanen, E., Leire, C. and Thidell, A. 2008. The Nordic Swan - From past } \\
\text { experiences to future possibilities: The third evaluation of the Nordic ecolabelling scheme. } \\
\text { TemaNord 2008:529. Copenhagen, Nordic Council of Ministers. } \\
\text { - } \quad \text { AMPHOS 21, 2011. Regional Ecolabelling Cooperation in the SC Countries. Discussion paper } \\
\text { prepared for the Consultation Workshop of the Regional Cooperation on Ecolabelling in SC } \\
\text { Countries Project held in Santiago, 17-18 November } 2011 . \\
\text { - DEFRA, 2010. Effective Approaches to Environmental Labelling of Food Products. } \\
\text { Department for Environment, Food and Rural Affairs, UK. } \\
\text { Prasad, M. 2012. Communicating Product Sustainability: Focus on Emerging Economies and } \\
\text { Developing Countries. Discussion Paper, International Workshop on Product Sustainability } \\
\text { Information. 16-17 February 2012, Bangkok, Thailand. } \\
\text { - Sengstschmid, H., Sprong, N., Schmid, O., Stockebrand, N., Stolz, H. and Spiller, A. 2011. EU } \\
\text { Ecolabel for food and feed products - feasibility study (ENV.C.1/ETU/2010/0025). Report for } \\
\text { DG Environment, European Commission, October 2011. Aylesbury, Oakdene Hollins } \\
\text { Research \& Consulting. } \\
\text { UNEP, 2007. Structure and functions of The African Ecolabelling Mechanism. } \\
\text { http://www.unep.org/roa/docs/pdf/StructureEcoLabelling\%20Mechanism.pdf } \\
\text { UNEP, 2008. Strategy Document of the African Ecolabelling Mechanism (AEM). } \\
\text { UNEP, 2010. Regional training workshop on ecolabelling for Latin American countries, with } \\
\text { focus on MERCOSUR members and associates. Rio de Janeiro, August 19-20. } \\
\text { AMPHOS 21, 2011.Regional Ecolabelling Cooperation in the SC Countries. Discussion paper } \\
\text { prepared for the Consultation Workshop of the Regional Cooperation on Ecolabelling in SC } \\
\text { Countries Project held in Santiago, 17-18 November 2011. }\end{array}$ \\
\hline
\end{tabular}

Table A.2: Interviews with international and SC experts

\begin{tabular}{|l|l|l|l|}
\hline Country & \multicolumn{1}{|c|}{ Name } & \multicolumn{1}{c|}{ Position } & Work done \\
\hline \multirow{5}{*}{ Argentina } & Alicia Moreno & $\begin{array}{l}\text { Punto Focal Alterno, Consejo de Expertos de } \\
\text { Gobierno en Producción y ConsumoSostenibles - } \\
\text { PNUMA, Dirección de ProducciónLimpia y } \\
\text { ConsumoSustentable }\end{array}$ & $\begin{array}{l}\text { Answered only part of the } \\
\text { SC interview }\end{array}$ \\
\cline { 2 - 5 } & Guillermo Zucal & $\begin{array}{l}\text { Gerencia de Seguridad y SaludOcupacional, } \\
\text { Dirección de Normalisación, IRAM, } \\
\text { InstitutoArgentino de Normalisación y Certificación }\end{array}$ & $\begin{array}{l}\text { Answered the SC } \\
\text { interview/Provided inputs } \\
\text { for recommendations }\end{array}$ \\
\cline { 2 - 5 } & María Virginia Vilariño & $\begin{array}{l}\text { CoordinadoraEnergía y } \\
\text { Clima,ConsejoEmpresarioArgentinopara el } \\
\text { DesarrolloSostenible I WBCSD Local Chapter }\end{array}$ & Answered the SC interview \\
\cline { 2 - 5 } & FlorenciaChavat & CERFOAR, Sistema de & Answered the SC interview \\
\hline
\end{tabular}




\begin{tabular}{|c|c|c|c|}
\hline & \multicolumn{3}{|c|}{$\begin{array}{l}\text { Final Report - Seizing eco-labelling and Sustainable Public Procurement opportunities in the } \\
\text { Southern Cone Region }\end{array}$} \\
\hline & & CertificacionForestalArgentino & \\
\hline & Carla Pascale & $\begin{array}{l}\text { DirecciónNacional de } \\
\text { RelacionesAgroalimentariasInternacionales } \\
\text { Secretaría de Agricultura, Ganadería y } \\
\text { PescaMinisterio de Agricultura, Ganadería y Pesca }\end{array}$ & Answered the SC interview \\
\hline \multirow{2}{*}{ Uruguay } & Beatriz Olivet & $\begin{array}{l}\text { Dirección Nacional de Medio Ambiente, } \\
\text { Universidad de Montevideo }\end{array}$ & Answered the SC interview \\
\hline & Adriana Gamboggi & InstitutoUruguayo de Normalisación - UNIT & Answered the SC interview \\
\hline \multirow{4}{*}{ Chile } & $\begin{array}{l}\text { Antonia Biggs and } \\
\text { AlwineWoischnik }\end{array}$ & División de Estudios, Ministerio del MedioAmbiente & Answered the SC interview \\
\hline & Ximena Ruz & $\begin{array}{l}\text { Consejo Nacional de Producción Limpia, Minesterio } \\
\text { del MedioAmbiente }\end{array}$ & $\begin{array}{l}\text { Group meeting following } \\
\text { production of draft report } \\
\text { executive summary }\end{array}$ \\
\hline & Pablo Prussing & Dirreción ChileCompra & $\begin{array}{l}\text { Group meeting following } \\
\text { production of draft report } \\
\text { executive summary }\end{array}$ \\
\hline & Paola Conca & Departamento Comercio Sustentable, PROChile & $\begin{array}{l}\text { Group meeting following } \\
\text { production of draft report } \\
\text { executive summary }\end{array}$ \\
\hline \multirow{2}{*}{ Paraguay } & Lilian Candia Ruiz & $\begin{array}{l}\text { Directora General INTN (Instituto Nacional de } \\
\text { Tecnología, Normalisación y Metrología) }\end{array}$ & Answered the SC interview \\
\hline & Julio César Bogado & Unión Industrial Paraguaya & Answered the SC interview \\
\hline \multirow{4}{*}{ Brazil } & $\begin{array}{l}\text { Luis Fernando Guedes } \\
\text { Pinto }\end{array}$ & Certificação Agrícola, IMAFLORA & Answered the SC interview \\
\hline & Carla Miranda & $\begin{array}{l}\text { Departamento de Economia e MeioAmbiente, } \\
\text { Ministerio do MeioAmbiente }\end{array}$ & Answered the SC interview \\
\hline & Guy Ladvocat & Gerente de Certificação de Sistemas, ABNT & Answered the SC interview \\
\hline & $\begin{array}{l}\text { Silvia Helena Galvãode } \\
\text { Miranda }\end{array}$ & $\begin{array}{l}\text { Professor od Applied Economics at ESALQ, } \\
\text { University of São Paulo }\end{array}$ & $\begin{array}{l}\text { Provided inputs for } \\
\text { recommendations }\end{array}$ \\
\hline \multirow{4}{*}{ International } & Christian Hagemann & GIZ, Germany & $\begin{array}{l}\text { Answered the general } \\
\text { interview }\end{array}$ \\
\hline & Lisbeth Engel Hansen & Ecolabel, Denmark & $\begin{array}{l}\text { Answered the general } \\
\text { interview }\end{array}$ \\
\hline & John Polak & Canada & $\begin{array}{l}\text { Answered the general } \\
\text { interview }\end{array}$ \\
\hline & Bjorn Erik Lonn & Ecolabel, Norway & $\begin{array}{l}\text { Answered the general } \\
\text { interview }\end{array}$ \\
\hline
\end{tabular}




\section{APPENDIX B: Feedback from UNEP Interim Report Presentation}

\section{UNEP Meeting Notes}

23 August 2012

\section{Key Points (raised during presentation):}

- Eco-index is not a reliable source for statistics on the presence of ecolabels in SC (SC) countries. ACTIONS: Need to define, "presence of ecolabels," and provide more detailed research on the ecolabel activity in each SC country.

\section{Key Points/Questions (raised after presentation):}

- Why aren't we also considering energy efficiency labelling governance models? ACTIONS: Consider the Eco Design Directive (name?) and other energy efficiency labelling governance models for the SC governance model.

- What are your next steps for implementing the model? ACTIONS: Present short, mid and long term stages of project development.

- It would be helpful to identify the existing ecolabels in the SC by ecolabel type (e.g. Type I, II, III). ACTIONS: Provide table clearly defining each ecolabel type (may already exist in report but was not included in the presentation).

- It was difficult to follow the logic of showing statistics on the countries and then jumping straight into a governance model. ACTIONS: Provide further justification on how we have developed the governance model based on the countries' statistics.

- What is the opportunity and incentives to merge these countries into a single SC ecolabel (e.g. trade, exports, etc)? ACTIONS: Justify whether merging the counties into a common SC ecolabel makes sense and what the benefits are if the SC countries carry this out (consider following up with expert contacts with these questions). Show, in detail, incentives for regional cooperation under a SC ecolabel.

- Rather than showing a single ecolabel governance model, it would be good to present several ecolabel governance models and show the pros and cons of each option. ACTIONS: Present several ecolabel governance models and show the pros and cons of each one with respect to use in the SC. Reveir discussion paper that was presented in Chile workshop to consider presented model options.

- If we are considering to use the $\mathrm{SC}$ ecolabel for exports, why not use existing foreign ecolabels instead of a new and unknown SC ecolabel (e.g. EU Flower for European countries)? ACTIONS: Justify if the research findings show that we should focus on ecolabelling export products and consider the benefits of having a SC ecolabel rather than an existing overseas ecolabel.

- How are ecolabels currently being applied in the SC, and what is the current demand for them? If there is a lack of demand then there should be more focus on sustainable procurement. ACTIONS: Provide more research on the current ecolabel activity within the SC (e.g. consumer demand, business and government procurement, etc.). Talk to consumer organisations to get insight on consumer demand for ecolabelled products. 
- The report needs to focus more on the overall objective by pulling away from the ecolabel governance model. The ecolabel governance model is only one means to meeting the overall objective. ACTIONS: Review the initial objective and proposal to focus report back onto the key objective.

- Consider the types of businesses that will be utilising the ecolabels (e.g. business to business, business to government, business to consumer, etc.) and select 2-3 pilot projects based on your research findings. ACTIONS: Determine what type of businesses will be utilising the ecolabel and identify 2-3 recommended pilot projects based on the research findings.

- Consider public procurement, what are the drivers for public use of ecolabels? ACTIONS: Follow up with UNEP's public procurement contacts and action plans and include findings into the report.

\section{ACTIONS:}

- Consider the Eco Design Directive (name?) and other energy efficiency labelling governance models for the SC governance model.

- Present short, mid and long term stages of project development.

- Provide table clearly defining each ecolabel type (may already exist in report but was not included in the presentation).

- Justify whether merging the counties into a common SC ecolabel makes sense and what the benefits are if the SC countries carry this out (consider following up with expert contacts with these questions). Show, in detail, incentives for regional cooperation under a SC ecolabel.

- Present several ecolabel governance models and show the pros and cons of each one with respect to use in the SC. Review discussion paper that was presented in Chile workshop to consider presented model options.

- Justify if the research findings show that we should focus on ecolabelling export products and consider the benefits of having a SC ecolabel rather than an existing overseas ecolabel.

- Provide more research on the current ecolabel activity within the SC (e.g. consumer demand, business and government procurement, etc.). Talk to consumer organisations to get insight on consumer demand for ecolabelled products.

- Review the initial objective and proposal to focus report back onto the key objective.

- Determine what type of businesses will be utilising the ecolabel and identify 2-3 recommended pilot projects based on the research findings.

- Follow up with UNEP's public procurement contacts and action plans and include findings into the report. 


\section{APPENDIX C: Regional Workshop Attendees}

Table C.1: List of Regional Workshop Attendees, Rio de Janeiro, Brazil, 6-9 November 2012

\begin{tabular}{|c|c|c|}
\hline Name & Country & Organisation \\
\hline Lic. Adrián Rosemberg & Argentina & $\begin{array}{l}\text { Centro Tecnológico para la Sustentabilidad } \\
\text { Universidad Tecnológica Nacional }\end{array}$ \\
\hline Diego Cejudo & Argentina & $\begin{array}{l}\text { Oficina Nacional de Contrataciones } \\
\text { Jefatura de Gabinete de Ministros }\end{array}$ \\
\hline Julia Perie & Argentina & Parlamento Del Mercosur \\
\hline $\begin{array}{l}\text { Carla Aparecida Magalhães Carsten } \\
\text { Braga de Miranda }\end{array}$ & Brazil & Ministério do Meio Ambiente \\
\hline Rivaldo Pinheiro Neto & Brazil & Ministério do Meio Ambiente \\
\hline Beatriz Martins Carneiro & Brazil & $\begin{array}{l}\text { Ministério do Desenvolvimento, Indústria e Comércio } \\
\text { Exterior - MDIC }\end{array}$ \\
\hline Antonio Juliani & Brazil & $\begin{array}{l}\text { Ministério do Desenvolvimento, Indústria e Comércio } \\
\text { Exterior - MDIC }\end{array}$ \\
\hline João Batista De Souza Aguiar Junior & Brazil & $\begin{array}{l}\text { Ministério do Desenvolvimento, Indústria e Comércio } \\
\text { Exterior - MDIC }\end{array}$ \\
\hline Guy Ladvocat & Brazil & ABNT \\
\hline Andreia Oliveira & Brazil & ABNT \\
\hline Renata Winhas Oliveira & Brazil & Brazilian Electronic Industry Association \\
\hline Camila Flores Orth & Brazil & APEX Brazil \\
\hline Rosaura Maria Nascimento de Morais & Brazil & INMETRO \\
\hline Leonardo Salema & Brazil & INMETRO \\
\hline Alwine Woischnik & Chile & Ministry of Environment \\
\hline Antonia Biggs Fuenzalida & Chile & Ministry of Environment \\
\hline Ximena Ruz & Chile & $\begin{array}{l}\text { Consejo Nacional de Producción Limpia } \\
\text { Ministry of Environment }\end{array}$ \\
\hline Pablo Prussing & Chile & Dirección ChileCompra \\
\hline Paola Conca & Chile & Departamento Comercio Sustentable, PROChile \\
\hline Luis Flores Mimica & Chile & Consumers International Regional Office for LAC \\
\hline Ben Kneppers & Chile & Fundación Chile \\
\hline Alejandro Florenzano Alvo & Chile & Fundación Chile \\
\hline Julio Cesar Bogado & Paraguay & Union Industrial Paraguaya \\
\hline Sonia Severino & Paraguay & Ministerio de Industria y Comercio \\
\hline Diana Carolina Centurion & Paraguay & Ministerio de Industria y Comercio \\
\hline Lilian Candia Ruiz & Paraguay & $\begin{array}{l}\text { Instituto Nacional de Tecnologia, Normalizacion y } \\
\text { Metrologia }\end{array}$ \\
\hline Roberto de Aceredo & Uruguay & Uruguayan Institute of Technical Standards \\
\hline Federico Souteras & Uruguay & Dirección de Medio Ambiente \\
\hline Lisbeth Engel Hansen & Denmark & Danish Standards \\
\hline Bjorn-Erik Lonn & Norway & Nordic Swan \\
\hline Gert Sonderskov Hansen & Denmark & Ministry of the Environment \\
\hline Mia Rahunen & Denmark & Nordic Council of Ministers \\
\hline Oliver Wolf & Spain & Joint Research Centre, European Commission \\
\hline Liazzat Rabbiosi & UNEP & UNEP DTIE \\
\hline Marina Bortoletti & UNEP & UNEP Brazil Office \\
\hline
\end{tabular}




\section{APPENDIX D: SC Context Overview}

Table D.1: GDP of SC Countries (World Bank, 2012)

\begin{tabular}{|c|c|c|c|c|c|c|c|c|c|}
\hline & & Argentina & Brazil & Chile & Paraguay & Uruguay & SC & LAC & World \\
\hline \multirow{4}{*}{ GDP } & $\begin{array}{l}2010 \text { US\$ } \\
\text { Billions }\end{array}$ & 369 & 2,143 & 216 & 18 & 39 & 2,786 & 5,180 & 63,135 \\
\hline & SC share & $13.2 \%$ & $76.9 \%$ & $7.8 \%$ & $0.7 \%$ & $1.4 \%$ & $100.0 \%$ & & \\
\hline & LAC share & $7.1 \%$ & $41.4 \%$ & $4.2 \%$ & $0.4 \%$ & $0.8 \%$ & $53.8 \%$ & $100.0 \%$ & \\
\hline & World share & $0.6 \%$ & $3.4 \%$ & $0.3 \%$ & $0.0 \%$ & $0.1 \%$ & $4.4 \%$ & $8.2 \%$ & $100.0 \%$ \\
\hline
\end{tabular}

Table D.2: Population and Surface Area of SC Countries (World Bank, 2012)

\begin{tabular}{|c|c|c|c|c|c|c|c|c|c|}
\hline & & Argentina & Brazil & Chile & Paraguay & Uruguay & SC & LAC & World \\
\hline \multirow{4}{*}{ Population } & $\$ M$ & 40.7 & 195.5 & 17.1 & 6.5 & 3.4 & 263.2 & 588.8 & $6,894.4$ \\
\hline & SC $\%$ & $15.5 \%$ & $74.3 \%$ & $6.5 \%$ & $2.5 \%$ & $1.3 \%$ & $100.0 \%$ & & \\
\hline & LAC $\%$ & $6.9 \%$ & $33.2 \%$ & $2.9 \%$ & $1.1 \%$ & $0.6 \%$ & $44.7 \%$ & $100.0 \%$ & \\
\hline & World \% & $0.6 \%$ & $2.8 \%$ & $0.2 \%$ & $0.1 \%$ & $0.0 \%$ & $3.8 \%$ & $8.5 \%$ & $100.0 \%$ \\
\hline \multirow{4}{*}{ Area } & Sq. $\mathbf{k m}$ & $2,736,690$ & $8,459,420$ & 743,530 & 397,300 & 175,020 & $12,511,960$ & $20,142,390$ & $129,710,339$ \\
\hline & SC \% & $21.9 \%$ & $67.6 \%$ & $5.9 \%$ & $3.2 \%$ & $1.4 \%$ & $100.0 \%$ & & \\
\hline & LAC $\%$ & $13.6 \%$ & $42.0 \%$ & $3.7 \%$ & $2.0 \%$ & $0.9 \%$ & $62.1 \%$ & $100.0 \%$ & \\
\hline & World \% & $2.1 \%$ & $6.5 \%$ & $0.6 \%$ & $0.3 \%$ & $0.1 \%$ & $9.6 \%$ & $15.5 \%$ & $100.0 \%$ \\
\hline
\end{tabular}

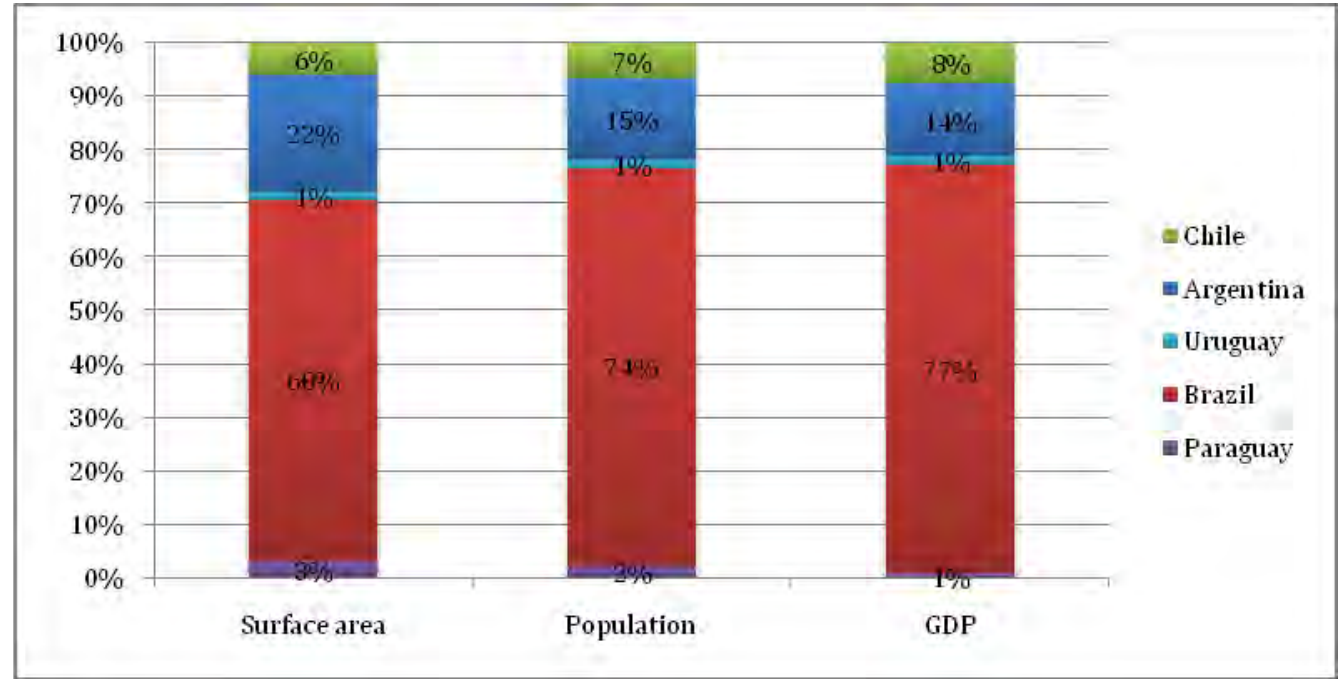

Figure D.1: Comparison of Surface Area, Population and GDP across SC countries (based on World Bank, 2012) 


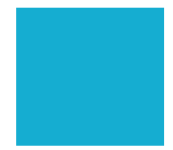

Final Report - Seizing eco-labelling and Sustainable Public Procurement opportunities in the Southern Cone Region

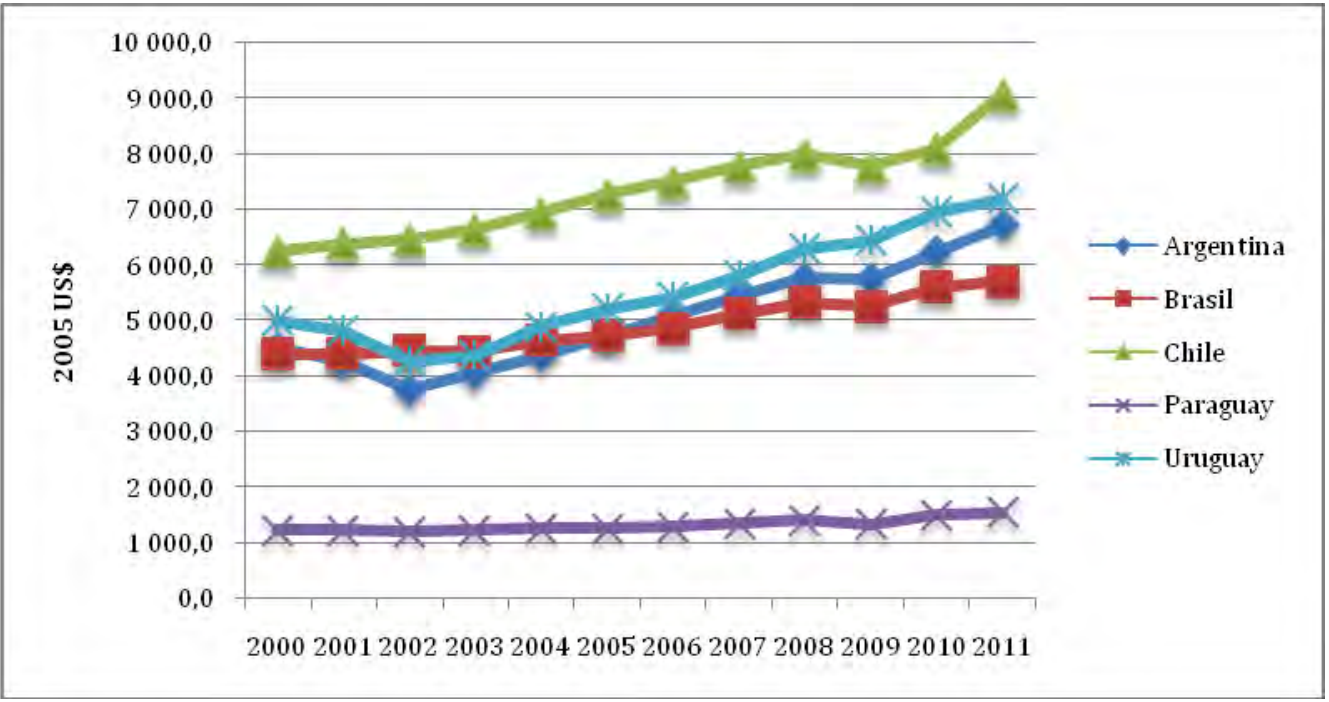

Figure D.2: GDP per capita in SC countries 2000-2011 (based on CEPAL, 2012) 


\section{APPENDIX E: SC Economics Context}

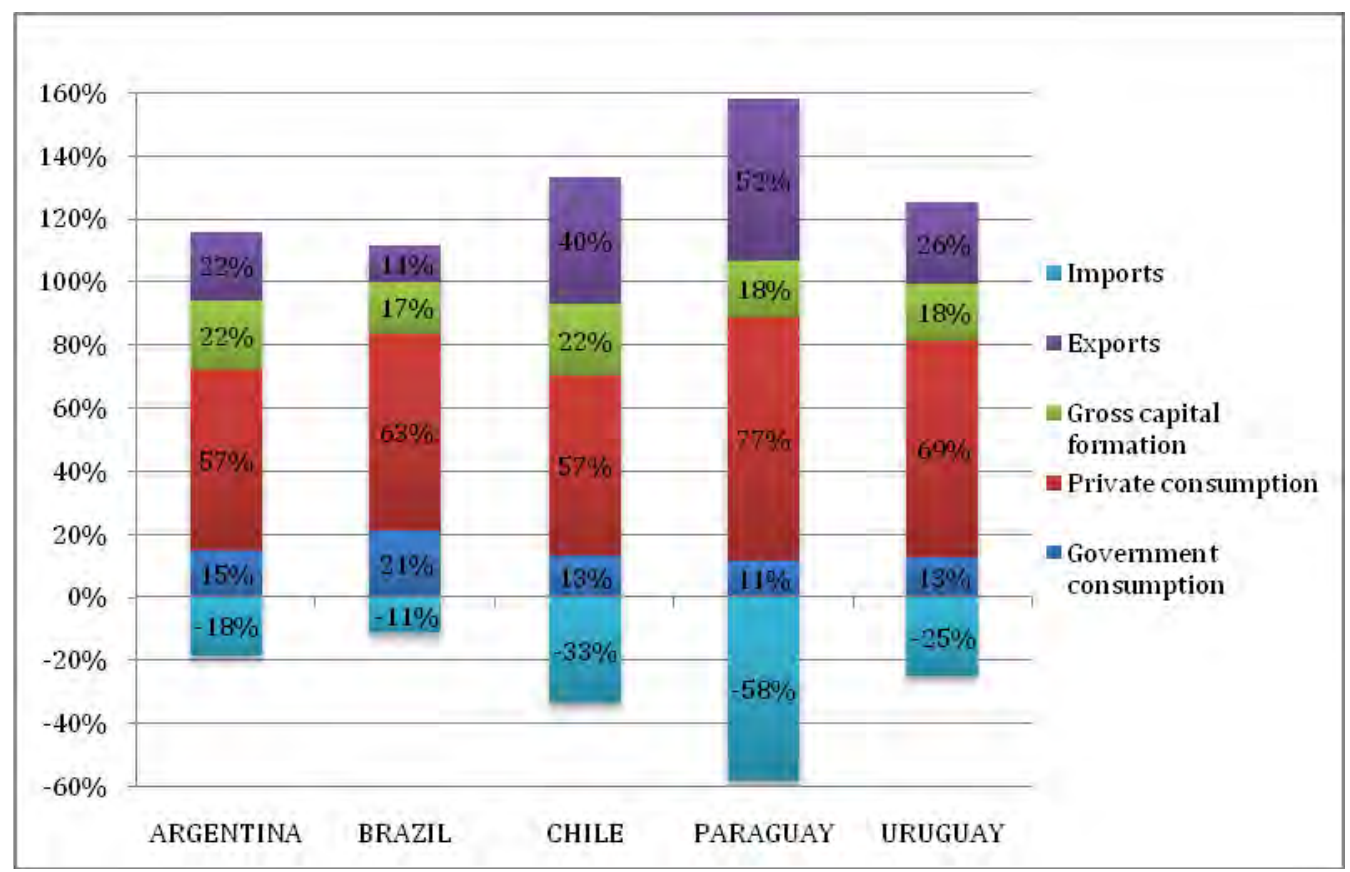

Figure E.1: GDP composition in SC countries $2010^{50}$ (based on UN, 2011)

Table E.1: Private Consumption Composition in SC Countries 2005 (CEPAL, 2007)

\begin{tabular}{|c|c|c|c|c|c|}
\hline & Argentina & Brazil & Chile & Paraguay & Uruguay \\
\hline Food and non-alcoholic beverages & $22.8 \%$ & $19.1 \%$ & $17.5 \%$ & $32.8 \%$ & $21.6 \%$ \\
\hline Housing, water, electricity and fuels & $16.7 \%$ & $15.8 \%$ & $18.6 \%$ & $18.5 \%$ & $19.2 \%$ \\
\hline Transport & $10.7 \%$ & $12.6 \%$ & $15.4 \%$ & $10.0 \%$ & $12.5 \%$ \\
\hline Health & $10.1 \%$ & $7.7 \%$ & $6.8 \%$ & $4.9 \%$ & $9.6 \%$ \\
\hline Home furniture, equipment and conservation & $4.8 \%$ & $6.6 \%$ & $7.4 \%$ & $5.3 \%$ & $6.9 \%$ \\
\hline Clothes and shoes & $4.8 \%$ & $4.4 \%$ & $8.1 \%$ & $6.8 \%$ & $5.6 \%$ \\
\hline Recreation and culture & $6.2 \%$ & $4.9 \%$ & $5.3 \%$ & $5.3 \%$ & $5.3 \%$ \\
\hline Restaurants and hotels & $5.0 \%$ & $4.8 \%$ & $2.8 \%$ & $3.5 \%$ & $3.8 \%$ \\
\hline Communications & $5.1 \%$ & $4.4 \%$ & $2.1 \%$ & $2.8 \%$ & $3.4 \%$ \\
\hline Education & $2.5 \%$ & $2.7 \%$ & $4.9 \%$ & $2.8 \%$ & $2.1 \%$ \\
\hline Alcoholic beverages and tobacco & $3.6 \%$ & $2.9 \%$ & $2.5 \%$ & $2.0 \%$ & $3.1 \%$ \\
\hline Diverse goods and services & $7.9 \%$ & $14.0 \%$ & $8.8 \%$ & $5.3 \%$ & $6.9 \%$ \\
\hline Total & $100.0 \%$ & $100.0 \%$ & $100.0 \%$ & $100.0 \%$ & $100.0 \%$ \\
\hline
\end{tabular}

\footnotetext{
${ }^{50}$ Note that imports are a negative contribution to GDP because the money goes abroad.
} 


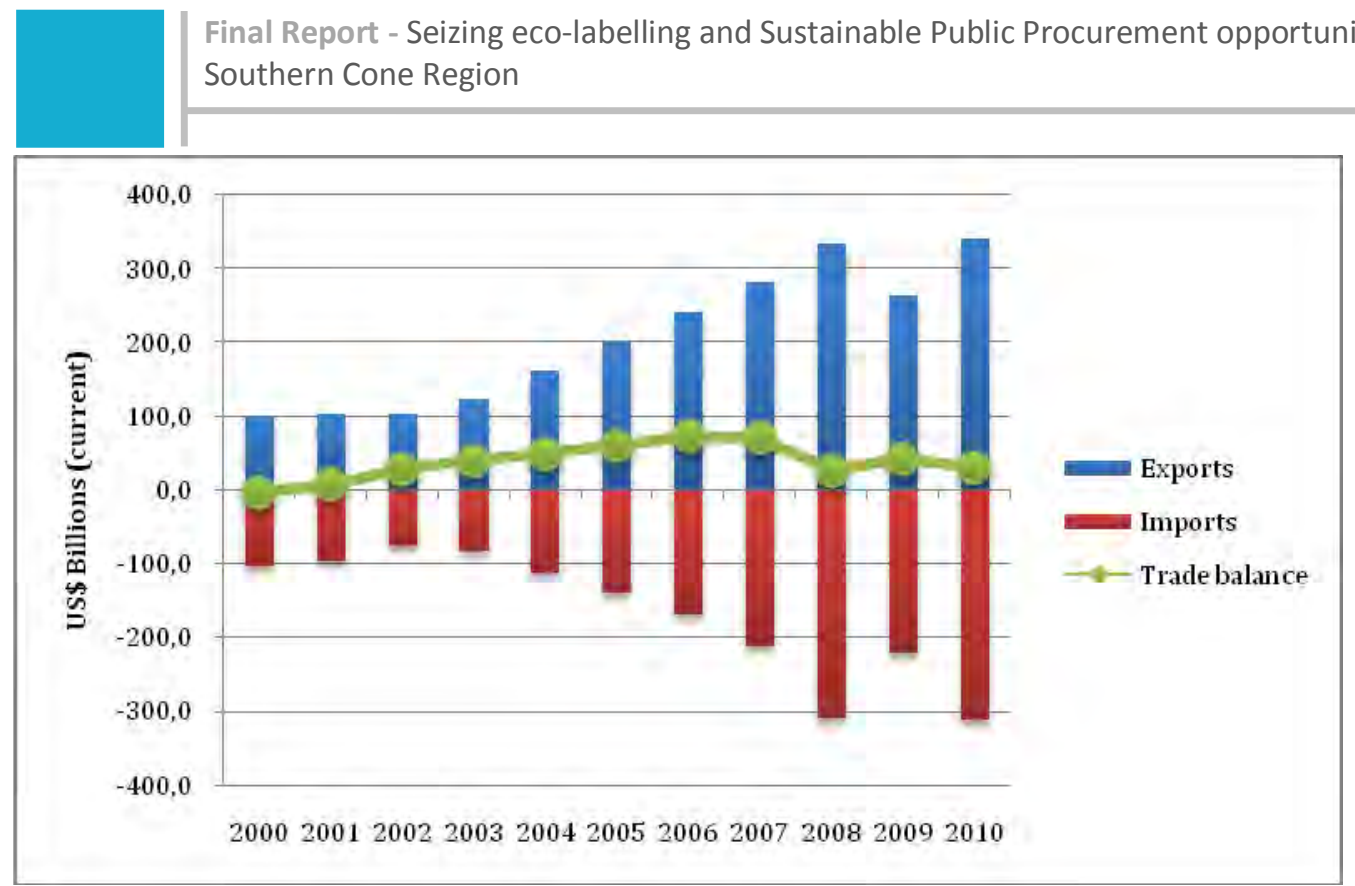

Figure E.2: Total imports, exports and trade balance (based on WTO, 2012)

Table E.2: Trade of SC countries 2010 (WTO, 2012)

\begin{tabular}{|c|c|c|c|c|c|c|c|c|}
\hline & & Argentina & Brazil & Chile & Paraguay & Uruguay & SC & World \\
\hline \multirow{3}{*}{ Exports } & 2010 US\$ Billions & 64.9 & 195.2 & 69.6 & 5.5 & 6.6 & 341.8 & $14,365.0$ \\
\hline & SC share & $19.0 \%$ & $57.1 \%$ & $20.4 \%$ & $1.6 \%$ & $1.9 \%$ & $100.0 \%$ & \\
\hline & World share & $0.5 \%$ & $1.4 \%$ & $0.5 \%$ & $0.0 \%$ & $0.0 \%$ & $2.4 \%$ & $100.0 \%$ \\
\hline \multirow{3}{*}{ Imports } & 2010 US\$ Billions & 56.1 & 180.3 & 56.2 & 12.3 & 8.6 & 313.5 & $14,875.0$ \\
\hline & SC share & $17.9 \%$ & $57.5 \%$ & $17.9 \%$ & $3.9 \%$ & $2.7 \%$ & $100.0 \%$ & \\
\hline & World share & $0.4 \%$ & $1.2 \%$ & $0.4 \%$ & $0.1 \%$ & $0.1 \%$ & $2.1 \%$ & $100.0 \%$ \\
\hline
\end{tabular}

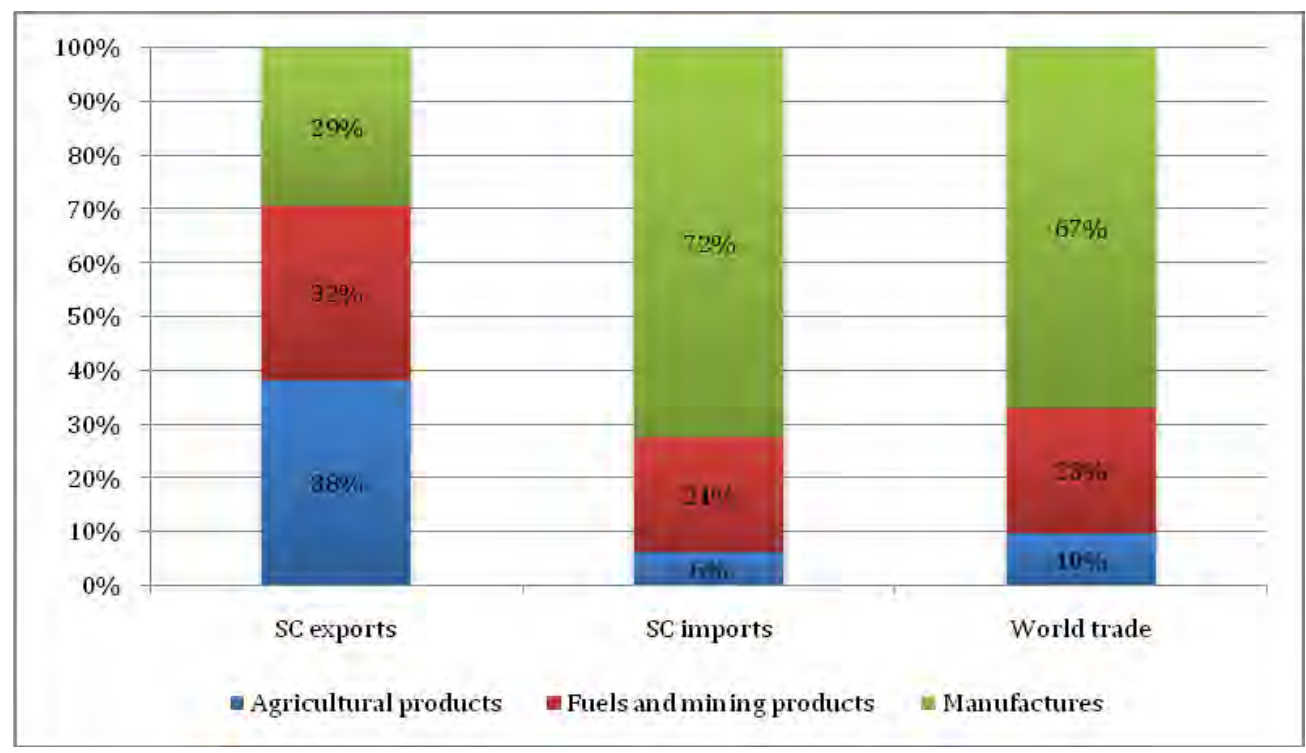

Figure E.3: SC and World trade composition 2010 (based on WTO, 2012) 


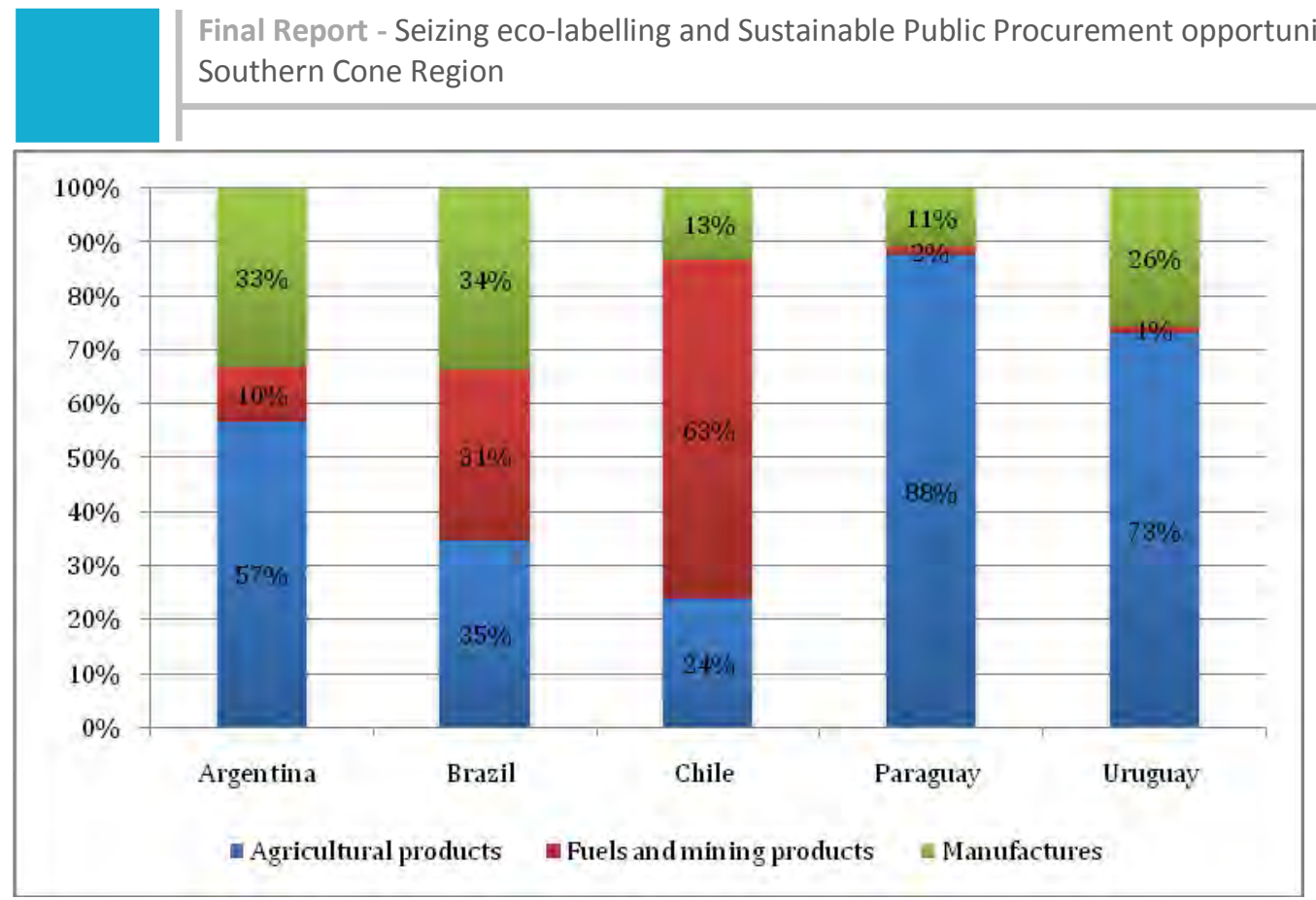

Figure E.4: SC countries exports composition 2010 (based on WTO, 2012)

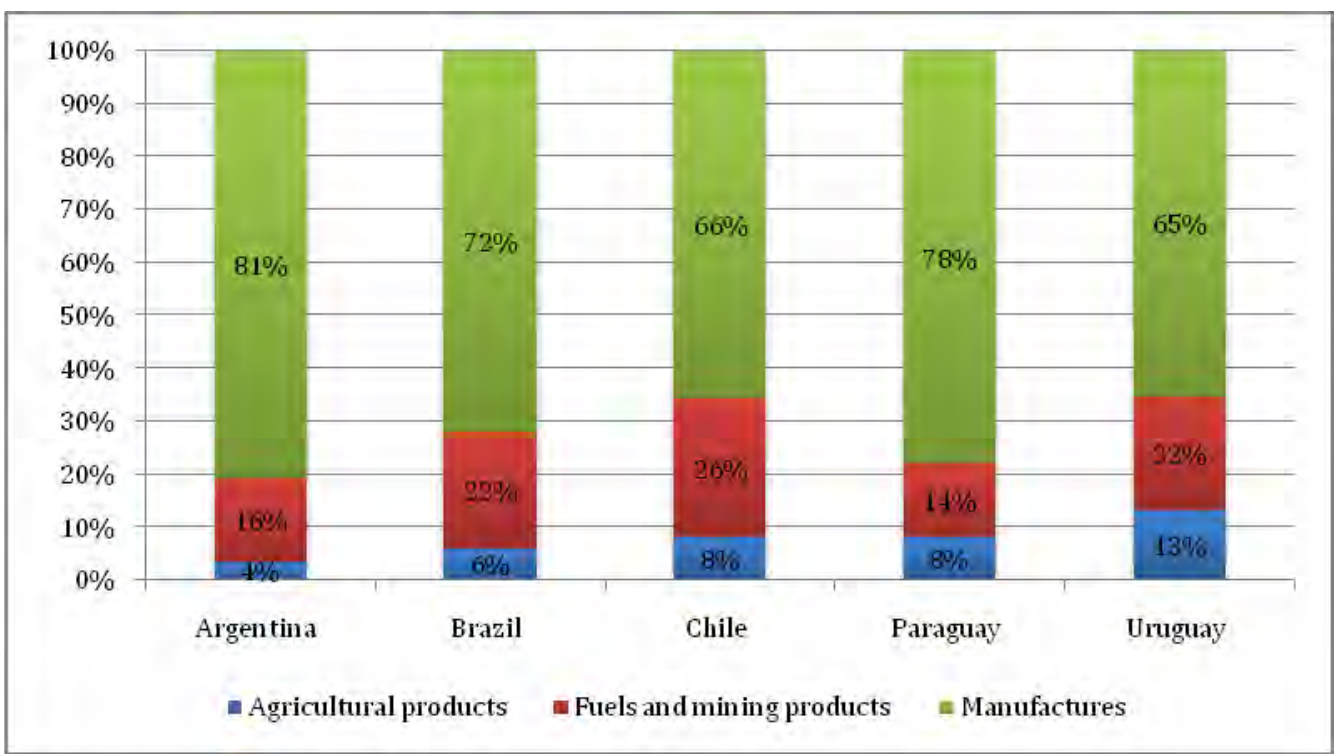

Figure E.5: SC countries imports composition 2010 (based on WTO, 2012)

Table E.6: Participation of SMEs en the total forma economy, percentages (based on Ferraro and Stumpo, 2010)

\begin{tabular}{|l|c|c|c|c|}
\hline Country & Number of firms & Employment & Sales & Exports \\
\hline Argentina & 26.8 & 43.6 & 41.0 & 8.4 \\
\hline Brazil & 15.4 & 42.6 & 25.9 & 12.5 \\
\hline Chile & 17.2 & 21.2 & 18.3 & 2.2 \\
\hline Paraguay & $\mathrm{na}$ & $\mathrm{Na}$ & $\mathrm{na}$ & $\mathrm{Na}$ \\
\hline Uruguay & 21.2 & 47.0 & $\mathrm{na}$ & $\mathrm{Na}$ \\
\hline
\end{tabular}

Table E.7: Productivity of SMEs relative to those of large enterprises (based on Buitelaar, 2010) 


\begin{tabular}{|c|c|c|c|c|}
\hline \multirow[b]{2}{*}{ Country } & \multicolumn{4}{|c|}{$\begin{array}{l}\text { Final Report - Seizing e } \\
\text { Southern Cone Region }\end{array}$} \\
\hline & Micro firms & Small enterprises & Medium enterprises & Large enterprises \\
\hline Argentina & 24 & 36 & 47 & 100 \\
\hline Brazil & 10 & 27 & 40 & 100 \\
\hline Chile & 3 & 26 & 46 & 100 \\
\hline Paraguay & na & $\mathrm{Na}$ & $\mathrm{Na}$ & na \\
\hline Uruguay & na & $\mathrm{Na}$ & $\mathrm{Na}$ & na \\
\hline Germany & 67 & 70 & 83 & 100 \\
\hline Spain & 46 & 63 & 77 & 100 \\
\hline France & 71 & 75 & 80 & 100 \\
\hline Italy & 42 & 64 & 82 & 100 \\
\hline
\end{tabular}




\section{APPENDIX F: SC Demographics Context}

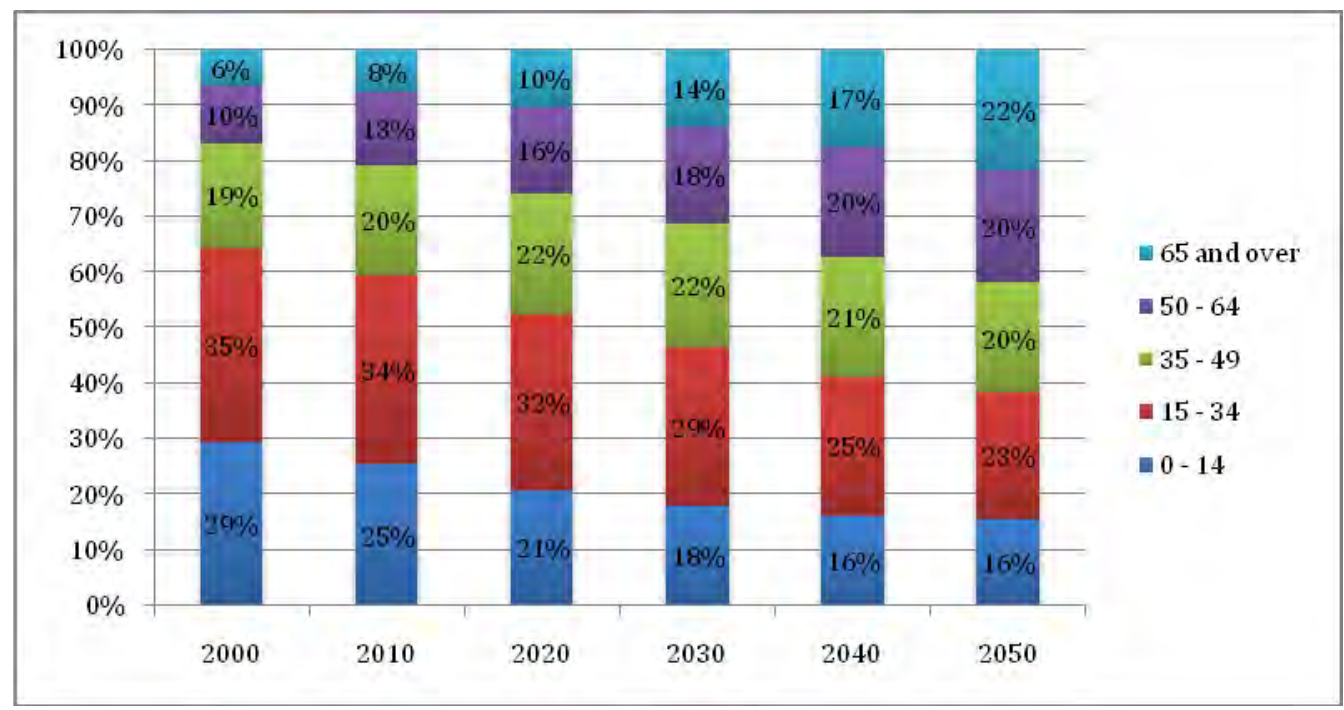

Figure F.1: SC population age distribution 2000 and 2050 (based on UN, 2011)

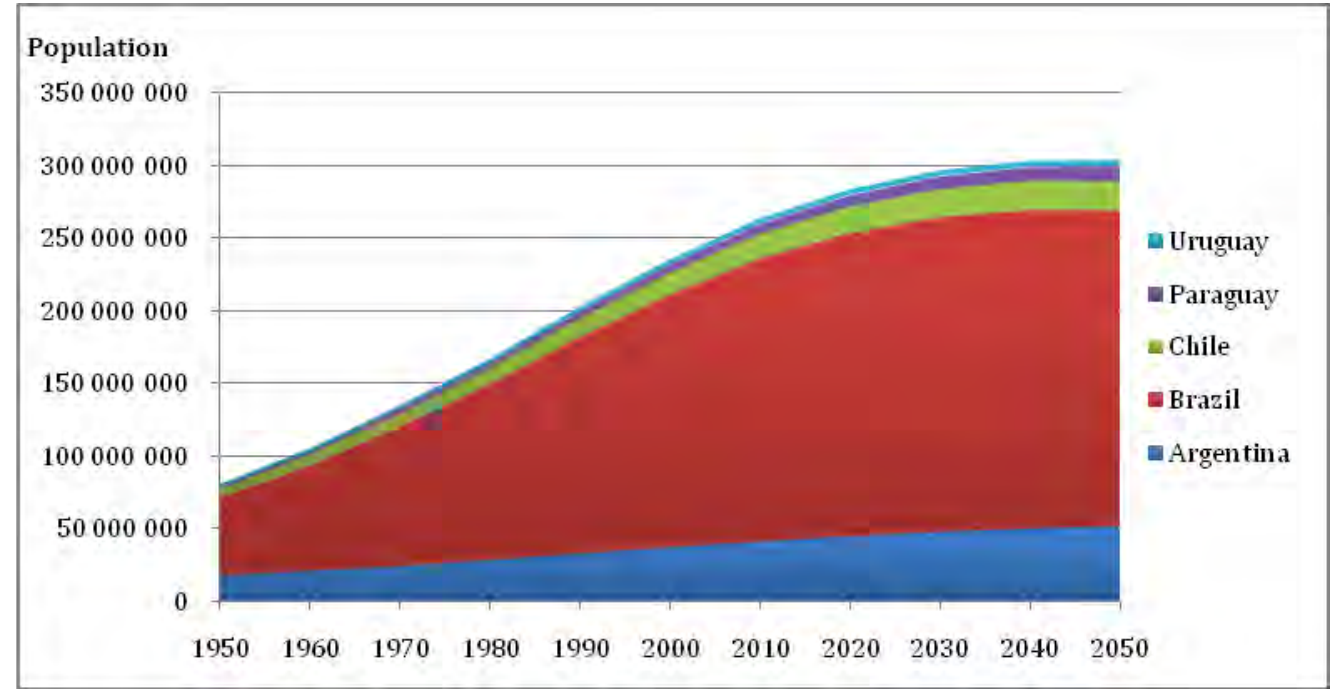

Figure F.2: SC population evolution 1950-2050 (based on UN, 2011)

Table F.1: Life expectancy of SC countries, years (based on World Bank, 2012)

\begin{tabular}{|l|c|c|c|c|c|c|c|c|c|c|c|}
\hline & 1960 & $\mathbf{1 9 6 5}$ & $\mathbf{1 9 7 0}$ & $\mathbf{1 9 7 5}$ & $\mathbf{1 9 8 0}$ & $\mathbf{1 9 8 5}$ & $\mathbf{1 9 9 0}$ & $\mathbf{1 9 9 5}$ & $\mathbf{2 0 0 0}$ & $\mathbf{2 0 0 5}$ & $\mathbf{2 0 1 0}$ \\
\hline World & 52.6 & 55.8 & 59.3 & 61.4 & 62.9 & 64.2 & 65.4 & 66.2 & 67.2 & 68.3 & 69.6 \\
\hline Argentina & 65.2 & 65.6 & 60.3 & 68.0 & 69.5 & 70.6 & 71.5 & 72.6 & 73.7 & 74.7 & 75.6 \\
\hline Brazil & 54.5 & 56.7 & 61.3 & 60.5 & 62.5 & 64.4 & 66.3 & 68.3 & 70.1 & 71.5 & 73.1 \\
\hline Chile & 57.0 & 59.3 & 62.3 & 65.5 & 69.2 & 71.9 & 73.6 & 75.0 & 76.8 & 78.3 & 78.9 \\
\hline Paraguay & 63.6 & 64.6 & 63.3 & 66.2 & 66.7 & 67.3 & 68.0 & 68.9 & 70.0 & 71.3 & 72.3 \\
\hline Uruguay & 67.8 & 68.5 & 64.3 & 69.1 & 70.2 & 71.5 & 72.5 & 73.5 & 74.9 & 75.6 & 76.2 \\
\hline SC & 57.3 & 58.9 & 65.3 & 62.4 & 64.3 & 66.1 & 67.8 & 69.5 & 71.2 & 72.5 & 73.9 \\
\hline
\end{tabular}


Table F.2: Literacy rate of SC countries, \% (based on World Bank, 2012)

\begin{tabular}{|l|r|}
\hline World (2010) & $\mathbf{8 4 . 1}$ \\
\hline Argentina (2009) & 97.7 \\
\hline Brazil (2008) & 90.0 \\
\hline Chile (2008) & 98.6 \\
\hline Paraguay (2007) & 94.6 \\
\hline Uruguay (2009) & 98.3 \\
\hline
\end{tabular}

Figure F.3: Tertiary education enrolment in SC countries, \% (based on World Bank, 2012)

\begin{tabular}{|l|c|c|c|c|c|}
\hline & 1975 & 1983 & 1999 & 2009 & $\begin{array}{c}\text { Growth 2009- } \\
1975\end{array}$ \\
\hline World & 11.0 & 13.1 & 18.3 & 28.1 & $154 \%$ \\
\hline Argentina & 26.6 & 25.0 & 47.9 & 71.2 & $168 \%$ \\
\hline Brazil & 10.1 & 10.8 & 14.5 & $25.6 *$ & $153 \%$ \\
\hline Chile & 14.6 & 13.8 & 38.1 & 59.2 & $304 \%$ \\
\hline Paraguay & 6.8 & 10.2 & 13.1 & 36.6 & $439 \%$ \\
\hline Uruguay & 15.1 & 24.1 & 33.8 & 63.3 & $319 \%$ \\
\hline
\end{tabular}

* This figure is for 2005.

Table F.4: Size of the middle class as \% of the population (based on Cárdenas et al., 2011)

\begin{tabular}{|l|c|c|}
\hline Country & $\mathbf{2 0 0 5}$ & $\begin{array}{c}\mathbf{2 0 3 0} \\
\text { (with projected growth under a BAU scenario) }\end{array}$ \\
\hline Argentina & 52.86 & 69.33 \\
\hline Brazil & 33.75 & 53.30 \\
\hline Chile & 46.22 & 69.29 \\
\hline Paraguay & 18.65 & 38.67 \\
\hline Uruguay & 55.84 & 77.13 \\
\hline
\end{tabular}

Table F.5: GDP per capita at constant 2005 US\$ prices (based on Cárdenas et al., 2011; CEPAL, 2012)

\begin{tabular}{|l|c|c|c|}
\hline Country & $\begin{array}{c}\text { Average per capita GDP growth } \\
\text { (2005-2030) }\end{array}$ & $\mathbf{2 0 1 1}$ & $\mathbf{2 0 3 0}$ \\
\hline Argentina & 2.78 & 6,716 & 13,144 \\
\hline Brazil & 2.14 & 5,715 & 10,142 \\
\hline Chile & 2.48 & 9,078 & 17,998 \\
\hline Paraguay & 2.2 & 1,543 & 2,785 \\
\hline Uruguay & 2.64 & 7,192 & 13,790 \\
\hline
\end{tabular}




\section{APPENDIX G: SC Environment Context}

\section{G.1 High Value Biodiversity Bioregions}

The SC region hosts three of the Earth's Biodiversity Hotspots defined by Conservation International (Myers, et. al., 2000). These Biodiversity Hotspots are defined by having exceptional levels of plant endemism and a serious degree of habitat loss. The World Wildlife Fund includes two additional places in the SC in its Priority Places (based on their biodiversity, their threats and opportunities for improvements). These regions are mapped in Figure G.1 and described in Table G.1, including their main threats.

An indicator of the abundant biodiversity in the region is that more than $10 \%$ of threatened amphibians, birds, mammals and reptiles and $6 \%$ of plants in the world are present in the SC. Approximately $14 \%$ of the SC's surface has some sort of protection status. Nevertheless, not all of the bioregions are represented in this protected surface, which is mainly concentrated in the tropical and Andean areas. (UNEP, 2008).

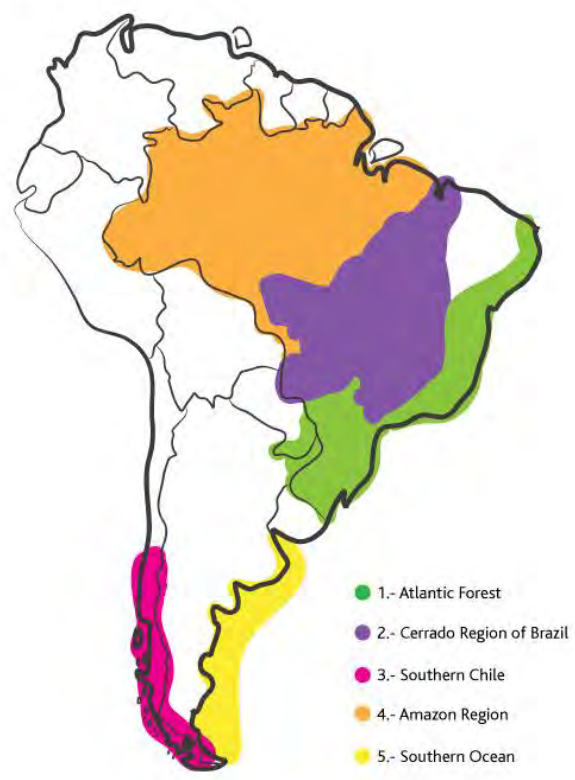

Figure G.1: Map of high value biodiversity bioregions in the Southern Cone (based on Conservation International, 2005; WWF, 2008)

Table G.1: Description of high value biodiversity bioregions in the Southern Cone (Sources: ${ }^{1}$ Conservation International, 2005; ${ }^{2}$ WWF, 2008)

\begin{tabular}{|l|l|l|}
\hline $\begin{array}{l}\text { High Value Biodiversity } \\
\text { Bioregion }\end{array}$ & Description & Main threats \\
\hline $\begin{array}{l}\text { 1. Atlantic Forest (mainly in } \\
\text { Brazil, includes areas of } \\
\text { Paraguay, Argentina and } \\
\text { Uruguay) }\end{array}$ & $\begin{array}{l}\text { Around 20,000 plant species live in this } \\
\text { tropical/subtropical forest region, 40\% of } \\
\text { which are endemic. Less than 10\% of the } \\
\text { original forest cover remains. }\end{array}$ & $\begin{array}{l}\text { Logging, expanding forestry and agriculture } \\
\text { (especially soybean?), cattle ranching, urbanization } \\
\text { and industrialisation (air and water pollution) }\end{array}$ \\
\hline $\begin{array}{l}\text { 2. Cerrado Region of } \\
\text { Brazil, }\end{array}$ & $\begin{array}{l}\text { Largest woodland-savanna in South America } \\
\text { (21\% of Brazil's area). Fire and drought } \\
\text { resistant plant species, high bird endemism } \\
\text { and presence of large mammals. }\end{array}$ & $\begin{array}{l}\text { Rapidly expanding agricultural frontier: mainly } \\
\text { soy, corn and cattle ranching }\end{array}$ \\
\hline 3. Southern Chile (including & High level of endemism caused by geographic & Introduced species, habitat fragmentation by \\
\hline
\end{tabular}




\begin{tabular}{|l|l|l|}
\hline $\begin{array}{l}\text { Winter Rainfall-Valdivian } \\
\text { Forest) }\end{array}$ & $\begin{array}{l}\text { isolation (between the Atacama Desert, the } \\
\text { Andes Mountains and the Pacific Ocean). }\end{array}$ & $\begin{array}{l}\text { forestry plantations, agriculture, urbanisation and } \\
\text { infrastructure. Aquaculture (mainly salmon) and } \\
\text { overfishing pose relevant pressures on the marine } \\
\text { environment. }\end{array}$ \\
\hline 4. Amazon Region ${ }^{2}$ & $\begin{array}{l}\text { Marine environment rich in plant and animal } \\
\text { life. }\end{array}$ & $\begin{array}{l}\text { Deforestation driven by expanding soybean } \\
\text { agriculture, cattle ranching, hydropower and other } \\
\text { infrastructure development, illegal and } \\
\text { unsustainable logging and oil exploration, climate } \\
\text { change. }\end{array}$ \\
\hline $\begin{array}{l}\text { 5. Southern Ocean (includes } \\
\text { the Argentinean coast) }\end{array}$ & $\begin{array}{l}\text { Marine environment rich in plant and animal } \\
\text { life. }\end{array}$ & $\begin{array}{l}\text { Unsustainable fishing, dumping of solid waste, } \\
\text { climate change. }\end{array}$ \\
\hline
\end{tabular}

\section{G.2 Main Environmental Pressures}

The region's economic activity is, and has historically been, centred on exports of primary goods or commodities. The extraction and production of these commodities, while generating economic growth, has generated over-exploitation of natural resources, deforestation, habitat fragmentation and pollution. What follows describes some of the main environmental stressors in the region.

- Soybean Cultivation: One of the main drivers for land use change in the SC is soybean cultivation (UNEP, 2010). Argentina, Brazil and Paraguay are amongst the world's main exporters of soybean products, and it is the main crop grown in Uruguay. Some of the impacts from soybean cultivation in the SC (UNEP \& CLAES, 2008) ${ }^{51}$ :

- Advance of the agricultural frontier towards natural areas (including the Atlantic Forest, Cerrado and Amazon bioregions)

- Habitat fragmentation and biodiversity reduction

- Soil and water pollution because of agrochemical use

- Soil erosion and compaction

Social impacts, such as the concentration of land ownership and neglect of staple food production for local consumption, are also of concern (WWF, 2003).

- Cattle Ranching: Started in the $16^{\text {th }}$ century with the arrival of European (Spanish and Portuguese) colonisation. It is widespread in Argentina, Paraguay, Uruguay, centre-east Brazil and southern Chile. Land-conversion, soil erosion due to over-grazing, high demand of resources for the cultivation of feed crops and high greenhouse gas emissions are caused by this activity.

- Forestry industry: Widespread plantation of exotic species (pine and eucalyptus) in Chile, Brazil and Uruguay. Detrimental effects include land-clearing and habitat fragmentation, plague and fire vulnerability, while beneficial effects (particularly in Chile) include erosion control of lands degraded by centuries of agriculture.

- Urbanisation and infrastructure: 
- Electricity generation and transmission: In Chile, both large hydro- and coal-power plants face major public opposition. In Brazil, Argentina and Paraguay large hydroelectric dams inundate large areas of valuable ecosystems.

- Urban growth and road construction increase habitat degradation and fragmentation; and bring about increased pressure due to the increase in human activity.

\section{- Other relevant environmental issues:}

- Land-use change for other crops (sugar cane, maize and others).

- Introduction of alien species.

- Mining: Copper and other metal mining in northern Chile cause water stress; soil, water and air pollution. Brazil: iron, bauxite, copper and rare metals. Argentina: copper and gold.

- Overfishing is an important issue in the Chilean and Argentinean coast; in southern Chile the salmon aquaculture industry is also cause for environmental concern.

- Illegal trade of native plants and animals.

- Hazardous materials and hazardous waste, and their flow between countries.

- Crop growing for biofuel production is an emerging issue.

\section{G.3 Resource Efficiency}

A report by UNEP \& Red Mercosur (2011) analyses the subject of resource efficiency in the region. The results include the following:

- Pollution potential in the SC is concentrated in the production of a few intermediate goods, particularly in the pulp and paper, wood, iron, plastic and chemical sectors.

- The environmental policies in Latin America have a certain delay in adapting to its new productive reality and international integration, characterised by the intensive use of natural resources (associated to the rise in commodities prices and demand for natural resources, mainly from Asia).

- There is a general tendency towards an increase in the use of agrochemicals per hectare of cropland in all the SC countries.

\section{G.4 Greenhouse Gas (GHG) Emissions}

Argentina and Chile have the highest per capita GHG emissions in the region, nearing the world average. Paraguay, Brazil, and Uruguay have lower GHG emissions, owing mainly to their higher use of hydroelectricity and thus lower dependency on fossil fuels for electricity generation. 


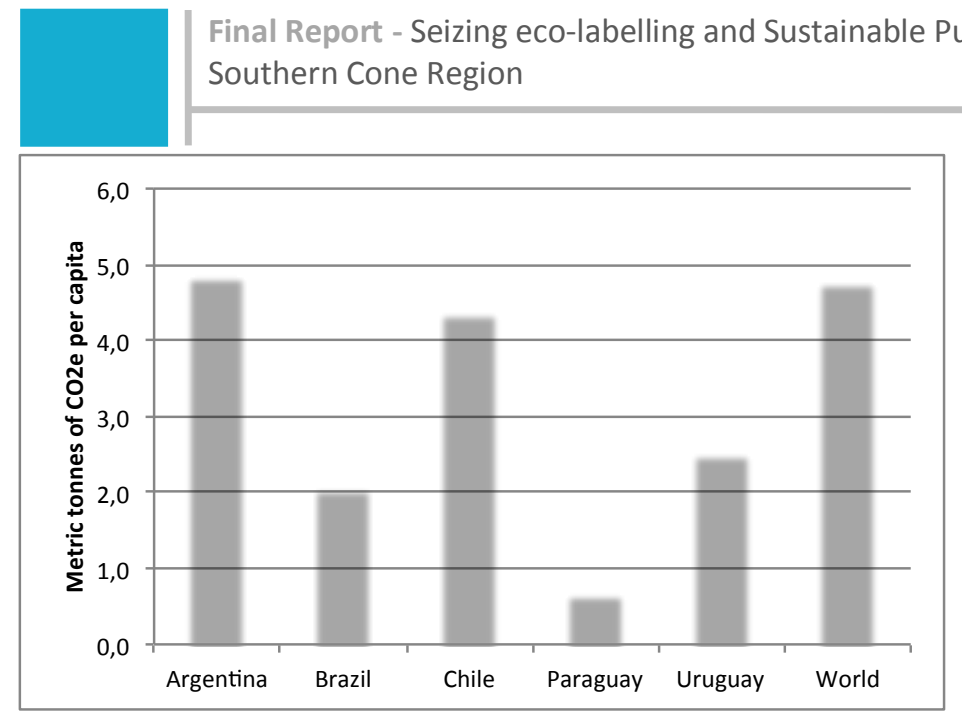

Figure G.2: Greenhouse gas emissions per capita in the Southern Cone countries, compared with world average. (World Bank, 2012)

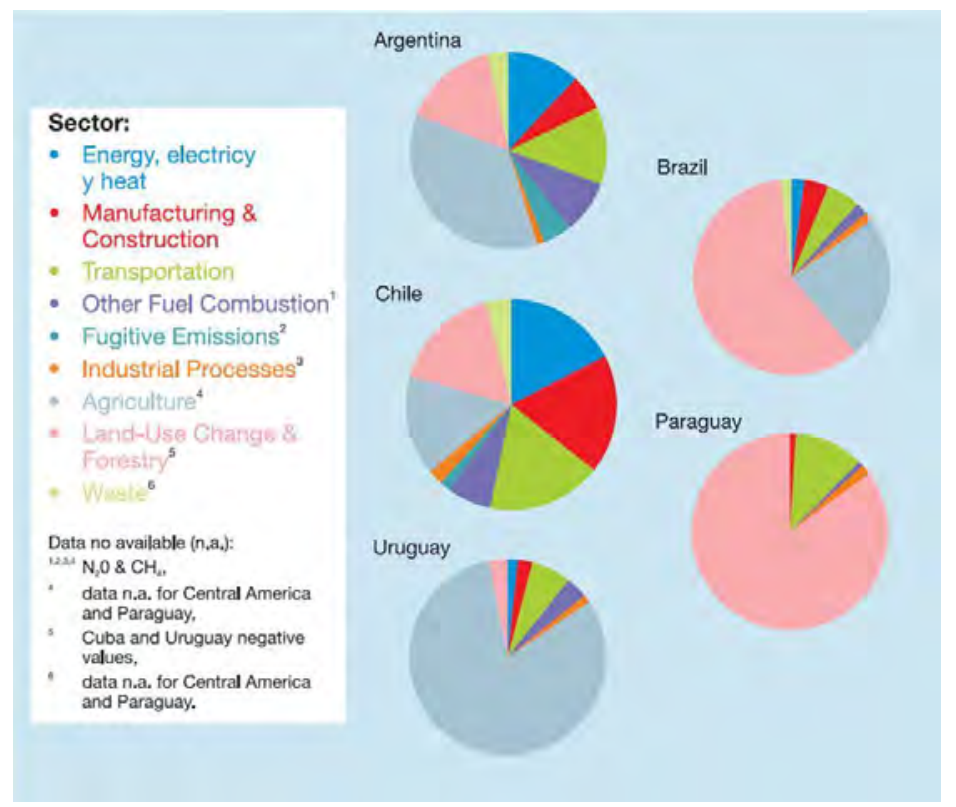

Figure G.3: \% Distribution of GHG emissions from energy generation, industrial activity, agriculture, waste and soil use change (adapted from EuropeAid, 2009)

\section{G.5 Regional Cooperation on Sustainable Consumption and Production in the SC}

As members of Mercosur, Argentina, Brazil, Paraguay and Uruguay signed a Framework Agreement on the Environment in 2001, with the objective of environmental protection and sustainable development, through the articulation of the economic, social and environmental dimensions, contributing to better environmental and lifestyle qualities of their people. The regional cooperation is coordinated by Mercosur's Working Subgroup on the Environment (SGT 6). In this context, the Mercosur Policy for Promotion and Cooperation on Sustainable Consumption and Production was approved in 2007.

According to UNEP, 2012:

The Mercosur SCP policy focuses primarily on the productive sector, and on small, micro, and medium-sized enterprises. Signatory countries commit to developing a competitiveness 
strategy driven by environmental performance criteria, aiming at the sustainable use of natural resources, encouraging the use of less polluting materials and minimising residues and toxic emissions.

The Mercosur SCP policy establishes the following guidelines:

- Harmonise production and environmental policies of the Mercosur countries

- Encourage cooperation between the public and private sectors on the implementation of SCP, such as sustainable public purchases and sustainable consumption

- Stimulate innovation for design and development of product and services with lower environmental impacts

- Strengthen formal and informal education on SCP; promote capacity development and knowledge among signatories

Brazil is currently implementing the "Brazilian Action Plan on SCP". This initiative is led by the Ministry of the Environment in partnership with local public and private organisations and UNEP ${ }^{52}$. The main focus of the strategy is set on sustainable public procurement, sustainable buildings and waste management. The objectives of the plan are to foster initiatives aligned with the concept of SCP, integrating it to efforts to confront climate change and to other priorities of Brazilian society, such as poverty alleviation, equitable distribution of benefits from development, preservation of biodiversity and natural resources.

Argentina has incorporated the Mercosur SCP policy into its national legislation, serving as the national SCP policy, while Uruguay is currently formulating its national action plan for SCP through a participatory process based on the Mercosur policy.

\footnotetext{
${ }^{52}$ Source: http://web2.unep.fr/globaloutlook/ShowPolicy.aspx?Policyld=140\&Lngld=1
} 


\section{APPENDIX H: SC Social Context}

\section{H.1 SC Human Development and Social Equality Indicators}

The Human Development Index (HDI) from the UNDP measures annually the overall development of all the nations, investigating the well-being through poverty, literacy, education, and health indicators. According to this study the five analysed countries of the SC have medium to very high level of development. ${ }^{53}$

The Gini Coefficient, visualising the grade of equality of national income distribution ${ }^{54}$ shows another perspective of social development of the SC Region. Figure H.4 represents the global results between 2007 and 2011 of the Gini Coefficient, where the SC reflects the highest levels of inequity in the world. This tendency has been observed over the last three decades. ${ }^{55}$

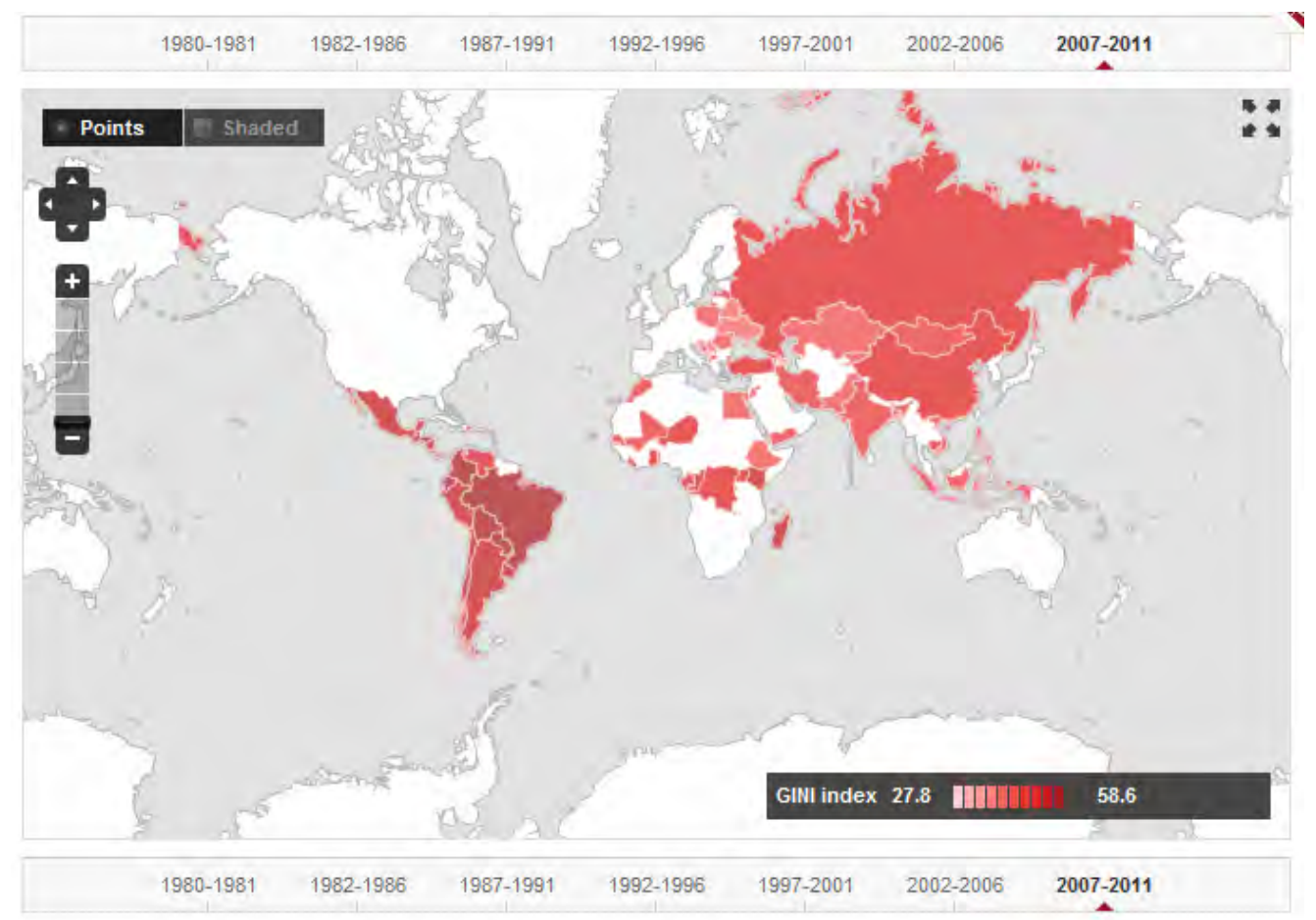

Figure H.1: World map of the Gini Coefficient (World Bank, 2011)

The presence of extreme inequality in income distribution and inequity reveal major challenges in SC countries in terms of social cohesion and development. The poverty indicates considerable heterogeneity among the analysed countries. The diversity follows a relatively common pattern: countries with a higher level of human development (Argentina, Chile and Uruguay) tend to have lower percentage of population living in poverty. ${ }^{56}$ The increasing urbanisation, cause and effect of urban poverty, is usually associated with a process of exclusion of large groups of the population, which results in violence, delinquency and insecurity in the cities.

\footnotetext{
${ }^{53}$ Very High HDI: Argentina and Chile; High HDI: Brazil and Uruguay; Medium HDI: Paraguay.

${ }^{54} \mathrm{Gini}$ coefficient of 0 expresses a perfect equality, on the other hand 100 means an absolute inequality

${ }^{55}$ The World Bank. http://data.worldbank.org/indicator/SI.POV.GINI/countries?display=map

${ }^{56}$ Poverty headcount ratio at $\$ 2$ a day (PPP) \% of the population (2009): Argentina 3.4\%, Brazil 10.8\%, Chile 2.7\%, Paraguay $14.2 \%$, Uruguay 1.6\%. Source: The World Bank; http://data.worldbank.org/indicator/SI.POV.2DAY
} 
The NGO "CorporaciónLatinobarómetro" releases an annual study analysing the public opinion of more than 400 million persons from 18 countries of Latin America. ${ }^{57}$ According to this study, the main social issue of Latin America is the delinquency and the public security (see Figure H.2).

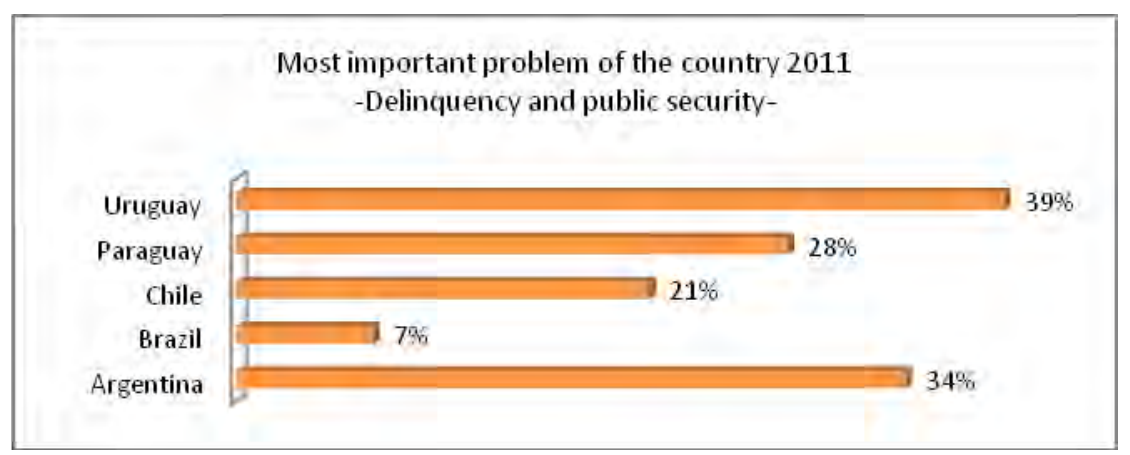

Figure H.2: Most important problem of the country (CorporaciónLatinobarómetro, 2011)

The countries of the SC do not completely reflect the same tendency; only two of them (Argentina and Uruguay) consider delinquency and public security as the main national problem. In the case of Paraguay, unemployment is the main worry of the habitants. On the other hand, there is an interesting phenomenon in Brazil; Crime and violence have increased noticeably in recent decades, having the highest homicide rate among the SC countries ${ }^{58}$, but the Brazilians consider the health system as their major problem. In Chile, the current social movements affect the perception of the public; in 2011, the major problem is seen in the education, in contrast to the earlier years, when delinquency and social security were considered as the most important preoccupations.

All the treated aspects are connected with each other. The inequity and the social gaps result in separated and disconnected social groups, where completely different perspectives and accesses of opportunities exist between them. The structural limits of poverty are rigorous and persistent, and especially many young people experience frustration and social exclusion. Therefore, the combination of extreme inequity and poverty creates a fertile basis for delinquency and violence.

${ }^{57}$ http://www.latinobarometro.org/latino/latinobarometro.jsp Informe 2011: http://www.emol.com/documentos/archivos/2011/10/28/20111028141231.pdf

${ }^{58} \mathrm{http}: / /$ www.unodc.org/documents/data-and-analysis/IHS-rates-05012009.pdf 


\section{APPENDIX I: SC Ecolabelling}

Table I.1: Existing SC Ecolabels Summary

\begin{tabular}{|c|c|c|c|c|c|c|c|}
\hline ECOLABEL & SECTOR & Type & $\begin{array}{l}\text { 1. Extraction \& } \\
\text { Treatment of Raw } \\
\text { Materials }\end{array}$ & $\begin{array}{l}\text { 2. Product } \\
\text { Manufacturing }\end{array}$ & $\begin{array}{l}\text { 3. Transport \& } \\
\text { Distribution }\end{array}$ & $\begin{array}{l}\text { 4. Product } \\
\text { Use }\end{array}$ & $\begin{array}{l}\text { 5. End of } \\
\text { Life }\end{array}$ \\
\hline $\begin{array}{l}\text { Forest Stewardship } \\
\text { Council (FSC) Chain } \\
\text { of Custody } \\
\text { Certification }\end{array}$ & $\begin{array}{l}\text { Building } \\
\text { products; Forest } \\
\text { products / Paper; } \\
\text { Packaging }\end{array}$ & IV & $\checkmark$ & $\checkmark$ & $\checkmark$ & & \\
\hline $\begin{array}{l}\text { Forest Stewardship } \\
\text { Council (FSC) } \\
\text { Forest } \\
\text { Management } \\
\text { Certification }\end{array}$ & $\begin{array}{l}\text { Forest products / } \\
\text { Paper }\end{array}$ & IV & $\checkmark$ & & & & \\
\hline $\begin{array}{l}\text { Programme for the } \\
\text { Endorsement of } \\
\text { Forest Certification } \\
\text { schemes (PEFC) }\end{array}$ & \begin{tabular}{|l} 
Building \\
products; \\
Buildings; Forest \\
products / Paper; \\
Furniture; \\
Packaging
\end{tabular} & IV & $\checkmark$ & & & & \\
\hline BASF Eco-Efficiency & Various products & IV & $\checkmark$ & $\checkmark$ & & $\checkmark$ & $\checkmark$ \\
\hline CarbonFree $^{\circledast}$ & Various products & IV & $\checkmark$ & $\checkmark$ & $\bar{\checkmark}$ & & \\
\hline CarbonNeutral $^{\circledast}$ & Various products & IV & & $\checkmark$ & $\checkmark$ & & \\
\hline $\begin{array}{l}\text { Cerflor Forest } \\
\text { Certification } \\
\text { Programme: Brazil }\end{array}$ & $\begin{array}{l}\text { Forest products / } \\
\text { Paper }\end{array}$ & IV & $\checkmark$ & & & & \\
\hline $\begin{array}{l}\text { Compostable: } \\
\text { Biodegradable } \\
\text { Products Institute } \\
\text { Label }\end{array}$ & $\begin{array}{l}\text { Forest products / } \\
\text { Paper; } \\
\text { Packaging; Other }\end{array}$ & IV & & & & & $\checkmark$ \\
\hline $\begin{array}{l}\text { Certfor Forest } \\
\text { Certification } \\
\text { Programme: Chile }\end{array}$ & $\begin{array}{l}\text { Forest products / } \\
\text { Paper }\end{array}$ & IV & $\checkmark$ & & & & \\
\hline $\begin{array}{l}\text { Sustainable } \\
\text { Forestry Initiative } \\
\text { (SFI) }\end{array}$ & $\begin{array}{l}\text { Building } \\
\text { products; Forest } \\
\text { products / Paper; } \\
\text { Packaging }\end{array}$ & IV & $\checkmark$ & $\checkmark$ & $\checkmark$ & & \\
\hline EU Ecolabel & Various products & 1 & $\checkmark$ & $\checkmark$ & $\bar{\checkmark}$ & $\sqrt{ }$ & $\checkmark$ \\
\hline ABNT Ecolabel & Various products & 1 & $\checkmark$ & $\checkmark$ & $\sqrt{\checkmark}$ & $\checkmark$ & $\checkmark$ \\
\hline $\begin{array}{l}\text { Falcão Bauer Eco } \\
\text { seal }\end{array}$ & Various products & $\begin{array}{c}\text { I and } \\
\text { III }\end{array}$ & $\checkmark$ & $\checkmark$ & & $\checkmark$ & \\
\hline GREENGUARD & Various products & IV & & & & $\checkmark$ & \\
\hline $\begin{array}{l}\text { SCS Recycled } \\
\text { Content }\end{array}$ & Various products & IV & $\checkmark$ & $\checkmark$ & & & \\
\hline SustentaX & Various products & IV & $\checkmark$ & $\checkmark$ & & & \\
\hline
\end{tabular}




\begin{tabular}{|c|c|c|c|c|c|c|c|}
\hline DIN-Gepruft & $\begin{array}{l}\text { Additives } \\
\text { (printing inks, } \\
\text { adhesives, etc.) }\end{array}$ & IV & & & & & $\checkmark$ \\
\hline Epeat & Electronics & IV & $\checkmark$ & $\checkmark$ & & $\checkmark$ & $\checkmark$ \\
\hline TCO Certified & Electronics & IV & $\checkmark$ & $\checkmark$ & $\checkmark$ & $\checkmark$ & $\checkmark$ \\
\hline TerraCycle & Various products & IV & & & & & $\checkmark$ \\
\hline $\begin{array}{l}\text { Green Globe } \\
\text { Certification }\end{array}$ & $\begin{array}{l}\text { Tourism; } \\
\text { Transport; Other }\end{array}$ & IV & $\checkmark$ & $\checkmark$ & $\checkmark$ & $\checkmark$ & $\checkmark$ \\
\hline EarthCheck & Tourism & IV & $\checkmark$ & $\checkmark$ & $\checkmark$ & $\checkmark$ & $\checkmark$ \\
\hline $\begin{array}{l}\text { Audubon } \\
\text { International }\end{array}$ & $\begin{array}{l}\text { Buildings; } \\
\text { Tourism; Waste } \\
\text { management; } \\
\text { Recycling; others }\end{array}$ & IV & & & $\checkmark$ & $\checkmark$ & $\checkmark$ \\
\hline $\begin{array}{l}\text { National Energy } \\
\text { Efficiency Label }\end{array}$ & Electronics & IV & & & & $\checkmark$ & \\
\hline
\end{tabular}

Table I.2: Details of national initiatives supporting ecolabels in the SC

\begin{tabular}{|c|c|c|}
\hline & Initiative & Details \\
\hline \multirow{9}{*}{ 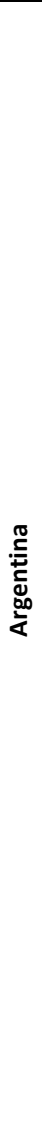 } & $\begin{array}{l}\text { National system for identification of } \\
\text { products and services for public } \\
\text { procurement (catalogue). }\end{array}$ & $\begin{array}{l}\text { Incorporation of products and services that fulfil sustainable criterion into the } \\
\text { National system for identification of products and services for public procurement } \\
\text { (catalogue). }\end{array}$ \\
\hline & Buendiseñoseal & $\begin{array}{l}\text { Buendiseño seal: Products obtain this seal through the fulfilment functional, } \\
\text { technological, environmental, commercial and social criterion. The seal promotes } \\
\text { the integration of the aspects just mentioned into one product. }\end{array}$ \\
\hline & $\begin{array}{l}\text { Forestry certification system for } \\
\text { Argentina (CERFOAR) }\end{array}$ & $\begin{array}{l}\text { Forestry certification system for Argentina (CERFOAR): Is a programme still in } \\
\text { development that aims at guaranteeing that the forestry products come from a } \\
\text { sustainably managed forest. }\end{array}$ \\
\hline & $\begin{array}{l}\text { Quality of electronic devices programme } \\
\text { (PROCAE) }\end{array}$ & $\begin{array}{l}\text { Quality of electronic devices programme (PROCAE): Existence of a label that } \\
\text { informs the energy efficiency of an electronic product through the categorisation } \\
\text { of different products through a previous analysis. }\end{array}$ \\
\hline & $\begin{array}{l}\text { Clean production programme in the city } \\
\text { of Buenos Aires (Buenos Aires Produce } \\
\text { MásLimpio }\end{array}$ & $\begin{array}{l}\text { Clean production programme in the city of Buenos Aires (Buenos Aires Produce } \\
\text { MásLimpio), Also including ecolabel initiative "Eco-selloPorteño" and "Eco- } \\
\text { selloArgentino" aims at promoting adoptions of technologies, productive process } \\
\text { and services that allow the efficient harmonisation of the economic growth, social } \\
\text { development, and environmental protection in Buenos Aires. }\end{array}$ \\
\hline & $\begin{array}{l}\text { Salteña Eco-efficient Management seal } \\
\text { (province of Salta) }\end{array}$ & $\begin{array}{l}\text { Salteña Eco-efficient Management seal (province of Salta). The aim of this seal is } \\
\text { that corporations along with different production sectors in the province of Salta } \\
\text { work towards a cleaner and more sustainable production. }\end{array}$ \\
\hline & $\begin{array}{l}\text { Environmental Management Programme } \\
\text { "ECO UIC" (Córdoba) }\end{array}$ & $\begin{array}{l}\text { Environmental Management Programme "ECO UIC" (Córdoba). The aim of this } \\
\text { programme is to promote Environmental Management for SMEs in the province of } \\
\text { Cordoba, in search of making these more competitive. }\end{array}$ \\
\hline & $\begin{array}{l}\text { Sustainable Industrial Development } \\
\text { project (DIS }\end{array}$ & $\begin{array}{l}\text { Sustainable Industrial Development project (DIS): Aims at promoting sustainable } \\
\text { industrial development focused on productive innovation as well as the regional } \\
\text { and sector development. }\end{array}$ \\
\hline & Industrial Strategic Plan 2020 & $\begin{array}{l}\text { Industrial Strategic Plan 2020: Aims to add value to the production stage of } \\
\text { Industries in Argentina on the basis of sustainable development. }\end{array}$ \\
\hline
\end{tabular}




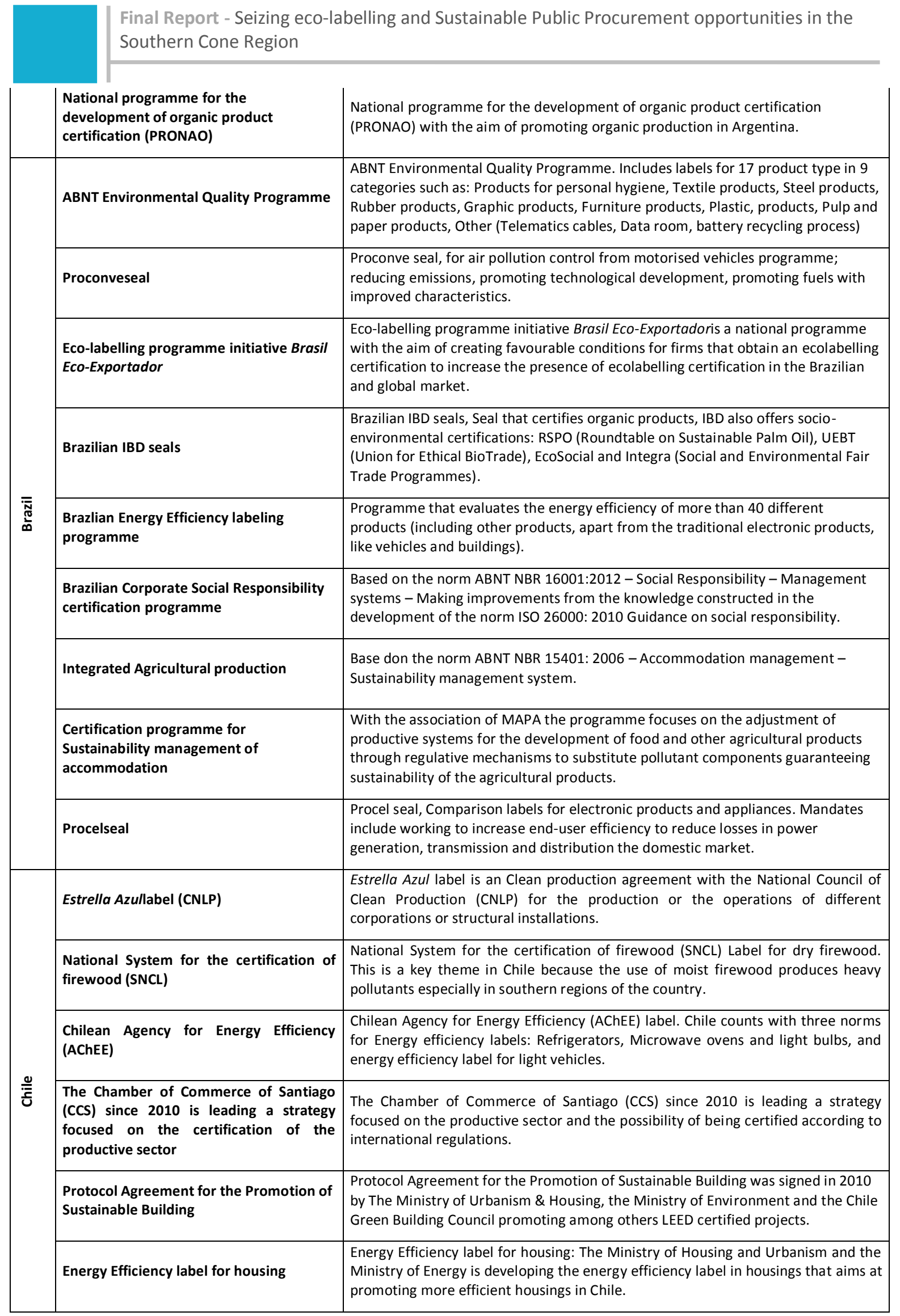




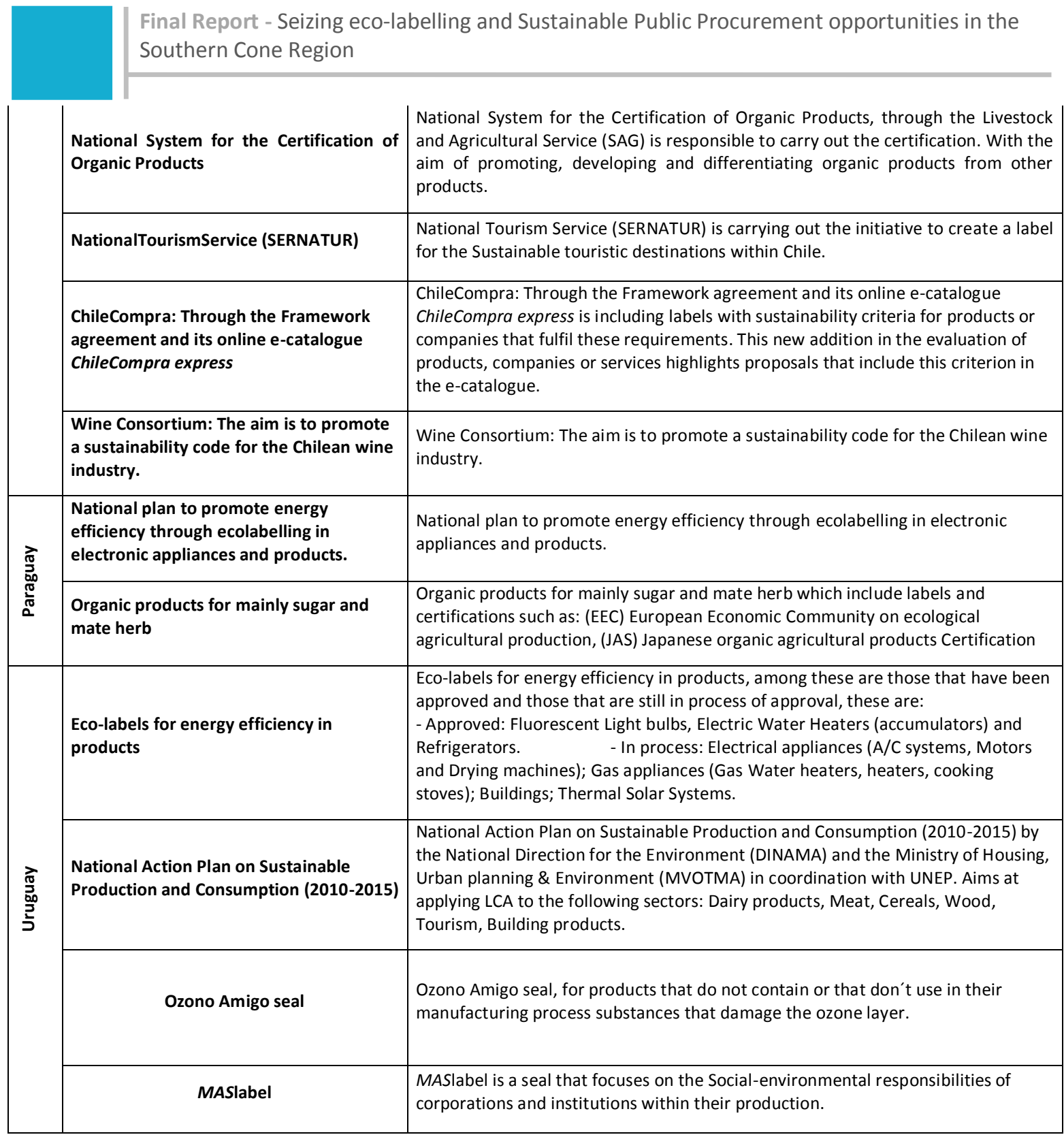




\section{APPENDIX J: SC Institutions}

Table J.1: Institutions by Country

\begin{tabular}{|c|c|}
\hline Country & Institutions \\
\hline \multirow{12}{*}{ Argentina } & National Office for Procurement, Argentinacompra \\
\hline & Ministry of Foreign Affairs \\
\hline & Ministry of Environment and Sustainable Development \\
\hline & Ministry of Federal Planning, Public Inversions and services, Secretariat of Energy \\
\hline & Argentinean Forestry Industry Federation (FAIMA) \\
\hline & Argentinean Forestry Association (AFoA) \\
\hline & Argentinean Manufacturers of Cellulose and Paper Association (AFCP) \\
\hline & Secretariat of Agriculture, Livestock, Fishing, and Food (SAGPyA) \\
\hline & National Institute of Industrial Technology INTI \\
\hline & Argentinean National Standardisation body (IRAM) \\
\hline & Argentine Accreditation Body (OAA) \\
\hline & Centro Tecnológico para la Sustentabilidad -CTS-UTN (Universidad Tecnológica Nacional) \\
\hline \multirow{14}{*}{ Brazil } & Brazilian Technical Norm Association (ABNT) \\
\hline & IMAFLORA \\
\hline & Brazilian IBD certifying organisation \\
\hline & Institute of Companies and Social Responsibility (ETHOS) \\
\hline & Ministry of Development, Industry and foreign Trade (MDIC), Secretariat of Foreign Trade \\
\hline & National Institute of Metrology, Quality and Technology (INMETRO - MDIC) \\
\hline & $\begin{array}{l}\text { Ministry of Agriculture, Livestock and Supply (MAPA) and Ministry of Agrarian Development } \\
\text { (MDA - represents the small scale and family farmers) }\end{array}$ \\
\hline & Ministry of Planning, Budget and Management, ComprasNet \\
\hline & Ministry of Environment (MMA) \\
\hline & Brazilian Association of Panel Wood Industries (ABIPA) \\
\hline & Brazilian Forestry Service (SFB) \\
\hline & Brazilian Institute for Renewable Natural Resources and the Environment (IBAMA) \\
\hline & National Council for the Environment CONAMA \\
\hline & Brazilian Association of the Mechanically Processed Wood Industry (ABIMCI) \\
\hline \multirow{7}{*}{ Chile } & National Direction of Public Procurement Chile, ChileCompra \\
\hline & National Council of Clean Production (CNLP) \\
\hline & Chilean Agency for Energy Efficiency (AChEE) \\
\hline & The Chamber of Commerce of Santiago (CCS) \\
\hline & Ministry of Urbanism \& Housing(MINVIU) \\
\hline & The Livestock and Agricultural Service (SAG) \\
\hline & National Tourism Service (SERNATUR) \\
\hline
\end{tabular}




\begin{tabular}{|c|c|}
\hline & $\begin{array}{l}\text { Final Report - Seizing eco-labelling and Sustainable Public } \\
\text { Southern Cone Region }\end{array}$ \\
\hline & Ministry of Environment \\
\hline & National Consumer Service (SERNAC) \\
\hline & Green Building Council Chile \\
\hline & National Institution of Standardisation (INN) \\
\hline & National Network of Metrology (RNM) \\
\hline & Ministry of Energy \\
\hline & National Direction of Public Procurement Paraguay, DNCP \\
\hline & Ministry of Agriculture and Livestock \\
\hline Paraguay & National Service for the Quality of Vegetables and Seeds \\
\hline & Inter-American Institute for Agriculture cooperation \\
\hline & Investigation and Education Centre for Eco development \\
\hline & National Chamber of Commerce and Services \\
\hline & National Planning and Budget Office \\
\hline & National Direction for Public Procurement \\
\hline & National Direction for the Environment (DINAMA) \\
\hline Uruguay & Ministry of Housing, Urban planning \& Environment (MVOTMA) \\
\hline & National Direction for Energy (DNE) \\
\hline & Ministry of Industry, Energy and Mining (MIEM) \\
\hline & National Management of Power stations and Electric transmission (UTE) \\
\hline & Uruguayan Institute of Technical Norms (UNIT) \\
\hline
\end{tabular}

Table J.2: Institutions according to the number of tendering with sustainability criterion (Contratações Públicas Sustentáveis, 2012)

\begin{tabular}{|l|c|c|}
\hline \multicolumn{1}{|c|}{ Institution } & Amount of tenders & $\%$ \\
\hline Ministry of Education & 621 & $42 \%$ \\
\hline Ministry of Defence & 283 & $19 \%$ \\
\hline Ministry of Justice & 78 & $5 \%$ \\
\hline Ministry of Agriculture \& Fishery & 65 & $4 \%$ \\
\hline Ministry of Treasury & 60 & $3 \%$ \\
\hline Ministry of Health & 45 & $3 \%$ \\
\hline Ministry of Environment & 38 & $2 \%$ \\
\hline Ministry of Labour & 31 & $2 \%$ \\
\hline Ministry of Science and Technology & 30 & \\
\hline
\end{tabular}




\begin{tabular}{|c|c|c|}
\hline $\begin{array}{l}\text { Final Re } \\
\text { Souther }\end{array}$ & $\mathrm{g}$ and $\mathrm{S}$ & ublic \\
\hline Others & 239 & $16 \%$ \\
\hline TOTAL & 1,490 & $100 \%$ \\
\hline
\end{tabular}

